\title{
Dissimilar Fiber Laser Welding between Dual Phase and High Strength Low Alloy Steels
}

By

\author{
Dennis Charles Parkes
}

Bachelors of Applied Science in Material Science and Engineering University of Toronto, Toronto, Canada, 2010

\author{
A thesis \\ Presented to Ryerson University \\ in partial fulfillment of the \\ requirements for the degree of \\ Master of Applied Science \\ in the Program of \\ Mechanical and Industrial Engineering
}

Toronto, Ontario, Canada, 2014

CDennis Parkes 2014 


\section{Author's Declaration}

I hereby declare that I am the sole author of this thesis. This is a true copy of the thesis, including any required final revisions, as accepted by my examiners.

I authorize Ryerson University to lend this thesis to other institutes or other individuals for the purpose of scholarly research.

I further authorize Ryerson University to reproduce this thesis by photocopying or by other means, in total or in part, at the request of other institutions or individuals for the purpose of scholarly research.

I understand that my thesis may be made electronically available to the public. 


\title{
Dissimilar Fiber Laser Welding between Dual Phase and High
}

\section{Strength Low Alloy Steels}

\author{
CDennis Parkes 2014 \\ Master of Applied Science \\ Department of Mechanical Engineering \\ Ryerson University
}

\begin{abstract}
With increasing use of dual phase steels in the automotive industry, it is important to have an understanding of how they behave when they are welded to conventional high strength low alloy steels (HSLA). Fiber laser welded dissimilar joints between DP980 and HSLA steels were evaluated in tension at low temperature $\left(-40^{\circ} \mathrm{C}\right)$, room temperature $\left(25^{\circ} \mathrm{C}\right)$, elevated temperature $\left(180^{\circ} \mathrm{C}\right)$, and in fatigue under different welding conditions. Triple dissimilar welds were tested in various combinations and with different types of protective zinc coatings to determine the effect that coatings play on the tensile and fatigue behaviour. Lastly, an analysis was done on how the change in DP980 chemistry could affect the final mechanical properties of their welded joints.
\end{abstract}




\section{Acknowledgements}

I would like to thank my supervisors Prof. Daolun Chen and Prof. Sanjeev Bhole for devoting so much time and effort in both guidance and discussion for the completion of this thesis. The help of Mr. D. Westerbaan and Dr. S. S. Nayak from Prof. Y. Zhou's group (University of Waterloo, Waterloo, Canada) was paramount to the success of this research project. I would also like to thank Mr. E. Biro (ArcelorMittal Global Research, Hamilton, Canada) for his critical comments and helpful discussion throughout the research project.

The assistance of J. Amankrah, R. Churaman, Q. Li, and A. Machin is gratefully acknowledged for the aid in performing the experiments. I would also like to thank all of my friends and family for their support throughout my degree; it would have been far more difficult without them. 
To

My Parents John Parkes and Chantal Ramsay

My Sisters Jessica and Alexandra

In loving memory of my Grandparents

And all of my Friends 


\section{Table of Contents}

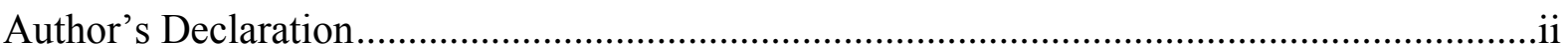

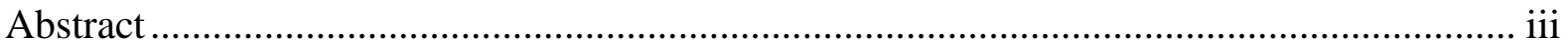

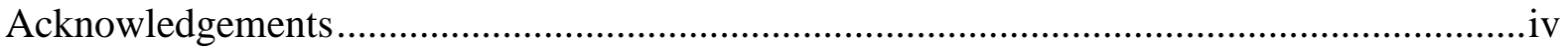

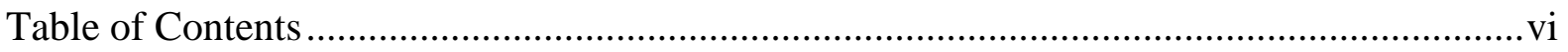

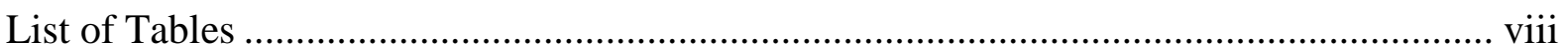

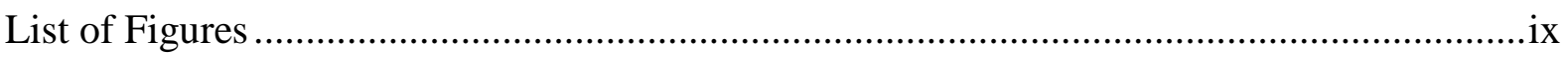

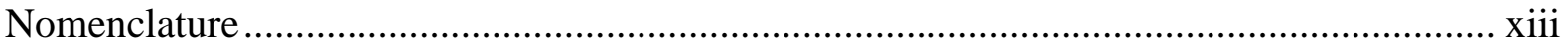

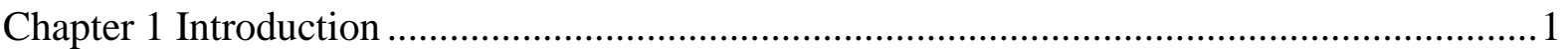

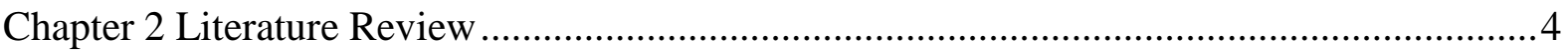

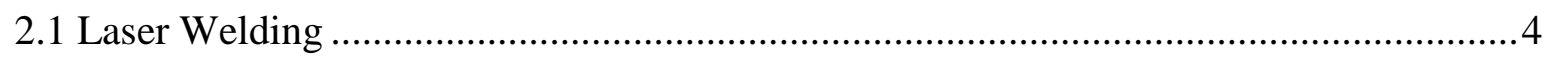

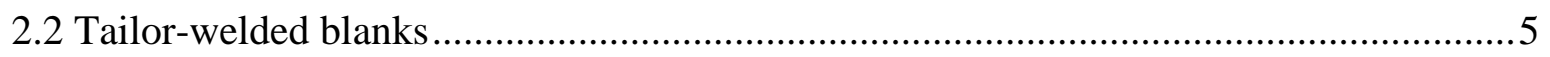

2.3 The issue with Tempered Martensite in the HAZ .......................................................

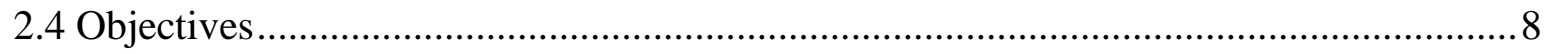

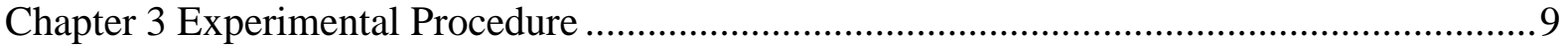

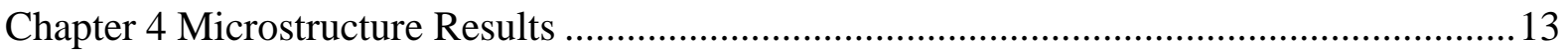

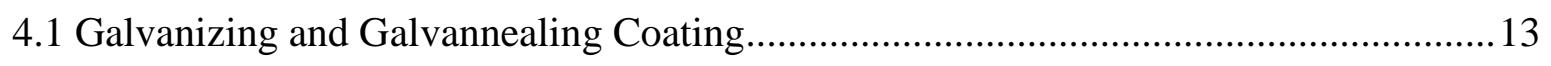

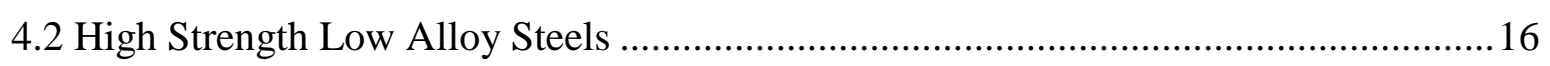

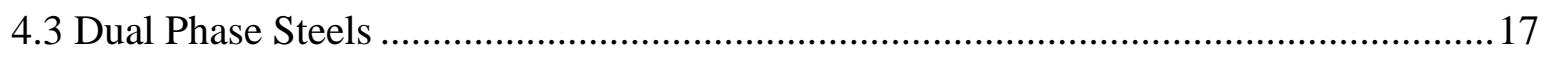

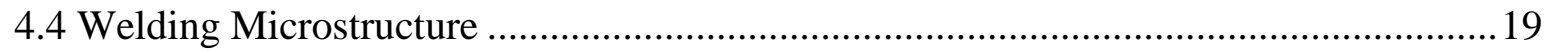

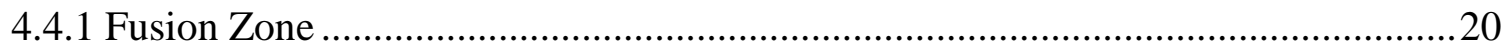

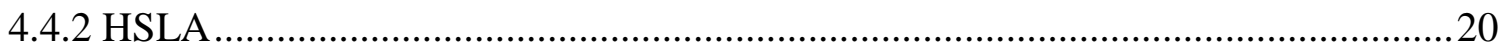

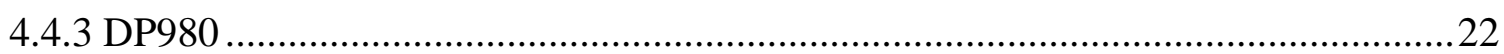

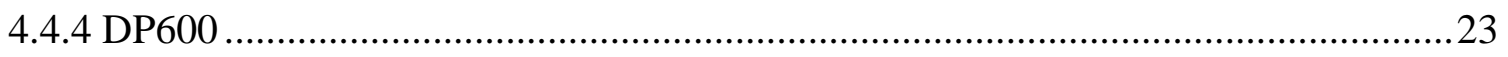

Chapter 5 Tensile and Fatigue Properties of Fiber Laser Welded Dissimilar Joints between High Strength Low Alloy and Dual-Phase Steels .............................................................25

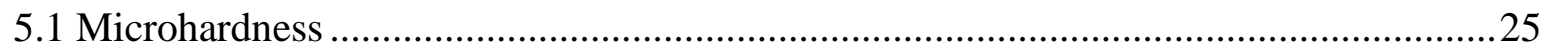

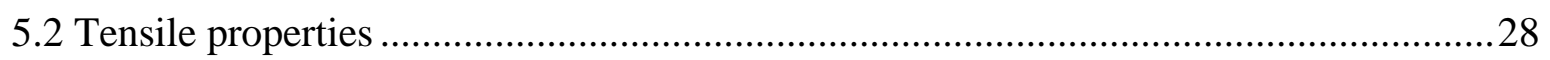

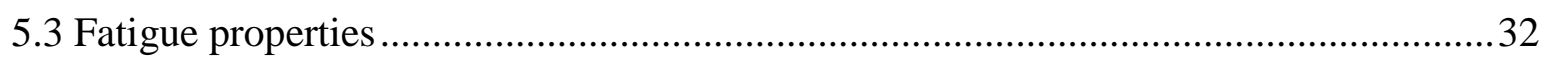

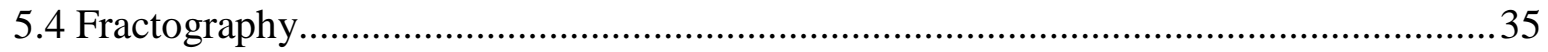

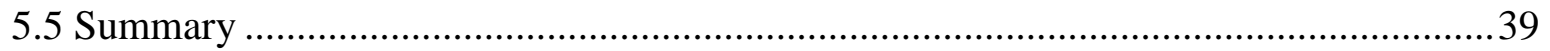


Chapter 6 Tensile Properties of Fiber Laser Welded Dissimilar Joints of High Strength Low Alloy and Dual-Phase Steels at Warm and Low Temperatures............................................4 42

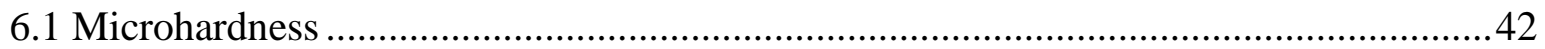

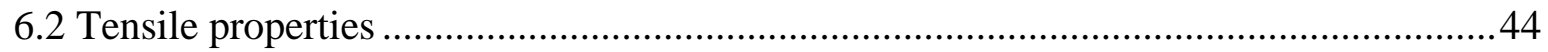

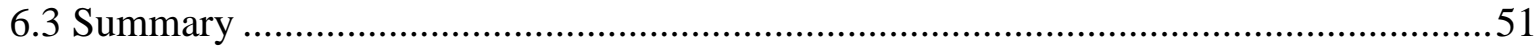

Chapter 7 Effect of Fiber Laser Welding Parameters on the Fatigue Properties of Dissimilar

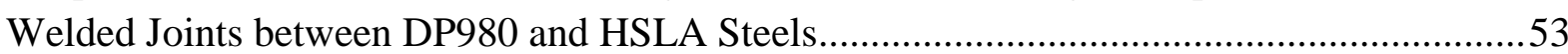

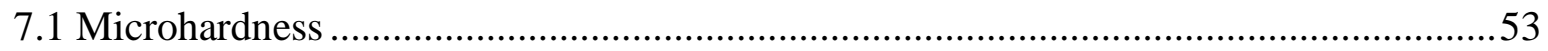

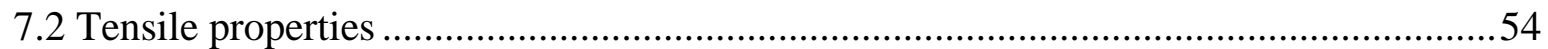

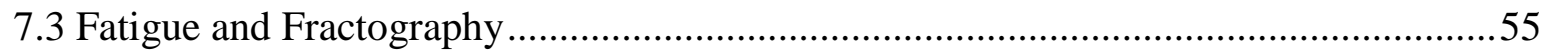

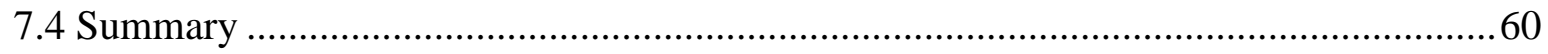

Chapter 8 Fatigue and Microstructure Comparison between Galvanized and Galvannealed

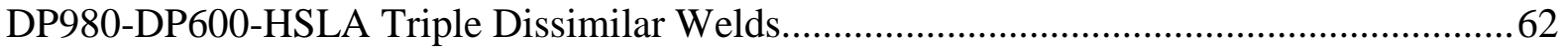

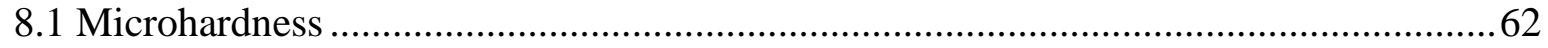

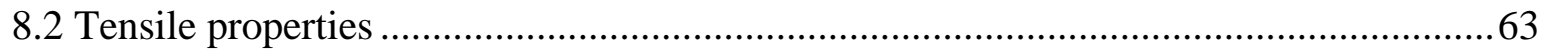

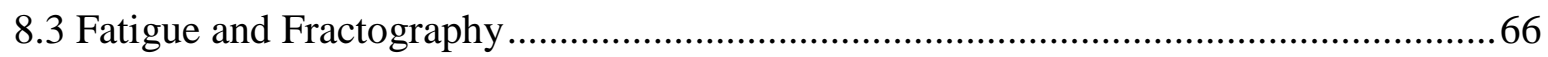

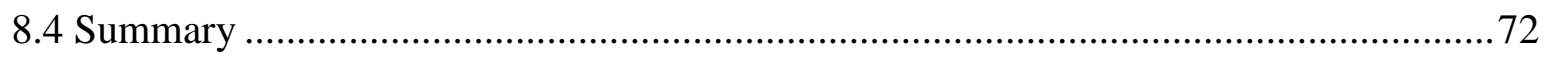

Chapter 9 Fiber Laser Welding of dual-phase DP980 steel: Effects of Heat Input and

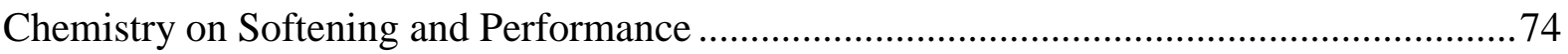

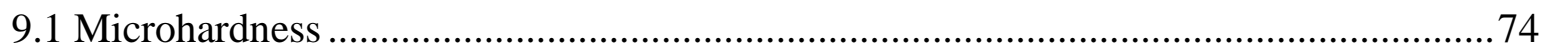

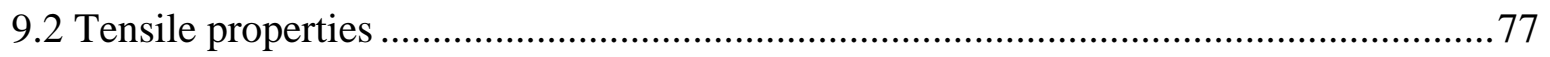

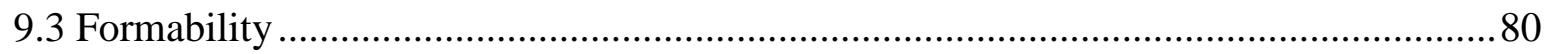

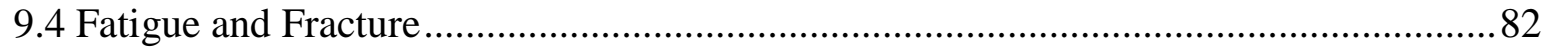

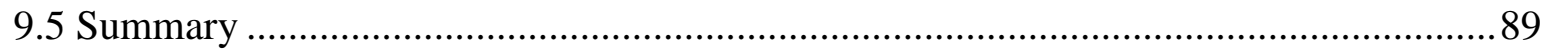

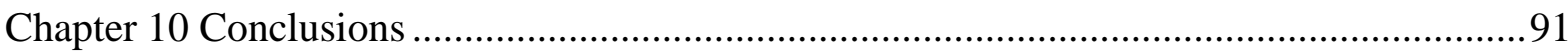

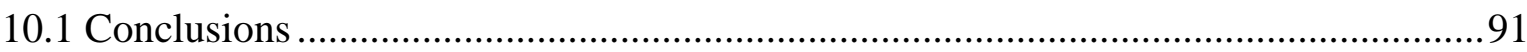

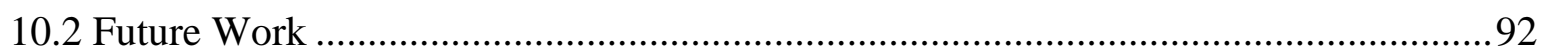

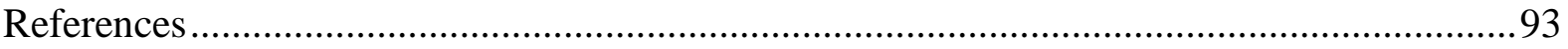

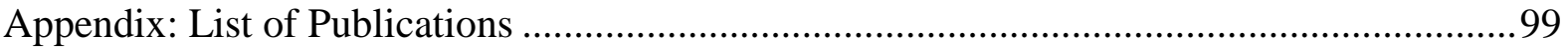




\section{List of Tables}

Table number Description

Page number(s)

2.1

A comparison of different laser welding systems [27].

5

3.1 List of sample chemistry.

9

3.2 Welding parameters.

5.1 Tensile properties and fatigue parameters $\sigma_{f}^{\prime}$ and $b$ for HSLA BM, DP980 BM, similar HSLA-HSLA and DP980DP980 welded joints, and dissimilar HSLA-DP980 welded joints.

7.1 Summary of fatigue and tensile properties.

8.1 Summary of tensile and fatigue data.

66

9.1

Soft zone properties of welded DP980 Rich and Lean steels.

9.3 Fatigue data for the DP980 Rich and Lean base metals and the different heat inputs. 


\section{List of Figures}

Figure number Description

Page number(s)

2.1 Current applications for TWBs in a car [32]. p.6

3.1 Schematic illustrations of the (a) HSLA-DP980 laser welded blank and (b) tensile and fatigue test specimen machined from and parallel to the region marked by the short-dashed lines in (a). (c) DP980-DP600-HSLA laser welded blank and (d) tensile and fatigue test specimen machined from and parallel to the region marked by the short-dashed lines in (c).

$4.1 \quad$ (a) GI coated DP980, (b) GA coated DP980, (c) GI coated DP600, (d) GA coated DP600, (e) GI coated HSLA, and (f) GA coated HSLA.

4.2 Summary of coating thickness.

BMs of (a) HSLA GI, and (b) HSLA GA.

4.4 BMs of (a) DP980 Lean GI, (b) DP980 Rich GI, (c) DP980 GA, (d) DP600 GI, and (e) DP600 GA.

The FZ microstructure of (a) high heat input joint (16 $\mathrm{m} / \mathrm{min}$ at $6 \mathrm{~kW})$, and (b) low heat input joint $(20.5 \mathrm{~m} / \mathrm{min}$ at $4 \mathrm{~kW}$ ). (M: martensite, B: bainite)

(a) HSLA GA upper-critical HAZ, (b) HSLA GA intercritical HAZ, (c) HSLA GI upper-critical HAZ, and (d) HSLA GI inter-critical HAZ.

(a) DP980 GI upper-critical HAZ, (b) HSLA GI intercritical HAZ, (c) DP980 GI sub-critical HAZ, (d) DP980 GA upper-critical HAZ, (e) HSLA GA inter-critical HAZ, and (f) DP980 GA sub-critical HAZ.

4.8 (a) HSLA GI upper-critical HAZ, (b) HSLA GI intercritical HAZ, (c) HSLA GA upper-critical HAZ, and (d) HSLA GA inter-critical HAZ.

5.1 Microhardness profile across the dissimilar HSLA-DP980 welded joint.

5.2 A comparison of hardness for the HSLA, DP980, and dissimilar welded joints made at a welding speed of 16 $\mathrm{m} / \mathrm{min}$, where the hardness data for the HSLA-HSLA and 
DP980-DP980 similar joints were taken from ref. [10].

5.3 Representative engineering stress versus engineering strain curves of the HSLA, DP980, and dissimilar welded joints tested at a strain rate of $1 \times 10^{-3} \mathrm{~s}^{-1}$.

5.4 Comparison of the S-N curves of the HSLA, DP980, and dissimilar welded joints tested at $\mathrm{R}=0.1,50 \mathrm{~Hz}$, and room temperature, where the DP980-DP980 and HSLA-HSLA curves are taken from [10].

5.5 Typical fatigue failure locations in the dissimilar HSLADP980 welded joints at stress amplitudes of (a) $250 \mathrm{MPa}$, (b) $200 \mathrm{MPa}$, and (c) $175 \mathrm{MPa}$.

SEM images illustrating the fatigue fracture surface of a dissimilar HSLA-DP980 welded joint tested at a stress amplitude of $250 \mathrm{MPa}$ : (a) overall view, (b) crack propagation region, where "c" in (a) indicates the necking region.

SEM micrographs depicting the fatigue fracture surface in a dissimilar HSLA-DP980 welded joint tested at a stress amplitude of $200 \mathrm{MPa}$ : (a) overall view, (b) fatigue crack initiation region, (c) crack propagation region, and (d) final fast fracture interface.

SEM micrographs of the fatigue fracture surface in a dissimilar HSLA-DP980 welded joint tested at a stress amplitude of $150 \mathrm{MPa}$ : (a) overall view, (b) fatigue crack initiation region, (c) crack propagation region, and (d) final fast fracture interface.

6.1 Microhardness profile of FLW HSLA-DP980 sample.

6.2 Comparison of tensile properties of the HSLA BM, HSLADP980 and HSLA-HSLA welded jointsat different temperatures: (a) YS, (b) UTS, (c) elongation, (d) EA, (e) work hardening coefficient.

6.3 Typical tensile curves of a) DP980 BM, b) DP980-DP980.

6.4 Typical tensile curves of a) HSLA-DP980, b) HSLAHSLA, c) HSLA BM.

6.5 Comparison of tensile properties of the DP980 FLWed joints and the BM tested at different temperatures: (a) YS, (b) UTS, (c) elongation, (d) EA, (e) work hardening coefficient.

7.1 Microhardness curves of HSLA-DP980 welded joints made 
with different welding conditions [48].

7.2 Tensile curves of HSLA-DP980 welded joints made under different welding conditions.

Typical fatigue fracture locations at (a) high stress amplitude, and (b) low stress amplitude.

7.4 Comparison of S-N curves of the HSLA-DP980 welded joints with different heat inputs.

Fatigue fracture surface features: initiation region (a) high heat input, and (b) low heat input. Propagation region: (c) high heat input and (d) low heat input. Fast fracture: (e) high heat input and (f) low heat input.

8.1 Microhardness of GI and GA coated DP980-DP600-HSLA triple dissimilar welds.

8.2 Tensile tests of GI coated triple dissimilar weld and relevant BMs.

8.3 Tensile test of GA coated triple dissimilar weld and relevant BMs.

8.4 Fatigue failure locations for GA coated triple dissimilar welds at (a) high stress amplitude, and (b) low stress amplitude.

Fatigue failure locations for GI coated triple dissimilar welds at (a) high stress amplitude, and (b) low stress amplitude.

8.6 S-N curve of GI coated triple dissimilar welds and related BMs. [10]

8.7 S-N curve of GA coated triple dissimilar welds and related BMs.

8.8 Fracture surface of GI coated triple dissimilar weld, (a) Overall fracture surface, (b) initiation region, (c) propagation region, (d) fast fracture region.

Fracture surface of GA coated triple dissimilar weld, (a) Overall fracture surface, (b) initiation region, (c) propagation region, (d) fast fracture region.

9.1 Vickers hardness profiles for low heat input welds; error bars show one standard deviation. 
9.2 Vickers hardness profiles for low heat input welds; error bars show one standard deviation.

9.3 Tensile curve for DP980 Rich at high and low heat inputs.

9.4 Tensile curve for DP980 Lean at high and low heat inputs.

80

9.5 Fracture location of Formed Domes.

82

9.6 S-N curve of DP980 Rich and Lean at the different heat inputs.

9.7 Typical fracture locations of both heat inputs (a) high stress amplitude Rich DP980, (b) low stress amplitude Rich DP980, (c) high stress amplitude Lean DP980, (d) low stress amplitude Lean DP980.

9.8

Overall fracture surfaces of relative low stress amplitude tests for (a) high heat input DP980 Rich, (b) low heat input DP980 Rich, (c) high heat input DP980 Lean, and (d) low heat input DP980 Lean.

9.9 Fracture initiation sites of (a) high heat input DP980 Rich, (b) low heat input DP980 Rich, (c) high heat input DP980 Lean, and (d) low heat input DP980 Lean.

9.10

Fracture propagation region of (a) high heat input DP980 Rich, (b) low heat input DP980 Rich, (c) high heat input DP980 Lean, and (d) low heat input DP980 Lean.

9.11 Fast Fracture region of (a) high heat input DP980 Rich, (b) low heat input DP980 Rich, (c) high heat input DP980 Lean, and (d) low heat input DP980 Lean. 
Nomenclature

\section{Acronym}

AHSS

BCC

BCT

BM

CAFE

CCT

DLW

DP

EA

EG

EISA

FCC

FLW

FZ

GA

GI

HAZ

HSLA

HT

LDH

LT

LWB

PTM

SEM

RT

TIG

TWB

UTS

YPP

YS

\section{Definition}

Advanced High Strength Steel

Body Centered Cubic

Body Centered Tetragonal

Base Metal

Corporate Average Fuel Economy

Continuous Cooling Curve

Diode Laser Welding

Dual Phase

Energy Absorption

Electrogalvannealing

Economic Independence and Security Act

Face Centered Cubic

Fiber Laser Welding

Fusion Zone

Galvannealed

Galvanized

Heat Affected Zone

High Strength Low Alloy

High temperature

Limiting Dome Height

Low Temperature

Laser Welded Blank

Partially Tempered Martensite

Scanning Electron Microscopy

Room Temperature

Tungsten Inert Gas

Tailor Welded Blank

Ultimate Tensile Strength

Yield Point Phenomenon

Yield Strength 


\section{Symbol}

$\sigma_{a}$

$\sigma_{f}$,

$\sigma_{T}$

$\varepsilon_{T}$

$b$

$N_{f}$

K

$n$

$H_{B M}$

$H_{H A Z}$

\section{Definition}

Cyclic stress amplitude, MPa

Fatigue stess coefficient, $\mathrm{MPa}$

True stress, MPa

True strain, \%

Fatigue strength exponent

Number of cycles

Strength coefficient, $\mathrm{MPa}$

Strain hardening exponent

Base metal hardness, VHN

Heat affect zone hardness, VHN 


\section{Chapter 1 Introduction}

With the increase in population in countries such as India and China where an increasing percentage of the population is entering the middle class salary bracket, the demand for automobiles is expected to increase significantly in these countries $[1,2]$. One of the challenges the automotive industry faces is to be able to meet the needs of this growing middle class. While increasing the number of vehicles on the road, another important factor of public concern is the impact these vehicles would have on the environment with $\mathrm{CO}_{2}$ emissions causing greenhouse effect in the atmosphere $[3,4]$. In order to help curb this, some government regulations have been introduced, one of which is called the Energy Independence and Security Act (EISA) which uses the Corporate Average Fuel Economy (CAFE) where it is up to manufacturers to meet the demands of the timelines in which the fuel economy of different sizes of cars must continually increases over time $[5,6]$. The drivers of these vehicles also see the impact in their wallets with the rising price in gasoline. In order to resolve these issues, automotive manufacturers are seeking ways of increasing productivity in their assembly plants by either making changes to the designs of the vehicles to safely reduce the amount of material used or by making changes to the materials that are currently used in their automobiles [7].

One of the major challenges with almost any material that is designed and made into a component is how it will behave in operation, primarily meaning how corrosion will affect it and what can be done to reduce or prevent it. Since normal carbon steel easily corrodes in water, it is necessary to protect it in order to prevent degradation and maintain operational structural integrity over time. For steels, hot dip galvanizing (GI) and hot dip galvannealing (GA) are two similar coating methods where a layer of zinc is used to inhibit corrosion. 
According to the galvanic series, zinc is more active (anodic) than steels. This means that if zinc and steel were both present in an aqueous solution, the zinc would be the anode and the steel the cathode, and material loss would occur on the zinc. Coated steel with a layer of zinc would mean that the zinc layer would corrode preferentially and keep the steel structure intact $[8]$.

In automotive construction, the primary material used for the structural components is steel. In order to meet the rising demands of CAFE, automotive manufacturers need to develop innovative methods for increasing the fuel economy of their vehicles. Many methods will be and have been devised already to rise to this challenge, but one of the most prominent methods is simply making vehicles lighter. Newer materials such as aluminum and magnesium alloys are being used to replace heavier steel components. However, some structural components still need to be made from steels. One method of decreasing the weight of these structural sections while still using steel would be to use very strong steel and simply use less of it in order to save weight. Advanced High Strength Steels (AHSS) are one such group of steels that include dual phase (DP) steels. DP steel is one of the popular members in the AHSS family [9], because of its high strength and good formability properties. More commonly used in automotive construction is high strength low alloy steel (HSLA) which have excellent formability.

The primary manufacturing process used in auto-body fabrication is welding. It is therefore important to understand the metallurgical and mechanical phenomena involved in the welding of DP and HSLA steels. If the increased usage of DP steels becomes the norm, it will be necessary to understand these phenomena in dissimilar combinations in order to better plan the construction of the next generation of vehicles. Furthermore, laser welding is usually used to manufacture welded blanks which are formed into different shapes of the auto-body parts $[10,11,12,13,14,15,16]$. There are many different laser welding techniques. Fiber 
laser, diode laser, $\mathrm{Nd}$ :YAG laser, and $\mathrm{CO}_{2}$ laser are the primary types of laser welding techniques available which have been previously applied to weld a variety of steels to evaluate and compare their benefits and detriments [11, 12, 13, 14, 15, 17]. Amongst these laser welding processes, fiber laser welding (FLW) is the newest with several advantages over the other types, including smaller beam divergence, low maintenance costs, higher efficiency, high precision and reliability, and compact size $[10,16,18,19]$. Thus, superior quality welds are able to be generally produced in FLW. 


\section{Chapter 2 Literature Review}

\subsection{Laser Welding}

Lasers are narrow beams of light that are created in a lasing medium by the stimulated emission of photons in which electrons are excited into higher energy states and then are reexcited causing the falling electron to emit a photon of light with energy related to that band gap of energy [20]. Creating a focused beam allows very high energy densities in comparison to other conventional welding techniques. Because of this property, laser welding techniques have played an ever advancing role in the joining of materials since the invention of high power solid state and gas lasers in the 1960s [16, 21, 22, 23, 24].

Since welding is the primary joining mechanism for metals in industry, it is necessary to understand the behaviour of these welds, how the welding process is performed, and how it can be modified in order to make the process more efficient. Currently, laser welding is used to make tailor welded blanks (TWBs) in automotive construction [25]. The most common lasers that are used are $\mathrm{CO}_{2}$ lasers, diode lasers, and Nd:YAG lasers for this process [26].

For a laser to be produced, a lasing medium is required in order to allow for the generation of the photons. As the names of each of the lasers suggest, those are the lasing mediums. For $\mathrm{CO}_{2}$ lasers, a mixture of $\mathrm{CO}_{2}$ gas with helium and nitrogen is used and produces a laser with a wavelength of $10.6 \mu \mathrm{m}$ at an efficiency of about $5-8 \%$. Nd:YAG has a lasing medium composed of an ytterium aluminum garnet that has been doped with neodymium. This produces a laser with a wavelength of about $1.08 \mu \mathrm{m}$ at an efficiency of 3-5\%. Diode lasers are produced from semi-conductors and usually have a wavelength of about $1.06 \mu \mathrm{m}$ at efficiencies ranging from 10-20\%. Lastly, fiber lasers are produced in a doped fiber medium with a wavelength of $1.07 \mu \mathrm{m}$ with efficiencies as high as $20-30 \%$ as summarized in Table 2.1. 
Table 2.1 A comparison of different laser welding systems [27].

\begin{tabular}{|c|c|c|c|c|c|c|}
\hline $\begin{array}{c}\text { Laser } \\
\text { system }\end{array}$ & Laser medium & $\begin{array}{c}\text { Average } \\
\text { output } \\
\text { power } \\
(\mathrm{kW})\end{array}$ & $\begin{array}{c}\text { Wavelength } \\
(\mu \mathrm{m})\end{array}$ & $\begin{array}{c}\text { Beam } \\
\text { quality } \\
(\mathrm{mm} \text { rad })\end{array}$ & $\begin{array}{c}\text { Efficiency } \\
(\%)\end{array}$ & $\begin{array}{c}\text { Welding } \\
\text { modes }\end{array}$ \\
\hline $\mathrm{CO}_{2}$ & $\begin{array}{c}\mathrm{CO}_{2} \text { mixed } \\
\text { with He and N }\end{array}$ & Up to 15 & 10.6 & 3.7 & $5-8$ & $\begin{array}{c}\text { Conduction } \\
\text { and key hole }\end{array}$ \\
\hline $\mathrm{Nd}$ :YAG & $\begin{array}{c}\text { Nd doped } \\
\text { yttrium } \\
\text { aluminum } \\
\text { garnet }\end{array}$ & Up to 6 & 1.06 & 12 & $3-5$ & $\begin{array}{c}\text { Conduction } \\
\text { and key hole }\end{array}$ \\
\hline Diode & $\begin{array}{c}\text { Semi- } \\
\text { conductors }\end{array}$ & 6 & 1.06 & $<12$ & $10-20$ & $\begin{array}{c}\text { Conduction } \\
\text { and key hole }\end{array}$ \\
\hline Fiber & Doped fiber & Up to 20 & 1.07 & 1.8 & $20-30$ & $\begin{array}{c}\text { Conduction } \\
\text { and key hole }\end{array}$ \\
\hline
\end{tabular}

Previous work has been done regarding these different lasers on DP steels $[10,11,12,13,14$, 15, 16], and for this project, a FLW system was used to produce the welded joints. The reason why FLW was chosen as the welding technique was due to several advantages it has over the other types of laser welding, including smaller beam divergence, low maintenance costs, higher efficiency, high precision and reliability, and compact size [10, 16, 18, 19]. Because of these characteristics, it is able to produce a higher quality weld at a better price in comparison to the other laser welding techniques. Part of this is due to the laser travelling along an optical fiber instead of the laser being transferred to the welding surface by a series of mirrors; the optical fiber is much more cost effective in moving the laser into position, while the mirror system is complex and needs to be carefully maintained and cleaned [28].

\subsection{Tailor-welded blanks}

TWBs are comprised of several steel sheets, sometimes with varying thicknesses and grades of steel welded into a single flat blank prior to being pressed into the final shape of the component (Fig. 2.1). This is done in order to achieve optimal material arrangement and helps to cut down on material usage [29]. In the early stages of TWBs in the 1960s, the 
TWBs were assembled using tungsten inert gas welding (TIG) which is a relatively slow process and, therefore, was not widely adopted. With increasing use of laser welding technology in the 1980s, the TWB method of construction began to increase in popularity because of the increase in production that it provided automakers by consolidating parts, reducing tolerances, reducing the amount of material used in the construction of the parts, and keeping or improving the structural stability of the parts $[30,31]$.

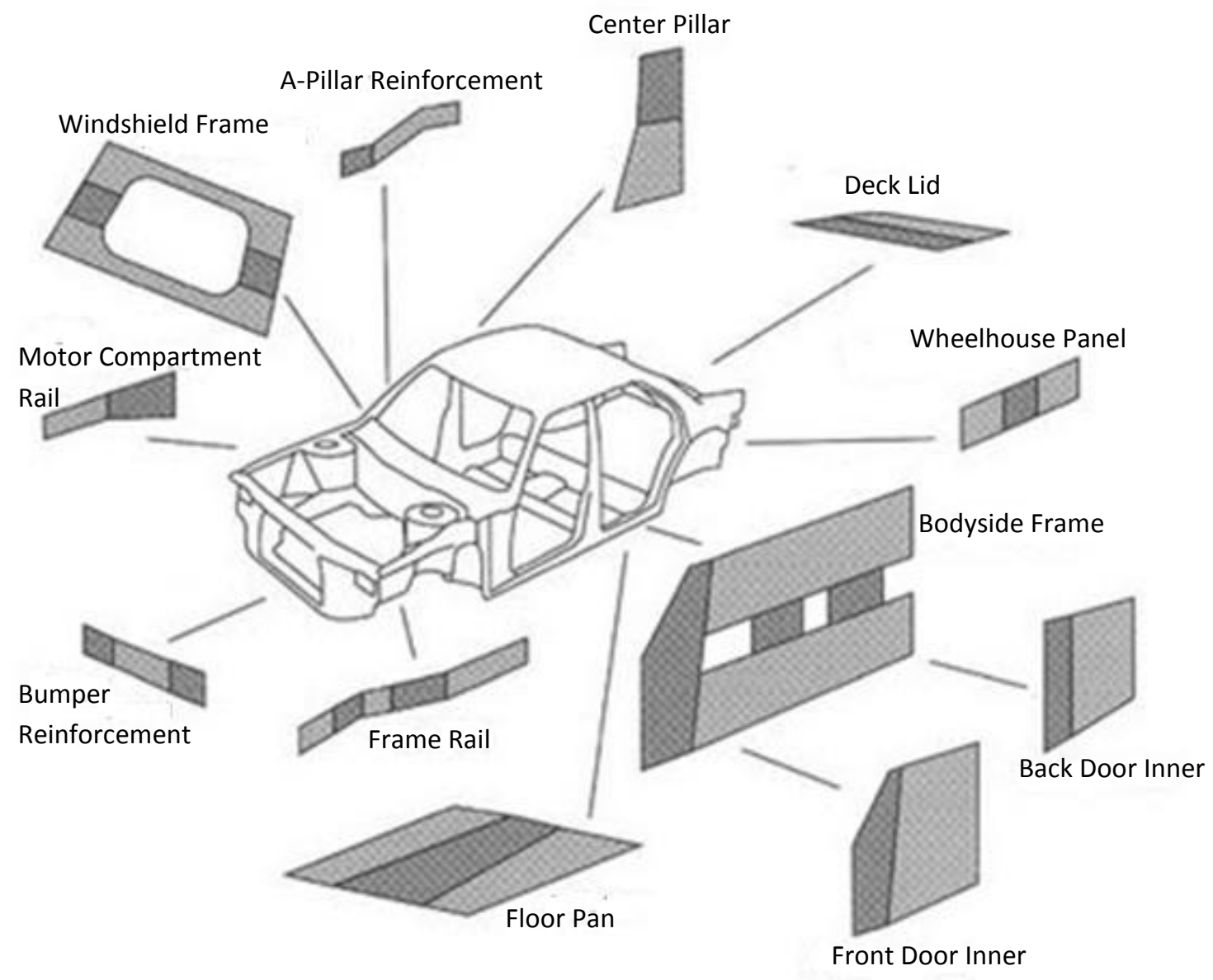

Fig. 2.1 Current applications for TWBs in a car [32].

The previously mentioned configurations can be complex in nature, meaning that a series of linear welds of different materials could be completely viable (triple dissimilar welds). It has 
also been shown that configurations of up to five laser welded blanks (LWBs) could be viable for construction of certain components [31].

\subsection{The issue with Tempered Martensite in the HAZ}

In a number of studies of DP600 and DP980 steels $[10,11,12,13,14,15]$ an important phenomenon that has commonly been observed in the DP980 welds is the formation of a "soft zone" at the sub-critical heat affected zone (HAZ), i.e., a drop in hardness below that of the BM $[10,11,12,13,14,15]$. The HAZ softening was observed to be dependent on the grade of the DP steel and the type of welding process used. The degree of HAZ softening also has a strong influence on the performance, e.g., formability, tensile properties, and fatigue resistance of the welded joints $[10,11,12,13,14,15,33]$. It is caused by the tempering of the martensite that is normally present in the BM when the temperature from the welding process in the $\mathrm{HAZ}$ drops just below the $\mathrm{Ac}_{1}$ line $\left(726^{\circ} \mathrm{C}\right)$ and gives the metastable martensite adequate energy to start to temper. Studies done by Farabi et al. [13, 15] on DP600 and DP980 using diode laser welding (DLW) showed drastic microstructural changes in the HAZ which had a negative effect on their tensile and fatigue properties. Xia et al. [12] also did a comparative study on the formability of DP980 and HSLA steel and found that the formability properties drastically decreased with the presence of a large sub-critical HAZ produced by DLW.

Several studies done by $\mathrm{Xu}$ et al. $[10,34]$ using DP980 and HSLA indicated that using a FLW technique was more beneficial in minimizing the HAZ softening, in both the magnitude of softening and the width of sub-critical HAZ, due to the higher power density as a result of the narrower beam diameter which allows welding at higher speeds. This allowed for minimal drops in the tensile strength of the DP980 steel. However, there have not been any studies done examining the effect of the sub-critical HAZ on the mechanical properties of 
dissimilarly FLWed HSLA and DP steel joints, and this is one of the main focuses of this thesis.

\subsection{Objectives}

The ultimate goal of this project is to increase automotive production for the industry through the use of FLW and to determine whether DP steels will be effective at making the next generation of cars safer and better for the environment through the reduction in weight that they can provide and from their higher strength. Recognizing that it might not be practical to replace every component with DP steel, the understanding of the dissimilar welded joint behaviour is important for the manufacturing of the TWB components. Therefore, it is the objective of this thesis to examine dissimilar welded joints between DP and HSLA steels that were FLWed together and to examine how the sub-critical HAZ that is formed in the welded DP steels affects the mechanical properties of the welded joint. In order to accomplish this, several parameters needed to be tested:

- The microstructure change across the dissimilar welded joints needed to be examined.

- The mechanical behaviour and the failure mechanisms of these dissimilar welded joints under both tensile and fatigue conditions needed to be tested.

- To understand the effect of practical environmental conditions, the dissimilar welded joints needed to be tested at elevated and low temperatures.

- To potentially increase production of automotive components the effect of welding speed and heat input needed to be identified.

- The potential effect of GI and GA coatings on mechanical properties of the FLWed joint needed to be determined.

- What kind of effect does the chemistry of DP980 have on the failure behaviour and the mechanical properties of the FLWed joints also needed to be examined. 


\section{Chapter 3 Experimental Procedure}

The starting materials in this study were two types of HSLA and DP600, and three types of DP980 steel sheets. For the HSLA and DP600 steels, one was with a hot dipped galvanized coating and the other with a galvannealed coating. The DP980 steels, a rich and lean chemistry, were GI coated while another DP980 sample with different chemistry was GA coated. All of the steel sheets have a thickness of $1.2 \mathrm{~mm}$ except the GI and GA DP600 which has a thickness of 1.05 and $1.15 \mathrm{~mm}$, respectively. The chemical compositions of all the steels are listed in Table 3.1.

Table 3.1 List of sample chemistry

\begin{tabular}{|c|c|c|c|c|c|c|c|c|c|c|}
\hline $\begin{array}{c}\text { Chapter } \\
\text { used }\end{array}$ & Steel & $\mathrm{C}$ & $\mathrm{Mn}$ & $\mathrm{Si}$ & $\mathrm{Al}$ & $\mathrm{Ni}$ & $\mathrm{Cr}$ & $\mathrm{Ti}$ & $\mathrm{Nb}$ & $\mathrm{Fe}$ \\
\hline $5-8$ & HSLA380-GI & 0.08 & 0.80 & 0.46 & 0.05 & 0.01 & 0.03 & 0.002 & 0.04 & Balance \\
\hline 8 & HSLA300-GA & 0.08 & 0.98 & 0.12 & 0.03 & 0.02 & 0.05 & 0.002 & 0.007 & Balance \\
\hline 8 & DP600-GI & 0.11 & 1.91 & 0.14 & 0.03 & 0.01 & 0.35 & 0.011 & 0.004 & Balance \\
\hline 8 & DP600-GA & 0.12 & 1.57 & 0.21 & 0.4 & 0.02 & 0.2 & 0.021 & 0.004 & Balance \\
\hline $5-9$ & DP980-GI-lean & 0.15 & 1.45 & 0.33 & 0.05 & 0.01 & 0.02 & 0.002 & 0.001 & Balance \\
\hline 9 & DP980-GI-rich & 0.09 & 2.1 & 0.3 & 0.05 & 0.0 & 0.2 & 0.0 & 0.0 & Balance \\
\hline 8 & DP980-GA & 0.097 & 2.19 & 0.33 & 0.04 & 0.01 & 0.21 & 0.022 & 0.016 & Balance \\
\hline
\end{tabular}

Welded blanks with a dimension of $200 \mathrm{~mm} \times 200 \mathrm{~mm}$ were initially fabricated for all types of joints. For the HSLA-DP980 dissimilar welded joint, $100 \mathrm{~mm} \times 100 \mathrm{~mm}$ sheets of GI coated HSLA and lean DP980 (Fig. 3.1(a) and Fig. 3.1(b)) were joined together, and the triple dissimilar welded joints were made from a $90 \mathrm{~mm} \times 200 \mathrm{~mm}$ sheet of both HSLA and DP980 and a $20 \mathrm{~mm} \times 200 \mathrm{~mm}$ sheet of DP600, the DP600 sheet was placed in the middle of the two other sheets and were welded together (Fig. 3.1(c) and Fig. 3.1(d)) using an IPG Photonics YLS-6000 fiber laser system attached to a Panasonic robotic arm. A summary of the welding parameters can be found in Table 3.2. 
(a)

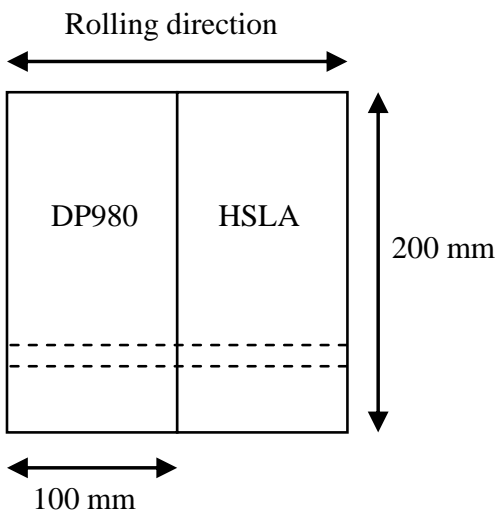

(b)

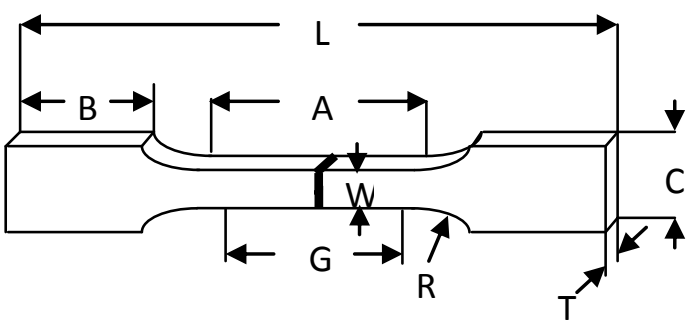

(c)

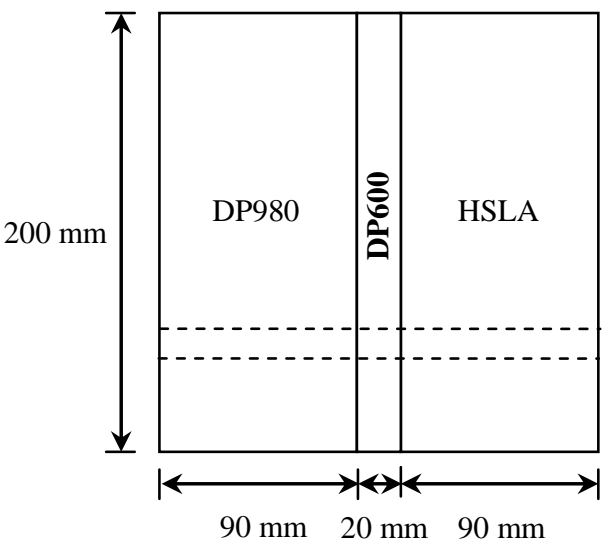

(d)

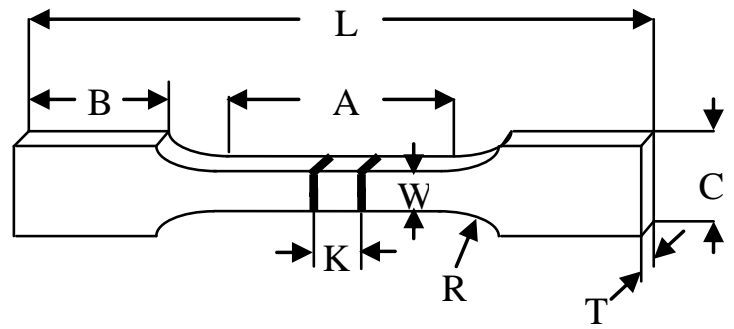

\begin{tabular}{|c|c|c|c|c|c|c|c|c|c|}
\hline Name & $\mathrm{G}$ & $\mathrm{K}$ & $\mathrm{W}$ & $\mathrm{R}$ & $\mathrm{L}$ & $\mathrm{A}$ & $\mathrm{B}$ & $\mathrm{C}$ & $\mathrm{T}$ \\
\hline Dimension (mm) & 50 & 20 & 12.5 & 12.5 & 200 & 57 & 50 & 20 & 1.2 \\
\hline
\end{tabular}

Fig. 3.1 Schematic illustrations of the (a) HSLA-DP980 LWB and (b) tensile and fatigue test specimen machined from and parallel to the region marked by the short-dashed lines in (a). (c) DP980-DP600-HSLA LWB and (d) tensile and fatigue test specimen machined from and parallel to the region marked by the short-dashed lines in (c). 
Table 3.2 Welding parameters

\begin{tabular}{|c|c|c|c|c|}
\hline Joint Type & $\begin{array}{c}\text { Laser Power } \\
(\mathrm{kW})\end{array}$ & $\begin{array}{c}\text { Welding Speed } \\
(\mathrm{m} / \mathrm{min})\end{array}$ & Shielding Gas & $\begin{array}{c}\text { Weld Angle } \\
\text { (degrees) }\end{array}$ \\
\hline DP980-DP600-HSLA GI & 4 & 20.5 & $99 \%$ Argon & 20 \\
\hline DP980-DP600-HSLA GA & 4 & 20.5 & $99 \%$ Argon & 20 \\
\hline DP980-DP980 Rich & 4 & 20.5 & $99 \%$ Argon & 20 \\
\hline DP980-DP980 Rich & 2 & 10 & $99 \%$ Argon & 20 \\
\hline DP980-DP980 Lean & 4 & 20.5 & $99 \%$ Argon & 20 \\
\hline DP980-DP980 Lean & 2 & 10 & $99 \%$ Argon & 20 \\
\hline DP980-DP980 Lean & 6 & 16 & None & 0 \\
\hline HSLA-DP980 & 6 & 16 & None & 0 \\
\hline HSLA-HSLA & 6 & 16 & None & 0 \\
\hline
\end{tabular}

A schematic illustration of the welded blank is shown in Figs. 3.1(b) and 3.1(d). It should be noted that a little concavity was observed in all the welds $(\sim 15 \%)$ as well as some misalignment in some of the welded joints. The subsequent mechanical testing was carried out on the samples in the as-welded state without any post-weld processing.

The metallographic samples used for the examination of microstructural changes were cut from the weld cross-section, then mounted, ground, polished, and etched with a $2 \%$ Nital solution. The etched samples were observed first using a light microscope attached to Clemex image analysis system software and then with a scanning electron microscope (JEOL JSM6380) equipped with three-dimensional fractographic analysis capacity. Vickers microhardness was measured on the polished samples across the weld using a computerized microhardness tester using a load of $200 \mathrm{~g}$ and a dwell time of $15 \mathrm{~s}$. All of the indentations 
were spaced far enough apart to prevent any potential effect of localized strain hardening caused by adjacent indentations. To ensure the validity of each test result, two calibration tests were carried out using a standard reference test block before the microhardness tests on the welded joints were conducted.

Tensile and fatigue test samples were machined from the welded blanks perpendicular to the welding direction in accordance with ASTM: E8/E8M, the example of which is indicated by the dashed line in Figs. 3.1(a) and 3.1(c) with the geometry and dimensions of the test coupons shown in Figs. 3.1(b) and 3.1(d). The specimens were machined in such a way that the weld lines were positioned at the center of the gauge length (Figs. 3.1(b) and 3.1(d)). Tensile tests were conducted using a fully computerized United tensile testing machine at room temperature at a strain rate of $1 \times 10^{-3} \mathrm{~s}^{-1}$. An extensometer with a gauge length of 50 $\mathrm{mm}$ and a strain limit of $20 \%$ was used to measure the strain during the tensile tests. Load control fatigue tests in line with ASTM: E466 were performed on a fully computerized Instron 8801 servo-hydraulic testing system. To avoid potential buckling of the test specimens, tension-tension cyclic loading at a stress ratio of $\mathrm{R}=0.1$ was applied at a frequency of $50 \mathrm{~Hz}$ and sinusoidal waveform. At least two specimens were tested in the tensile tests and fatigue tests at each of the cyclic stress amplitudes. The results that are reported in this thesis are the average values of these multiple tests, and are fairly close to each other $(< \pm 10 \%)$. After the fatigue tests were completed, the fatigue fracture surfaces were examined via scanning electron microscopy (SEM) to identify the fatigue crack initiation sites and the propagation mechanism. 


\section{Chapter 4 Microstructure Results}

\subsection{Galvanizing and Galvannealing Coating}

Putting a GI coating on steel involves a few different preparatory stages: first a cleaning stage where excess dirt and oil are removed in order to ensure a clean surface for the coating, then a pickling stage where the cleaned steel is placed in acid to remove any rust that might be already present on the steel, and finally, a flux solution to prevent further oxidation before the GI coating is placed onto the steel. The steel is then submerged in molten zinc bath for a period of time; the zinc and iron interfaces react to form the zinc coating.

A GA coating is similar to a GI coating in that the prepping procedures are the same and involve dipping the steel in the molten zinc. However, the steel is kept in the bath for a shorter period of time in order to reduce the thickness of the zinc coating. The next stage is an annealing treatment at around $500^{\circ} \mathrm{C}$ to $570^{\circ} \mathrm{C}$ where diffusion of iron into the zinc occurs [35]. This creates different layers of intermetallics as the iron moves through the thickness of the zinc coating $[36,37]$.

Since one material was GI coated and the other GA coated, this creates a special surface that can be seen in Fig. 4.1(a). Fig. 4.1(a) shows the zinc coating from GI DP980 and Fig. 4.1(b) shows the $\mathrm{Zn}-\mathrm{Fe}$ coating from the GA process on DP980. In each type of material, the general surface finish looks relatively similar (Figs. 4.1(a) to 4.1(f)). This is due to the similarity in the coating process rather than a material specific effect. It can also be observed that the coatings on the GI coated samples are thicker than the GA coated ones, and a summary of the different thicknesses can be observed in Fig. 4.2. The annealing process for GA coated samples occurs between $500^{\circ} \mathrm{C}$ to $570^{\circ} \mathrm{C}$, which leads to the reason for the difference in thickness between the GI and GA samples which is that if the GA coating was 
thicker, a longer annealing process would be needed in order to allow for adequate diffusion of iron into the zinc coating. Therefore, the coating thickness is kept to a minimum in the GA process to allow for the different $\mathrm{Zn}$-Fe phases to form throughout the coating [36]. In the GA coating, cracks can be seen, whereas in the GI coating, there are none. This is likely cause by rollers used during the GI process prior to the annealing stage in order to smooth out the surface [35]. 
Gl Coated
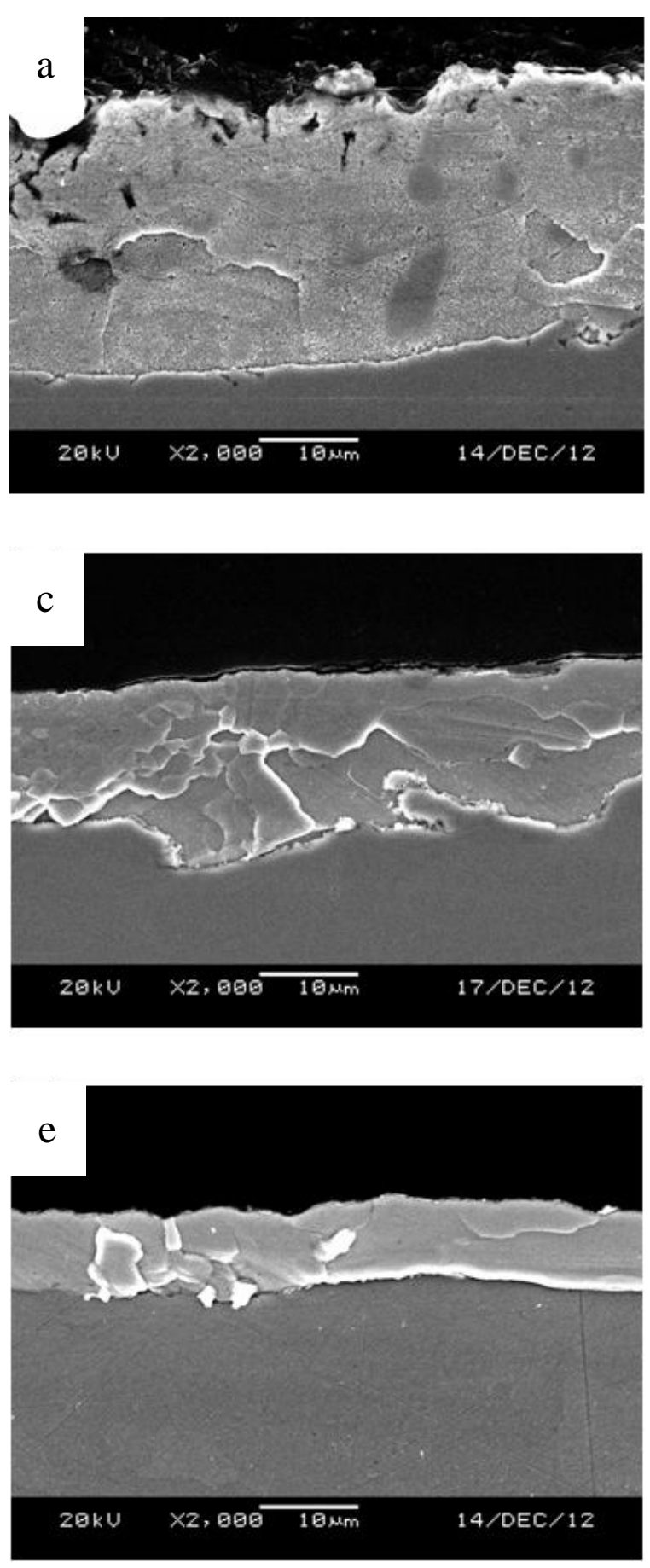

GA Coated
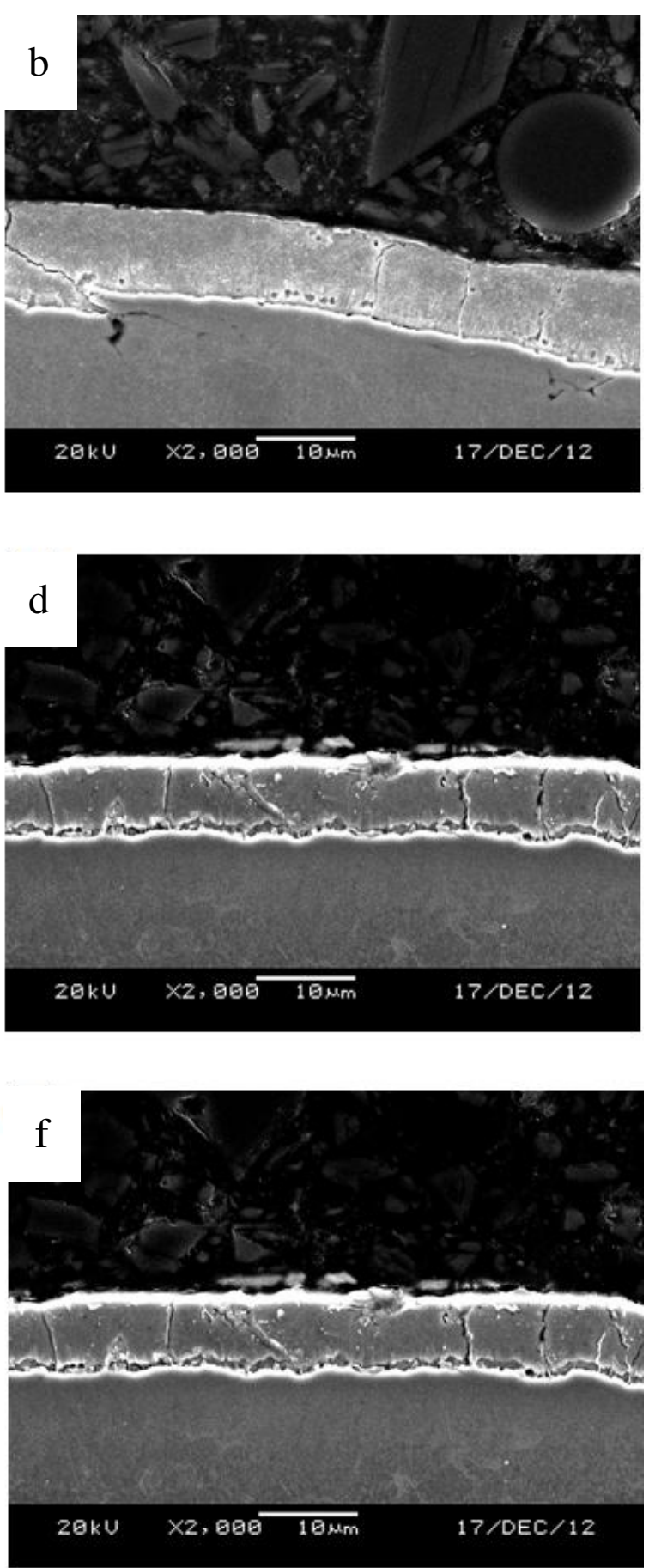

Fig.4.1 (a) GI coated DP980, (b) GA coated DP980, (c) GI coated DP600, (d) GA coated DP600, (e) GI coated HSLA, and (f) GA coated HSLA. 


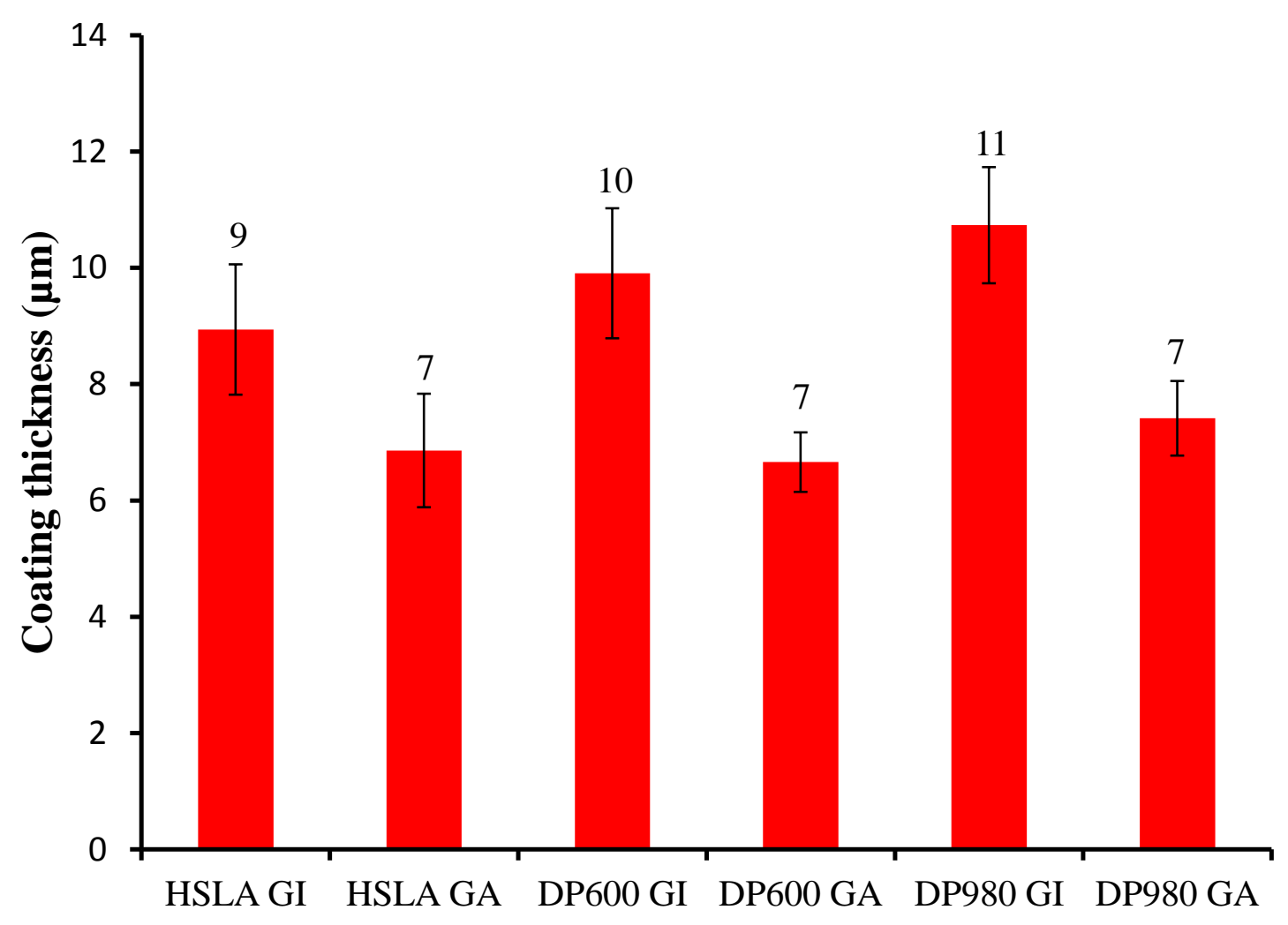

Fig. 4.2 Summary of coating thickness.

\subsection{High Strength Low Alloy Steels}

The manufacturing of HSLA steels occurs primarily for their high strength and good corrosion resistance in comparison to carbon steels. Common alloying elements in HSLA steels are $\mathrm{Mn}, \mathrm{Ni}, \mathrm{Nb}, \mathrm{N}, \mathrm{V}, \mathrm{Cr}, \mathrm{Mo}$, and Ti. These alloying elements help change the properties of HSLA in different ways; some add strength to the ferrite matrix, and some increase the corrosion resistance [38]. In general, the microstructure of HSLA is made up of a fine grained ferrite matrix. Ferrite $(\alpha)$ which has a body centered cubic structure $(B C C)$ is present in the lower temperature region. It can be noted that the amount and soluble carbon in ferrite structure is only $0.022 \mathrm{wt} \% \mathrm{C}$ at $727^{\circ} \mathrm{C}$. In this work, two types of HSLA samples were used, one GI coated and the other one GA coated. Fig. 4.3(a) shows the GI coated HSLA sample which shows the fine ferrite grains with the dispersed ultra fine alloyed carbides that were previously mentioned. In the GA coated HSLA samples (Fig. 4.3(b)), there 
are no carbides present; instead, there are fine pearlite phases that have been localized at the grain boundaries.
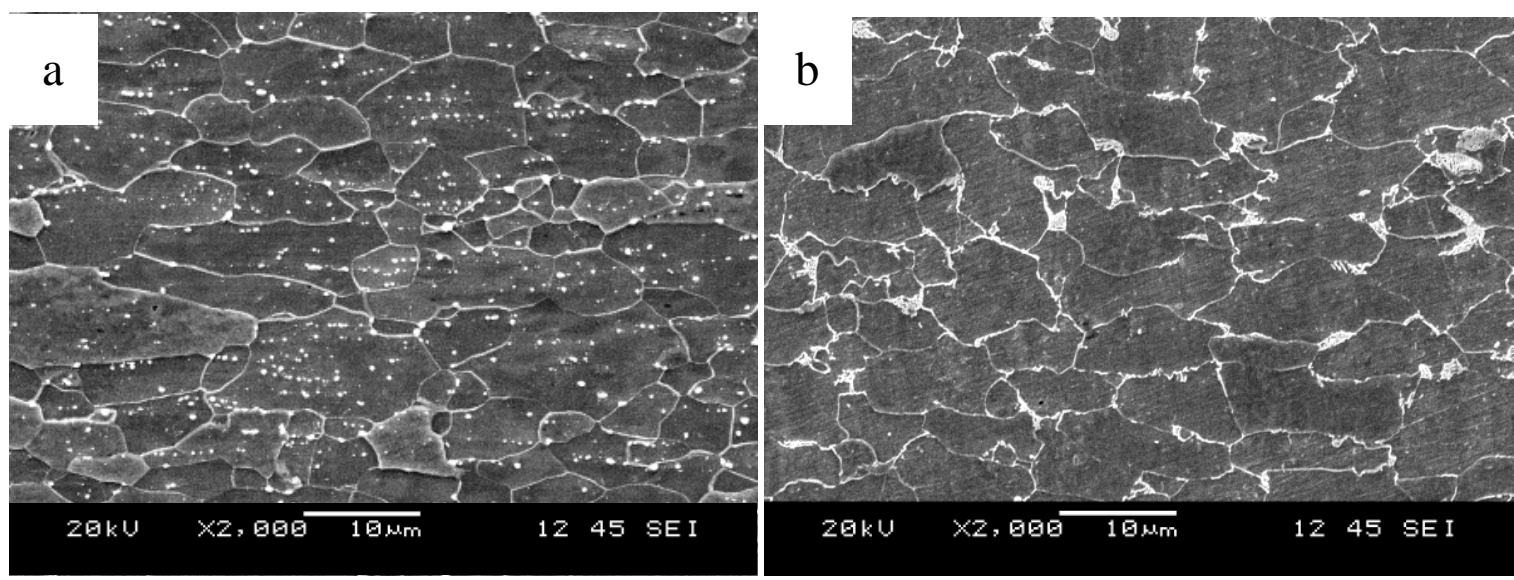

Fig. 4.3 BMs of (a) HSLA GI, and (b) HSLA GA.

\subsection{Dual Phase Steels}

Cooling rates play a very important role in steel microstructure, and that has a strong effect on the mechanical properties of the steel. One common method of strengthening low carbon steel would be to raise it to an elevated temperature such that the steel is in the austenite region of the phase diagram, and then to quench the steel. This forms martensite which has a body centered tetragonal (BCT) structure. This transformation is caused because of the high carbon solubility in face centered cubic (FCC) austenite rapidly transforming into BCC ferrite which has low carbon solubility. Since there is no time for diffusion to occur during the cooling process, the carbon remains in the lattice structure and the BCC lattice is elongated into a BCT structure $[39,40]$.

DP steels, as the name suggests, are composed of two phases, ferrite and martensite. They are made by inter-critically annealing low carbon steel so it is between the $\mathrm{Ac}_{1}$ and $\mathrm{Ac}_{3}$ lines so that a ferrite and austenite structures form; the austenite transforms into martensite and the ferrite remains stable giving the DP structure. The DP steels that were used in this work were 
DP600 and DP980; the number in the name denotes the minimum ultimate tensile stress (UTS) of the steel.

The DP980 steels that were used in this work were two different DP980 samples with a GI coating, one with a rich chemistry and the other with a lean chemistry, and one with a GA coating; their BM microstructures can be seen in Figs. 4.4(a) to 4.4(c). It should be noted that the amount of martensite present in each of these samples is significantly more than that of the DP600 samples; this is the primary difference between their strength. It can also be noted that in the DP980 Lean GI has simply ferrite and martensite as the microstructure, whereas the DP980 Rich GI had the ferrite and martensite matrix but also showed the presence of some bainite $(\sim 7 \%)$. The DP980 GA sample shows a microstructure that is still highly martensitic but has had a small amount of tempering occur to its martensite phase; this is likely due to the GA process being held for a short period of time at above $500^{\circ} \mathrm{C}$ [35]. The DP600 steels were both GI and GA coated and their microstructures can be seen in Figs. 4.4(d) and 4.4(e). The microstructure, as previously mentioned, consisted of martensite islands embedded in a ferrite matrix, but the strength of DP600 is not very high, since the volume fraction of martensite in the matrix is relatively low. It should be noted that there is no significant appearance of tempered matensite in the GA coated DP600 as in the GA coated DP980. 

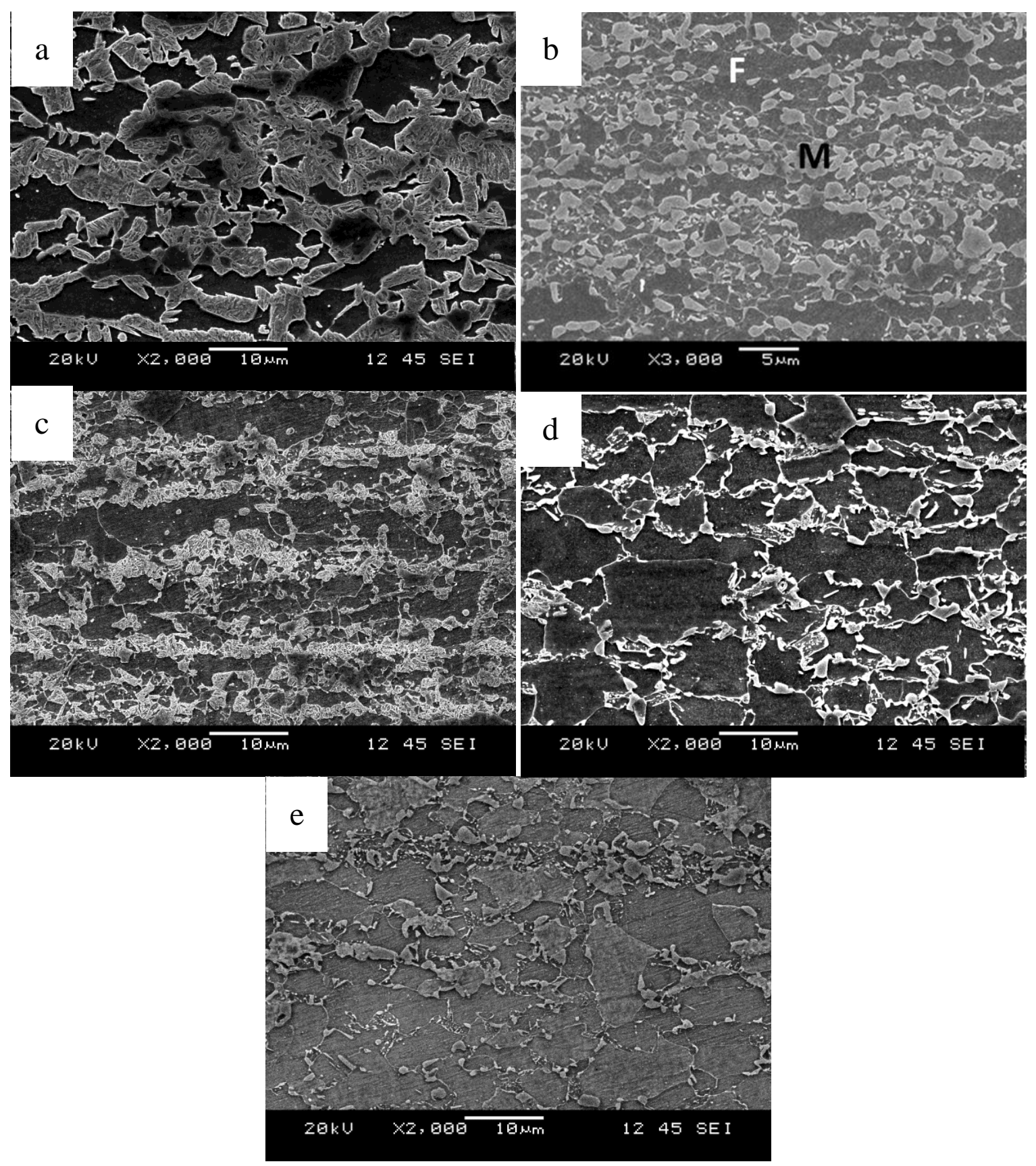

Fig. 4.4 BMs of (a) DP980 Lean GI, (b) DP980 Rich GI, (c) DP980 GA, (d) DP600 GI, and (e) DP600 GA.

\subsection{Welding Microstructure}

In this section, the microstructure of the welded joints within the HAZ will be outlined and discussed as to its formation within the different materials. From these microstructures, correlations will be drawn regarding how the mechanical properties of the joints change with changing microstructure. 


\subsubsection{Fusion Zone}

The fusion zone (FZ) microstructure depends on the welding speed and heat input that were used. Since it was a fusion weld, the material liquefied and then directionally solidified. Depending on the welding parameters, the welds contained a mostly martensitic structure with a lathy morphology and about $\sim 8 \%$ bainite for the high heat input weld (Fig. 4.5(a)) and $\sim 15 \%$ bainite for the low heat input weld (Fig. 4.5(b)). The microstructure developed in the FZ was strongly dependent on the cooling rate involved in the welding process. The continuous-cooling transformation (CCT) diagram of weld metal of low carbon steel shows that the FZ microstructure, depending on the cooling rate, could contain a combination of grain boundary ferrite, side-plate ferrite, acicular ferrite, bainite, and/or martensite [10, 39, 40].
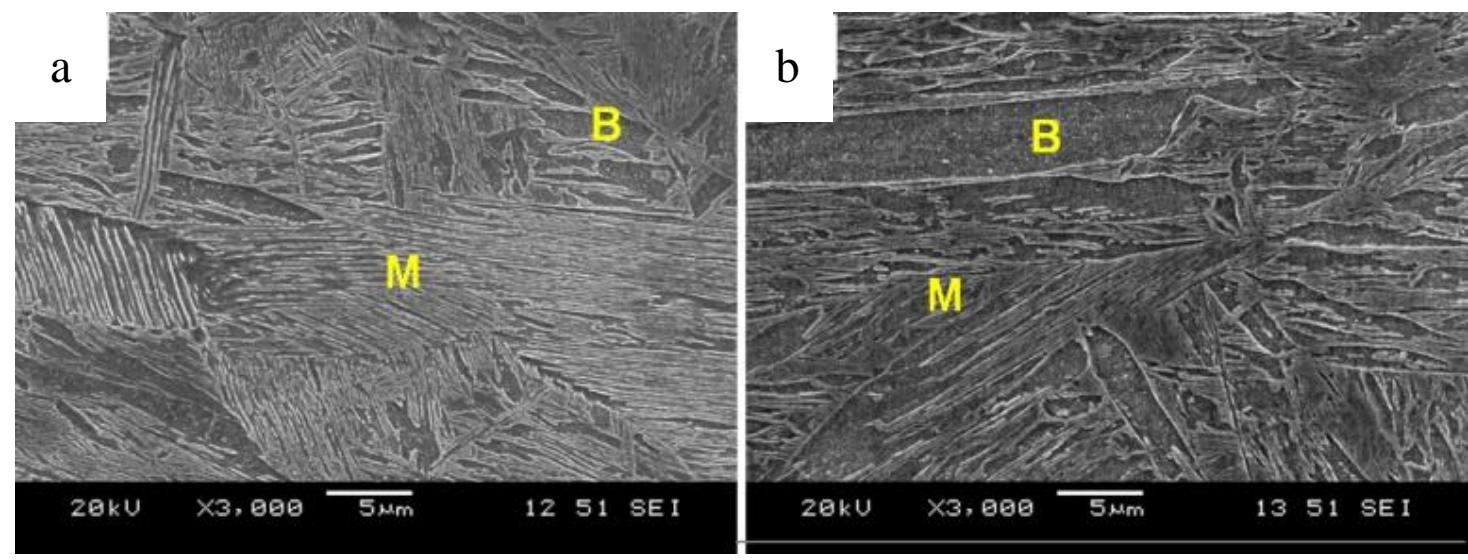

Fig.4.5 The FZ microstructure of (a) high heat input joint ( $16 \mathrm{~m} / \mathrm{min}$ at $6 \mathrm{~kW})$, and (b) low heat input joint $(20.5 \mathrm{~m} / \mathrm{min}$ at $4 \mathrm{~kW})$. (M: martensite, B: bainite)

\subsubsection{HSLA}

As previously iterated in the section on HSLA BM, the HSLA BM microstructure consists of fine grained ferrite matrix with a uniform dispersion of fine alloy carbides for the GI coated samples, and a similarly fine grained ferrite matrix with alloyed carbides present in the grain boundaries but not within the grains in the GA coated sample. The microstructure in the HAZ 
of the HSLA welded joints can be broken down into different regions within the HAZ, the upper-critical HAZ, and the inter-critical HAZ. The upper-critical HAZ is where the temperature rose above the $\mathrm{Ac}_{3}$ line, meaning that upon cooling, a martensitic transformation occurred causing it to become a mostly martensitic structure with a very small fraction of ferrite (see Figs. 4.6(a) and 4.6(c)). The inter-critical HAZ is the region that is formed when the temperature is in between the $\mathrm{Ac}_{1}$ and $\mathrm{Ac}_{3}$ lines so that a partially martensitic transformation occurs. It can be seen in Figs. 4.6(b) and 4.6(d) that there is ferrite, martensite and bainite present in the region.

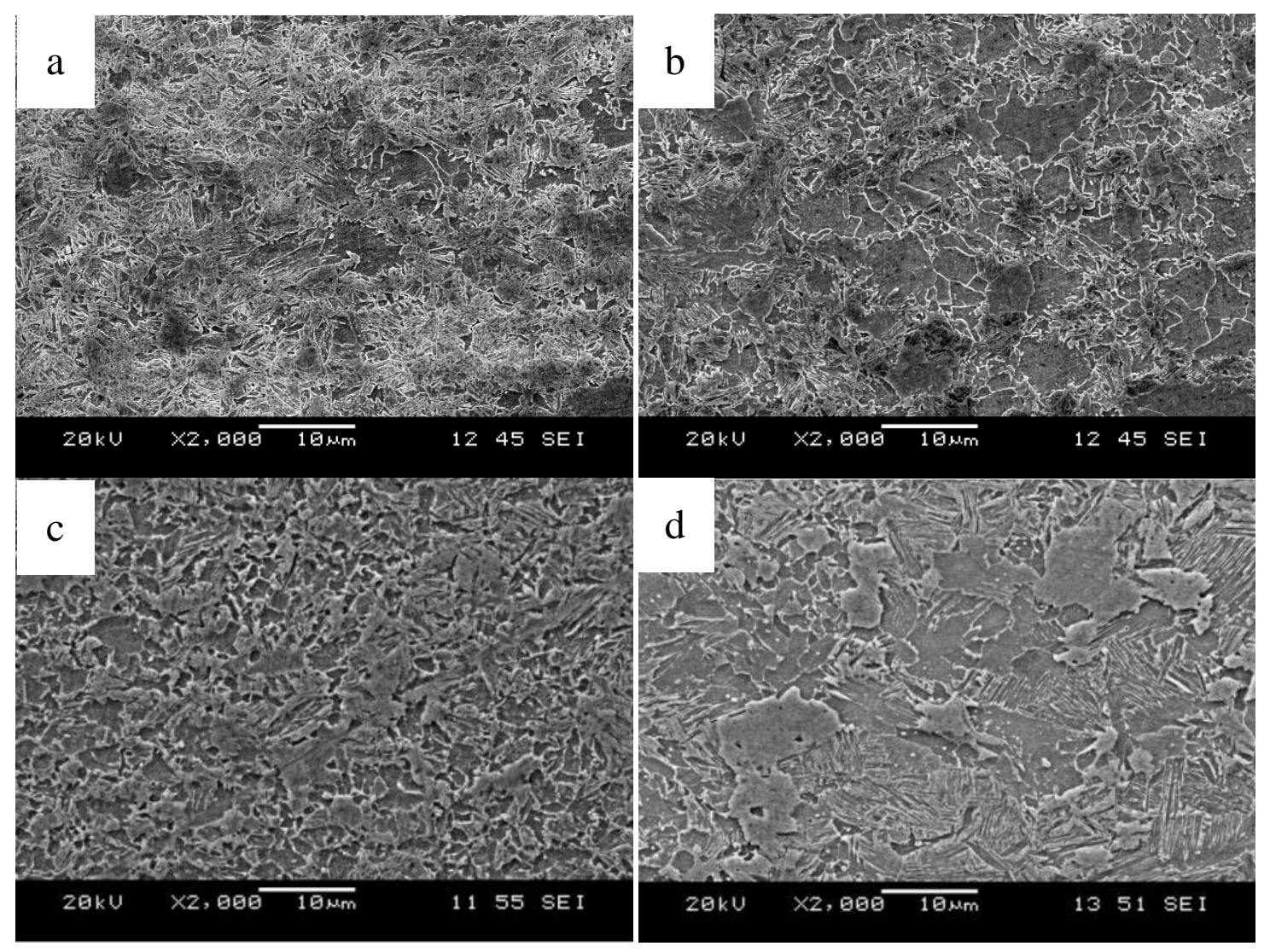

Fig. 4.6 (a) HSLA GA upper-critical HAZ, (b) HSLA GA inter-critical HAZ, (c) HSLA GI uppercritical HAZ, and (d) HSLA GI inter-critical HAZ. 


\subsubsection{DP980}

Fig. 4.7 shows the SEM images detailing the HAZ microstructure obtained in DP980 welded joints. The DP980 HAZ contained three different regions: the upper-critical HAZ, the intercritical HAZ and the subcritical HAZ. The upper-critical HAZ experienced temperatures above $\mathrm{Ac}_{3}$ line, the inter-critical HAZ temperatures were between the $\mathrm{Ac}_{1}$ and $\mathrm{Ac}_{3}$ lines, and in sub-critical HAZ the temperature was below the $\mathrm{Ac}_{1}$ line. The upper-critical HAZ, as in the HSLA material, showed an increased fraction of transformed martensite as compared to the (Figs. 4.7(a) and 4.7(d)). In the inter-critical HAZ (Figs. 4.7(b) and (e)), like in the HSLA weld, austenite formed since the temperature rose above $\mathrm{Ac}_{1}$ line of the steel and subsequently transformed to form martensite which was different from BM martensite and the volume fraction of which increased as we moved away from the $\mathrm{Ac}_{1}$ line (subcritical and inter-critical HAZ boundary) towards the $\mathrm{Ac}_{3}$ line (boundary between inter-critical and upper-critical HAZ). The subcritical HAZ showed that the pre-existing martensite from the BM decomposed into partially tempered martensite (PTM), as can be seen in Figs. 4.7(c) and 4.7(f). Tempering of BM martensite in the fusion welding of DP980 steel has been reported in a number of previous studies $[10,11,12,13,14,15,41,42]$. 

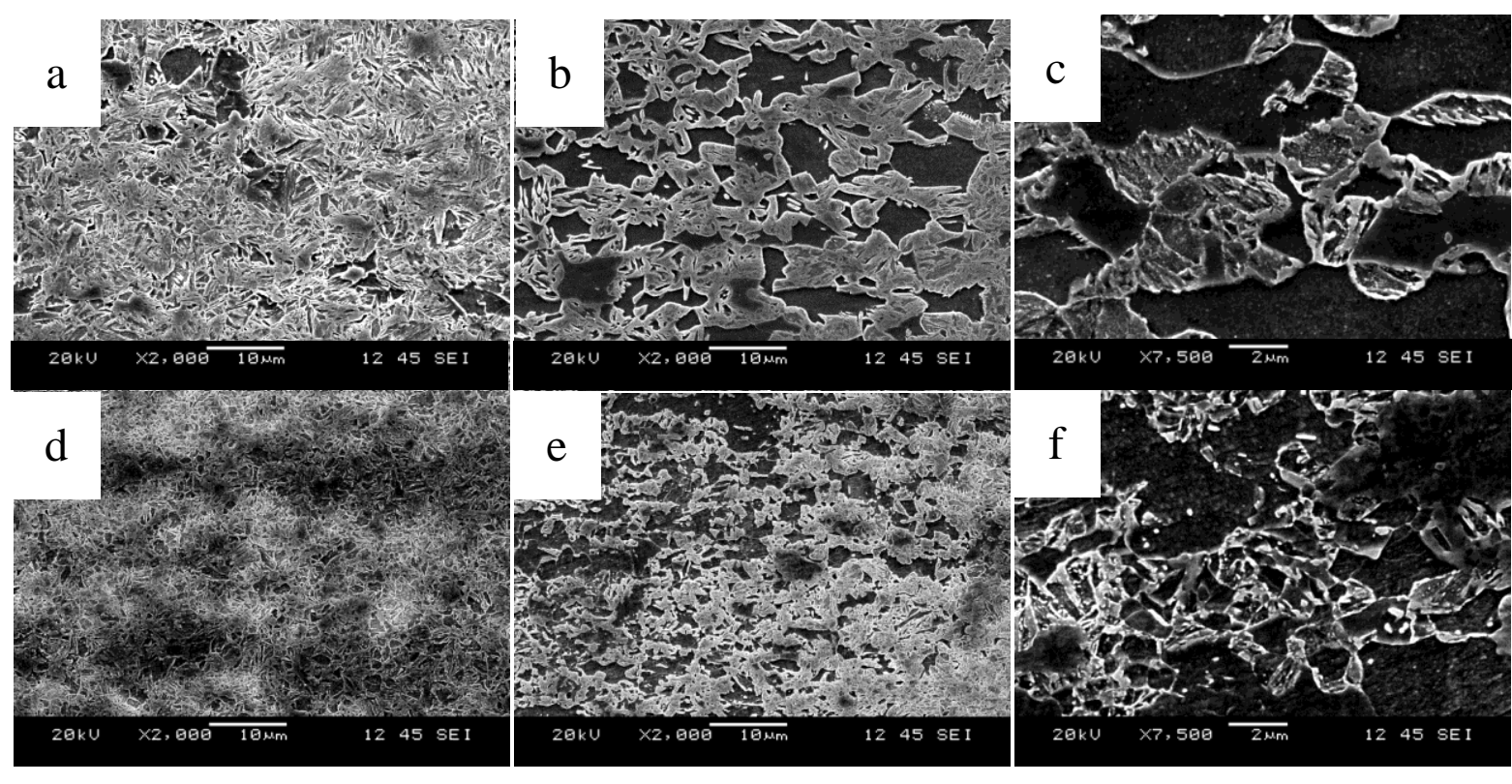

Fig. 4.7 (a) DP980 GI upper-critical HAZ, (b) HSLA GI inter-critical HAZ, (c) DP980 GI sub-critical HAZ, (d) DP980 GA upper-critical HAZ, (e) HSLA GA inter-critical HAZ, and (f) DP980 GA subcritical HAZ.

\subsubsection{DP600}

The DP600 HAZ has a similar microstructure to the previous DP980 and HSLA HAZs. The DP600 HAZ has similar sub regions to the HSLA material, and it has an upper-critical HAZ (Figs. 4.8(a) and 4.8(c)) and an inter-critical HAZ (Figs. 4.8(a) and 4.8(c)), but no observable subcritical HAZ because the amount of martensite in the matrix is fairly low and the speed of the weld did not produce a sufficiently high temperature over a long enough period of time to cause a lot of tempering which has been seen with high heat inputs from Nd:YAG lasers and showed a very small amount of softening in the sub-critical HAZ [13]. 

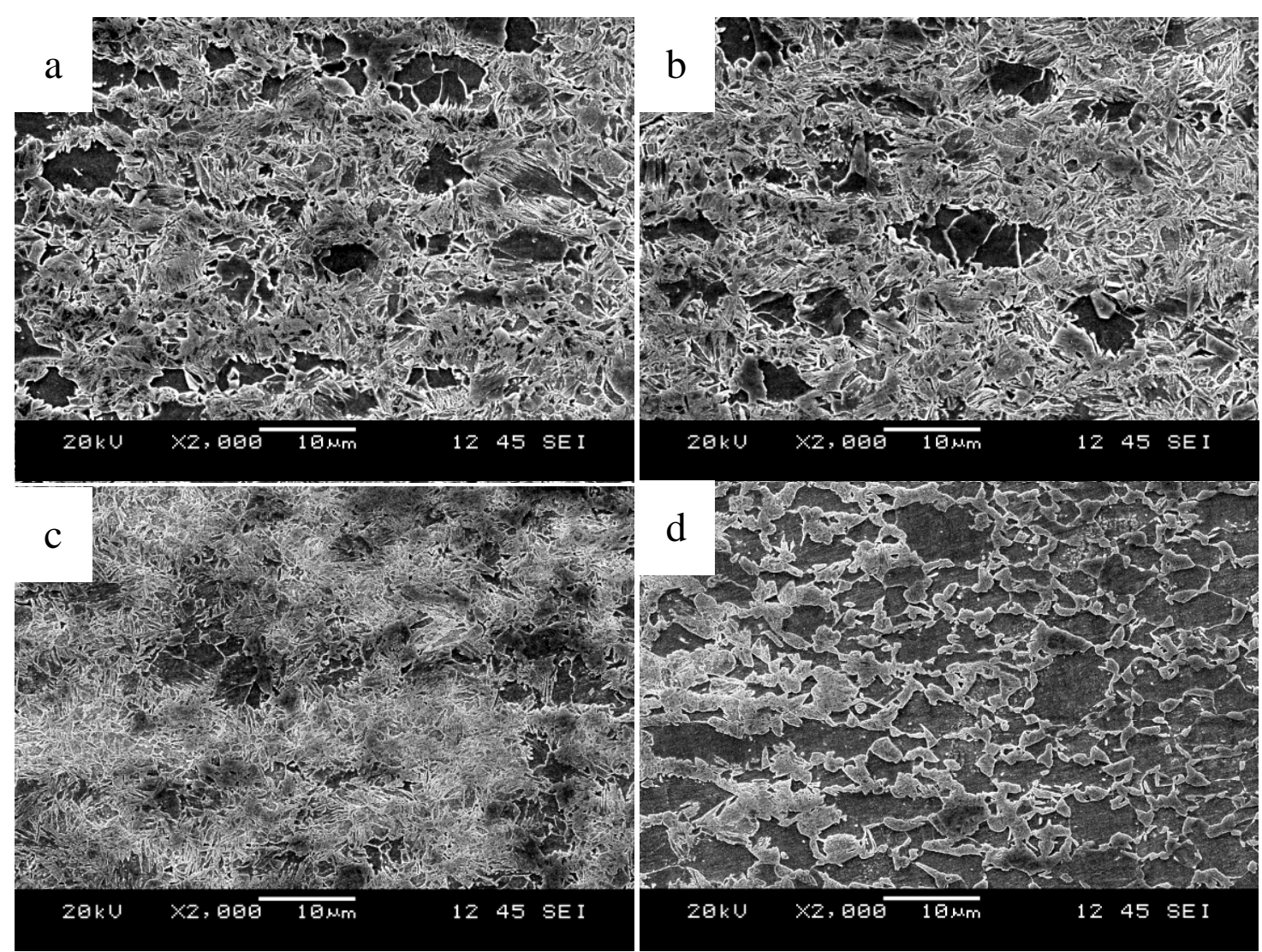

Fig. 4.8 (a) HSLA GI upper-critical HAZ, (b) HSLA GI inter-critical HAZ, (c) HSLA GA uppercritical HAZ, and (d) HSLA GA inter-critical HAZ. 


\section{Chapter 5 Tensile and Fatigue Properties of Fiber Laser Welded Dissimilar Joints between High Strength Low Alloy and Dual-Phase Steels}

To facilitate the design of laser welded blanks and promote a widespread use of DP steels in the automotive industry, the relationships between the microstructural change involved in FLW and the static and dynamic performance of the welded joints must be carefully evaluated so as to guarantee the reliability and durability of the parts, as well as the overall safety of the passenger vehicles. The present study is an extension of previous work, which was aimed at characterizing the dissimilar FLWed joints of DP980 and HSLA with respect to the microstructure change and fatigue performance.

\subsection{Microhardness}

Using a similar approach as Song et al. [43], the microhardness profile across the dissimilar HSLA-DP980 welded joint is presented in Fig. 5.1. It is seen that the hardness profile exhibited an asymmetric characteristic with a higher hardness on the DP980 side and a lower hardness on the HSLA side. In particular, a soft zone appeared on the DP980 side, but it was absent on the HSLA side. For the sake of a better comparison, the hardness data across the similar HSLA-HSLA and DP980-DP980 welded joints are plotted in Fig. 5.2. It is seen that both the HSLA-HSLA welded joint and the HSLA side of the dissimilar HSLA-DP980 welded joint had a similar trend of hardness variation with a constant and uniform BM hardness followed by a sharp increase through the HAZ up into the FZ. This was due to the fact that the microstructure of the HSLA BM was composed of fine ferrite grains with dispersed alloy carbides (Fig. 4.3(a)), while in the inter-critical and upper-critical zones of the HAZ, there was a gradual transformation into martensite which accounted for the increase in hardness up to the FZ with a highly martensitic structure (Figs. 4.8(c) and 4.8(d)) [10]. It is also seen from Fig. 5.2 that the hardness change on the DP980 side of the dissimilar welded 
joint was equivalent to that of similar DP980-DP980 welded joint, where there was a relatively high hardness in the $\mathrm{BM}$ arising from the structure of a ferrite matrix with a higher volume faction of martensite (Fig. 4.4(a)). From the BM across the HAZ into the FZ, the soft zone in the HAZ formed in the sub-critical region, where the temperature experienced in the welding process was below the $\mathrm{Ac}_{1}$ line of the steel, leading to tempering of $\mathrm{BM}$ martensite with the extent of tempering decreasing with decreasing temperature, i.e., moving away from the $\mathrm{Ac}_{1}$ line towards the $\mathrm{BM}$. This tempering effect resulted in a localized decrease in hardness as seen in the hardness profile (Figs. 5.1 and 5.2) as a valley [10, 34, 41].

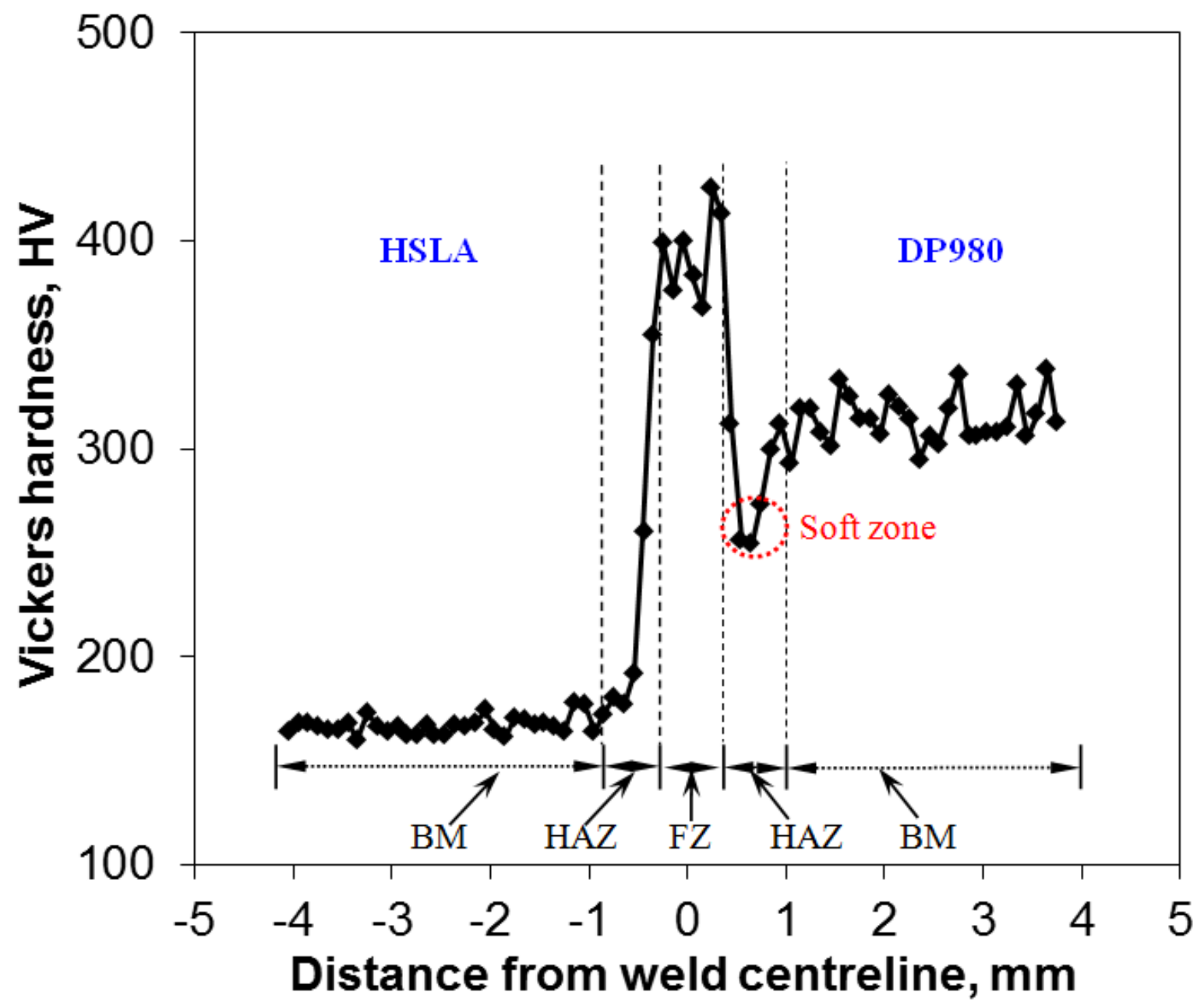

Fig. 5.1 Microhardness profile across the dissimilar HSLA-DP980 welded joint. 
It is of particular interest to observe that inside the FZ there were two distinct hardness subregions associated with two different materials (i.e., $~ 390 \mathrm{HV}$ on the HSLA side and $\sim 410$ HV on the DP980 side). This was a result of the difference in chemistry between HSLA and DP980, where the carbon and manganese contents of DP980 were higher than that of HSLA (nearly doubled as listed in Table 3.1), leading to a higher carbon martensite upon solidification and rapid cooling in the vicinity of DP980 steel. That is, the hardenability in the sub-region near the DP980 steel was higher due to the presence of a higher amount of alloying elements $[39,40]$. Since the time involved in the liquid state and the subsequent solidification during the FLW was very short, there was little or insufficient diffusion in the FZ, which implied that the FZ was still in the form of segregation between the two materials. This is why two sub-regions could be observed in the FZ of the dissimilar HSLA-DP980 welded joint (Fig. 5.1), although the morphology and amount of martensite appeared roughly the same. 


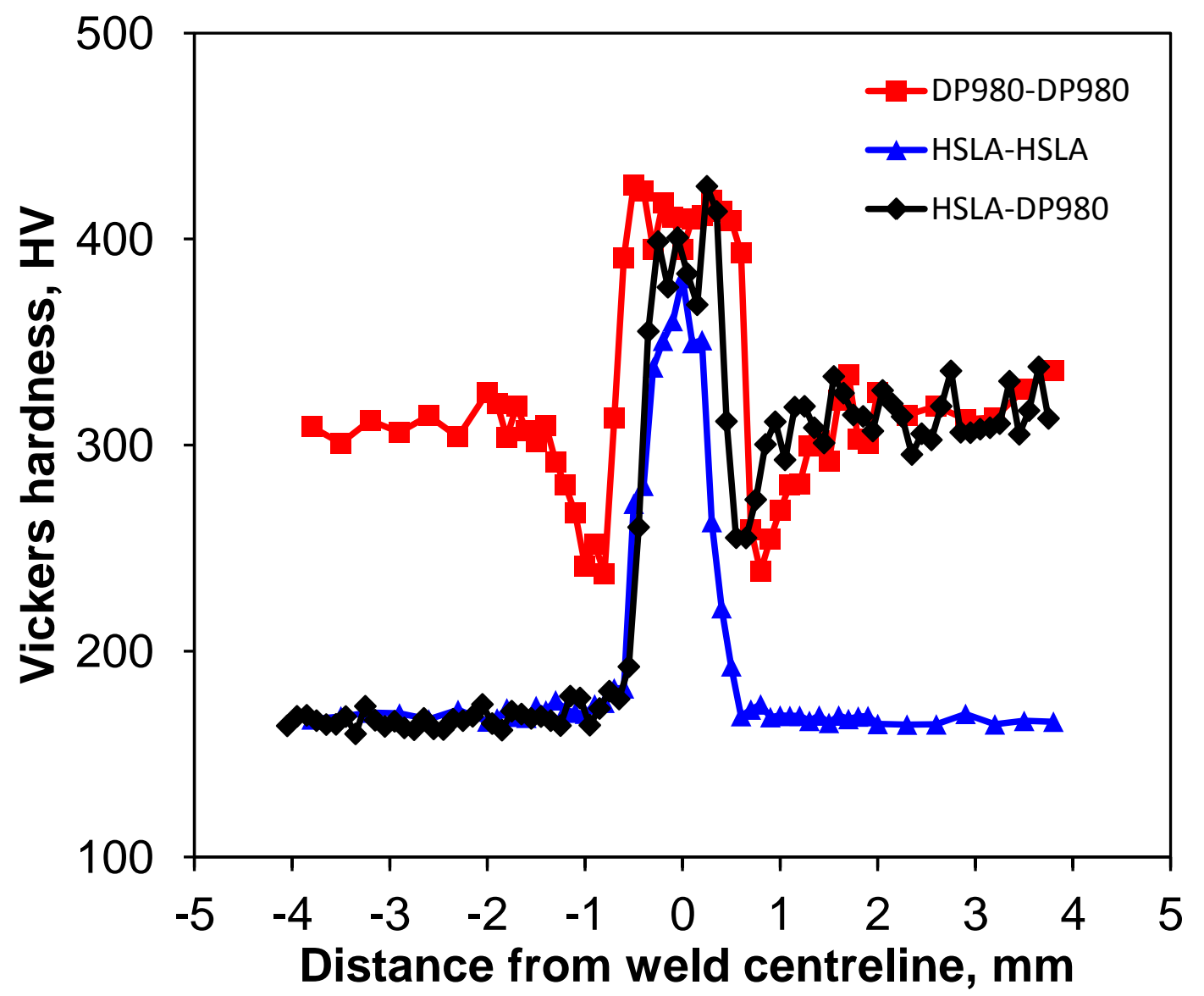

Fig. 5.2 A comparison of hardness for the HSLA, DP980, and dissimilar welded joints made at a welding speed of $16 \mathrm{~m} / \mathrm{min}$, where the hardness data for the HSLA-HSLA and DP980-DP980 similar joints were taken from ref. [10].

\subsection{Tensile properties}

The representative engineering stress versus engineering strain curves of the similar HSLAHSLA and DP980-DP980, and dissimilar HSLA-DP980 welded joints are illustrated in Fig. 5.3. The details of the tensile test results are given in Table 5.1. In the similar HSLA-HSLA welded joints, the yield stress (YS), UTS, and the strain to failure after FLW were observed to be very close to those of the BM within the experimental scatter. For example, the YS and UTS of the HSLA-HSLA welded joints were $446 \mathrm{MPa}$ and $529 \mathrm{MPa}$, respectively, which were very close to those of the BM which had a YS of $455 \mathrm{MPa}$ and UTS of $546 \mathrm{MPa}$, respectively, with a joint efficiency of $97 \%$ (Table 5.1). These tensile results suggested that 
the FLW process did not deteriorate the tensile properties of the HSLA steel, which was apparently attributed to the fact that in the HSLA-HSLA welded joints no soft zone occurred in the HAZ (Figs. 5.1 and 5.2) that was detrimental to the mechanical properties of the welds [10]. This was also corroborated by the observations that the failure of HSLA-HSLA welded joints during tensile testing consistently occurred in the BM.

Table 5.1 Tensile properties and fatigue parameters $\sigma_{f}^{\prime}$ and $b$ for HSLA BM, DP980 BM, similar HSLA-HSLA and DP980-DP980 welded joints, and dissimilar HSLA-DP980 welded joints [10].

\begin{tabular}{|l|c|c|c|c|c|c|c|c|}
\hline $\begin{array}{l}\text { Welding } \\
\text { type }\end{array}$ & $\begin{array}{c}\text { YS } \\
(\mathrm{MPa})\end{array}$ & $\begin{array}{c}\text { UTS } \\
(\mathrm{MPa})\end{array}$ & $\begin{array}{c}\text { Elongation } \\
(\%)\end{array}$ & $\begin{array}{c}\text { Joint } \\
\text { efficiency }\end{array}$ & $\begin{array}{c}\text { Fatigue } \\
\text { limit } \\
(\%)\end{array}$ & $\begin{array}{c}\text { Fatigue } \\
\text { ratio }\end{array}$ & $\begin{array}{c}\sigma_{f}^{\prime} \\
(\mathrm{MPa})\end{array}$ & $b$ \\
\hline $\begin{array}{l}\text { HSLA- } \\
\text { HSLA }\end{array}$ & 446 & 529 & 22.3 & 97 & 125 & 0.236 & 328 & - \\
\hline $\begin{array}{l}\text { HSLA- } \\
\text { DP980 }\end{array}$ & 467 & 548 & 15.4 & $\sim 100$ & 175 & 0.319 & 371 & - \\
\hline $\begin{array}{l}\text { HSLA } \\
\text { BM }\end{array}$ & 455 & 546 & 24.7 & - & 200 & 0.366 & 302 & - \\
\hline $\begin{array}{l}\text { DP980 } \\
\text { BM }\end{array}$ & 720 & 1095 & 14.2 & - & 250 & 0.228 & 1019 & - \\
\hline $\begin{array}{l}\text { DP980- } \\
\text { DP980 }\end{array}$ & 720 & 1067 & 5.3 & 97 & 150 & 0.141 & 1169 & - \\
\hline
\end{tabular}

In contrast to the HSLA-HSLA welded joints, the DP980-DP980 welded joints showed a lower strain to failure (5.3\%). However, the UTS (1067 MPa) was also very close to that of the DP980 BM (1095 MPa), indicating a high joint efficiency (97\%) as well (Fig. 5.3 and 
Table 5.1). Obviously, the strength of the DP980-DP980 welded joints made with the FLW did not decrease in spite of the presence of soft zone, while the strength of the joints made with the DLW exhibited a fair amount of decrease $[12,34]$. This was obviously related to the narrower and less severe soft zone in the present fiber laser welded joints (Figs. 5.1 and 5.2). It follows that the smaller laser beam spot size and higher power intensity in conjunction with a higher welding speed in the FLW greatly improved the strength of the welded joints by reducing the detrimental effects of soft zone by narrowing it down significantly. However, the decrease in ductility of the DP980-DP980 welded joints was still attributed to the presence of soft zone. With progressive loading beyond the UTS, the plastic deformation of the similar DP980-DP980 welded joints concentrated in the soft zone due to its lower strength, causing a premature failure and thus a lower strain to failure [10, 34]. Similar results were also found by Hazratinezhad et al. using DP980 steel with an Nd:YAG laser [41]. 


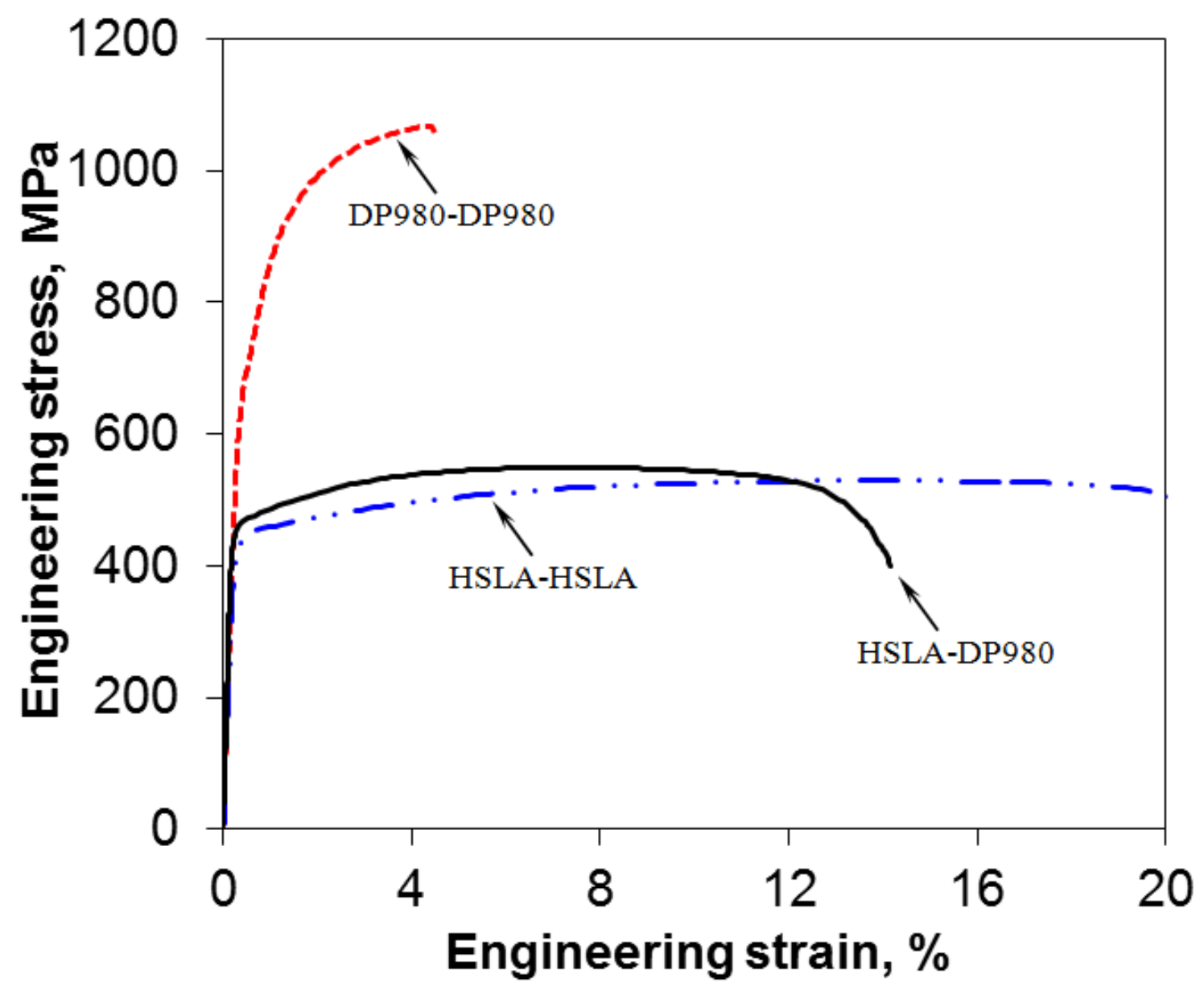

Fig. 5.3 Representative engineering stress versus engineering strain curves of the HSLA, DP980, and dissimilar welded joints tested at a strain rate of $1 \times 10^{-3} \mathrm{~s}^{-1}$.

As seen from Table 5.1, while the YS (467 MPa) and UTS (548 MPa) of the dissimilar HSLA-DP980 welded joints were well below those of the similar DP980-DP980 welded joints, they were essentially the same as those of the HSLA BM or similar HSLA-HSLA welded joints. Based on the UTS of HSLA BM rather than that of DP980 BM, the joint efficiency of the present dissimilar HSLA-DP980 welded joints indeed reached about $100 \%$. It should be noted that the experimentally obtained slightly higher YS and UTS of the dissimilar HSLA-DP980 welded joints than those of HSLA BM were considered to be due to experimental error, since it would be impossible to have a joint efficiency of over $100 \%$. It is of special interest to observe that the dissimilar HSLA-DP980 welded joints showed a 
considerable (nearly three-fold) improvement in the strain to failure (15.4\%), compared with the similar DP980-DP980 welded joints (5.3\%), although it was lower than that of the similar HSLA-HSLA welded joints (22.3\%). It was observed that the DP980 side of the dissimilar weld did not yield at all during tensile testing, with almost all the plastic deformation taking place on the HSLA side. Panda et al. found similar results for a limited dome height formability test of a DLW HSLA-DP980 sheet [44]. It is clear that the presence of the soft zone in the HAZ of the DP980 side did not have any effect on the YS and UTS of the dissimilar HSLA-DP980 welded joints. This was understandable since the lowest hardness value at the valley of soft zone (255 HV) was still higher than that of the HSLA BM (167 HV), as shown in Fig. 5.1. As a result, only HSLA would yield during tensile loading.

\subsection{Fatigue properties}

Fatigue tests of the similar HSLA-HSLA and DP980-DP980, and dissimilar HSLA-DP980 welded joints were carried out at room temperature at a stress ratio of $\mathrm{R}=0.1$, and the obtained S-N curves are plotted in Fig. 5.4. Like the tensile testing, the dissimilar HSLADP980 welded joints behaved nearly the same as the similar HSLA-HSLA welded joints. The similar DP980-DP980 welded joints exhibited a much higher fatigue strength in the low cycle fatigue regime below $\sim 5 \times 10^{4}$ cycles, although there was no big difference in the high cycle fatigue regime where the experimental scatter also became larger. At a high stress amplitude of 350-450 MPa in the similar DP980-DP980 welded joints, some yielding would occur since the maximum stress at $\mathrm{R}=0.1$ exceeded the $\mathrm{YS}$ of $720 \mathrm{MPa}$ (Table 5.1). As the stress amplitude decreased, the fatigue life became longer but more scattered. This was due to a more sensitive effect of the soft zone in the HAZ and the concavity [45] that was present in 
the welded joints, as shown in Fig. 4.7(c). Similar weld concavity was reported in [34, 46, 47] as well.

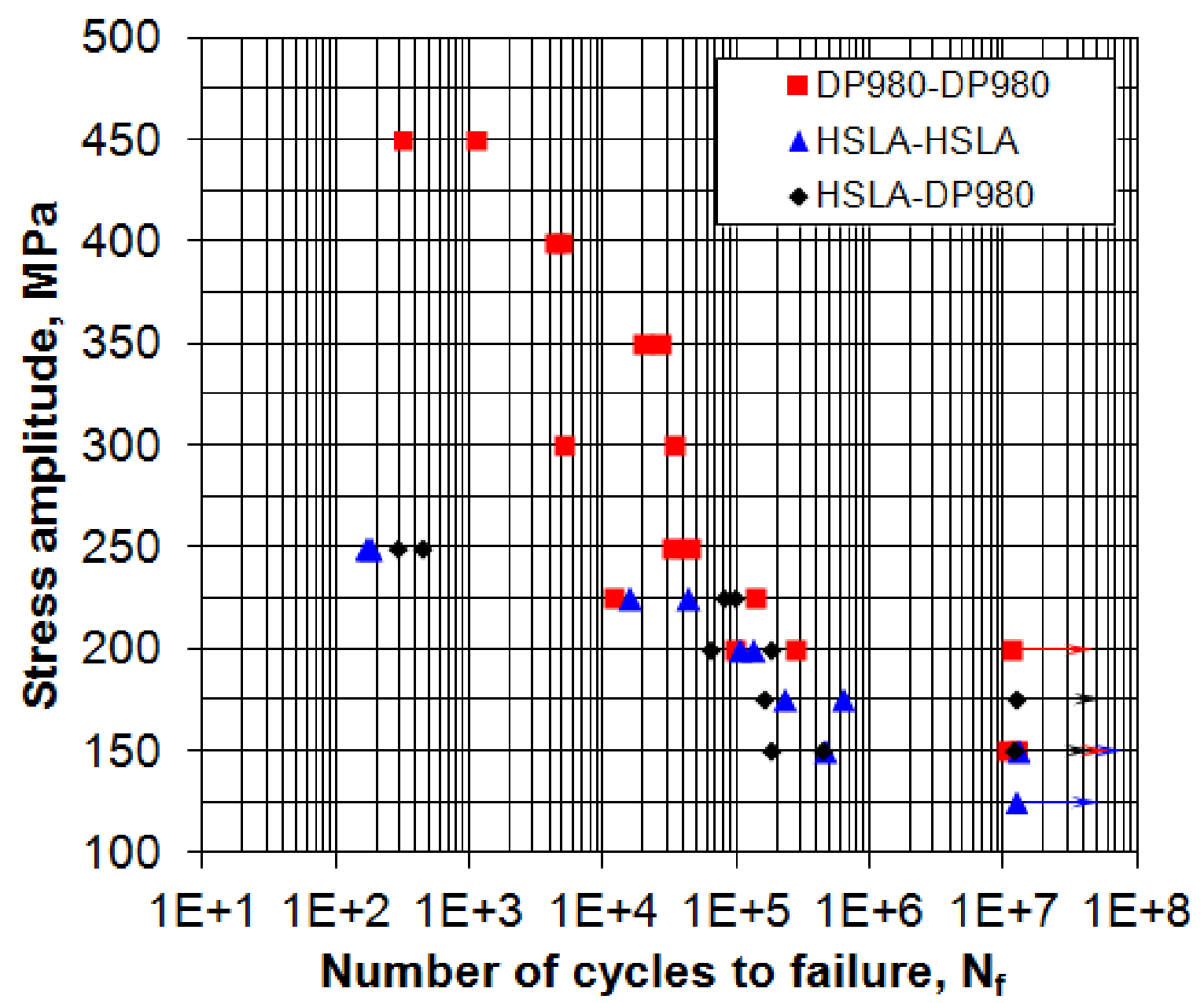

Fig. 5.4 Comparison of the S-N curves of the HSLA, DP980, and dissimilar welded joints tested at $\mathrm{R}=0.1,50 \mathrm{~Hz}$, and room temperature, where the DP980-DP980 and HSLA-HSLA curves are taken from [10].

Likewise, in the similar HSLA-HSLA welded joints and dissimilar HSLA-DP980 welded joints, at high stress amplitudes of 225-250 MPa, the peak stress was above the yield stress of HSLA BM (Table 5.1), causing the yielding and failure in the BM, as shown in Fig. 5.5(a). At the lower stress amplitudes (i.e., below $200 \mathrm{MPa}$ ) there was a larger scatter in the experimental data since the samples failed in the weld area (Figs. 5.5(b) and 5.5(c)), which was related to the stress concentration developed by the concavity in the welds [46, 47]. 
Since the samples that are subjected to cyclic loading were reported to be more susceptible to heterogeneous changes in the microstructure than those done in a tensile test $[33,46]$, it is thus not difficult to understand that the fatigue data obtained at the lower stress amplitudes would exhibit a larger scatter than the tensile data due to the large microstructural change across the weld and the presence of weld concavity.
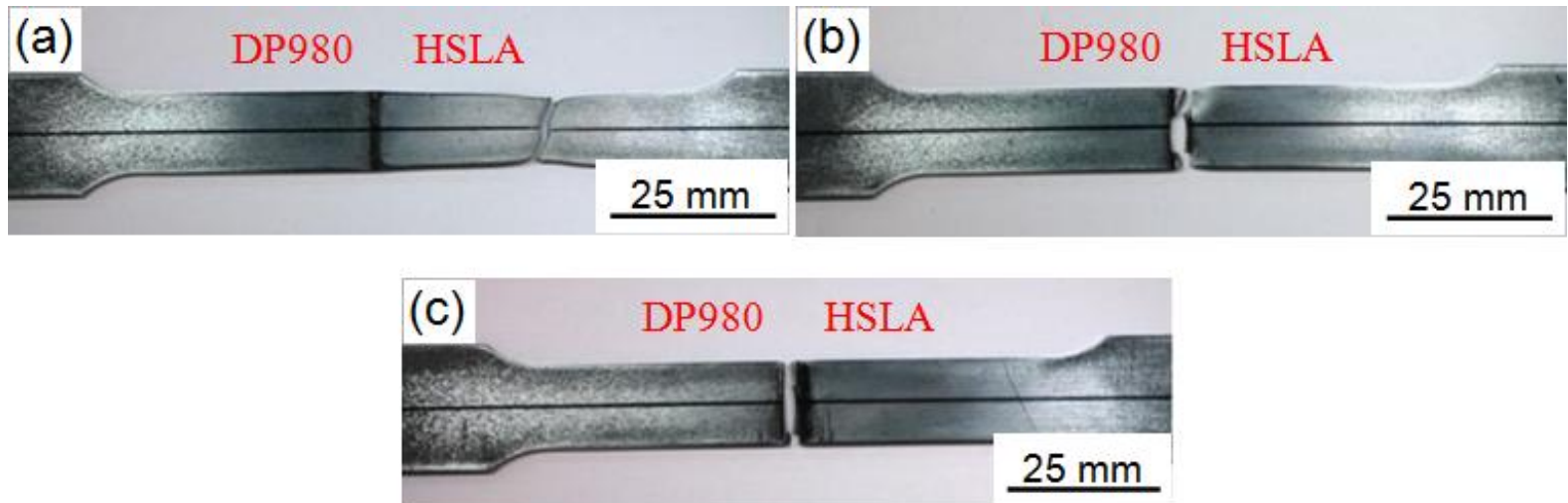

Fig. 5.5 Typical fatigue failure locations in the dissimilar HSLA-DP980 welded joints at stress amplitudes of (a) $250 \mathrm{MPa}$, (b) $200 \mathrm{MPa}$, and (c) $175 \mathrm{MPa}$.

The S-N plot in Fig. 9 could be expressed using the Basquin equation [33, 46],

$$
\sigma_{a}=\sigma_{f}{ }^{\prime}\left(2 N_{f}\right)^{b}
$$

where $\sigma_{a}$ is the cyclic stress amplitude, $\sigma_{f}{ }^{\prime}$ is the fatigue strength coefficient defined by the stress intercept at $2 N_{f}=1, N_{f}$ is the number of cycles to failure $\left(2 N_{f}\right.$ is the number of reversals to failure), and $b$ is the fatigue strength exponent. The values of these parameters obtained by fitting the data points according to Eqn. (5.1) are tabulated in Table 2. The fatigue life of the welded joints could be estimated based on the values of $\sigma_{f}{ }^{\prime}$ and $b$. Eqn. (5.1) indicates that the higher the value of $\sigma_{f}{ }^{\prime}$ and the smaller the absolute value of $b$, which is always negative, the longer the fatigue life. It is seen from Table 2 that the HSLA-related specimens (i.e., HSLA BM, similar HSLA-HSLA welded joints, and dissimilar HSLA-DP980 welded joints) 
had an equivalent set of $\sigma_{f}{ }^{\prime}$ and $b$ values within the experimental scatter, giving rise to roughly the same overall fatigue life (Fig. 5.4). In comparison with the HSLA-related specimens, while the absolute value of fatigue strength exponent, $|b|$, of the DP980 BM and similar DP980-DP980 welded joints was higher, which was supposed to give rise to a lower fatigue life, the fatigue strength coefficient $\sigma_{f}{ }^{\prime}$ was nearly or over three times higher, leading to a much higher fatigue life. Such a seemingly conflicting set of $\sigma_{f}{ }^{\prime}$ and $b$ values via their combined effects determine the overall fatigue of these similar and dissimilar welded joints and BM. It should be noted that the lower fatigue ratio (i.e., the ratio of the fatigue limit to the UTS) in the DP980 BM and similar DP980-DP980 welded joints, in comparison with to the HSLA-related specimens, was mainly due to the fact that the UTS of the DP980-DP980 welded joints had nearly twice that of the HSLA and only had a slightly higher fatigue limit (Table 5.1). These conclusions were also found by $\mathrm{Xu}$ et al. using similar HSLA-HSLA and DP980-DP980 welded joints [10].

\subsection{Fractography}

Some typical SEM images of a fatigue fracture surface of a dissimilar HSLA-DP980 welded joint tested at a high stress amplitude of $250 \mathrm{MPa}$ are shown in Fig. 5.6. Interestingly, no clear crack initiation area could be seen (Fig. 5.6(a)) as the failure was primarily caused by the yielding in the BM region on the HSLA side (Fig. 5.5(a)) due to the high maximum stress beyond the YS of HSLA at this cyclic stress level, which could be confirmed by the tapered region seen around the fracture surface, indicated by "c" in Fig. 5.6(a). Fatigue crack propagation was basically characterized by the occurrence of fatigue striations in conjunction with the dimples and plastic ridges, as shown in Fig. 5.6(b) [10]. 

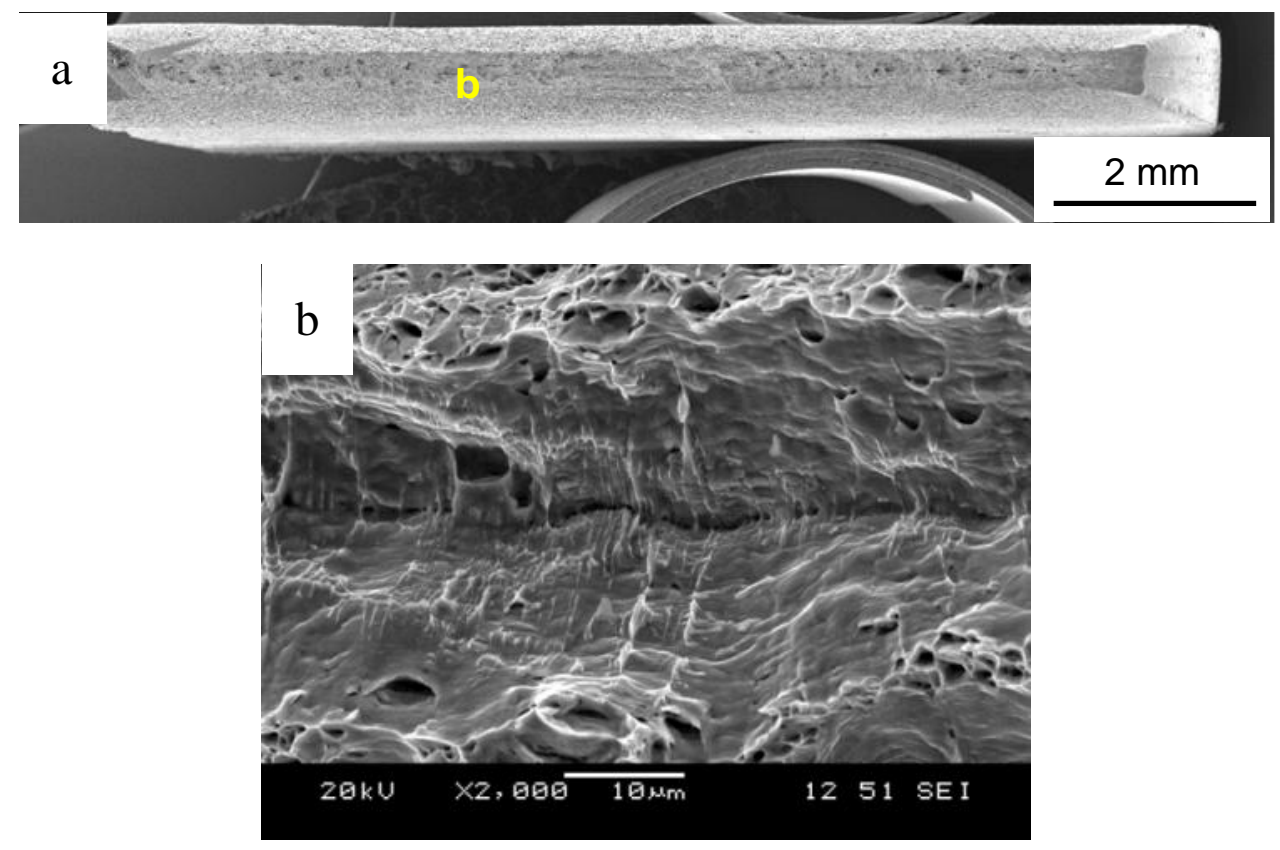

Fig. 5.6 SEM images illustrating the fatigue fracture surface of a dissimilar HSLA-DP980 welded joint tested at a stress amplitude of $250 \mathrm{MPa}$ : (a) overall view, (b) crack propagation region, where "c" in (a) indicates the necking region.

Figs. 5.7 and 5.8 show typical fracture surfaces of the dissimilar HSLA-DP980 welded joints that failed at stress amplitudes of $200 \mathrm{MPa}$ and $150 \mathrm{MPa}$, respectively. Since the failure occurred in the weld area, in this case at the intermediate and lower stress amplitudes (Figs. 5.5(b) and 5.5(c)), rather than being caused by the plastic deformation at the high stress amplitude of $250 \mathrm{MPa}$ (Figs. 5.5(a) and 5.6), the fatigue crack initiation site can be clearly identified, as marked as "b" in the overall images of Figs. 5.7(a) and 5.8(a). From the magnified images showing the crack initiation area in Figs. 5.7(b) and 5.8(b), it is seen that crack initiation basically occurred from the specimen surface due to the stress concentration arising from the presence of concavity. Fatigue striations can be seen in the propagation region in Figs. 5.7(c) and 5.8(c), where fatigue damage progressively accumulated as the propagation approached the final fracture, with the border area of the transition from the fatigue crack propagation to the final fast fracture shown in Figs. 5.7(d) and 5.8(d). The final fast fracture area consisted of characteristic dimples [9]. This is understandable since HSLA 
is very ductile with a ductility of $\sim 25 \%$ (Table 5.1 ). It should be noted that, while in the dissimilar HSLA-DP980 welded joints a soft zone was present on the DP980 side and no soft zone was present at all on the HSLA side (Figs. 5.1 and 5.2), fatigue failure at the lower stress amplitudes still occurred close to the HSLA due to the lower hardness or strength of HSLA itself. Furthermore, all tensile test samples were observed to fail in the BM on the HSLA side, like the situation shown in Figs. 5.5(a) and 5.6(a). Therefore, it can be concluded from the present study that the existence of a soft zone in the dissimilar HSLA-DP980 welded joints, as long as it is small and narrow, would not affect both the tensile properties and fatigue resistance. To enhance the fatigue strength of such dissimilar welded joints, further efforts are needed to get rid of the weld concavity. 

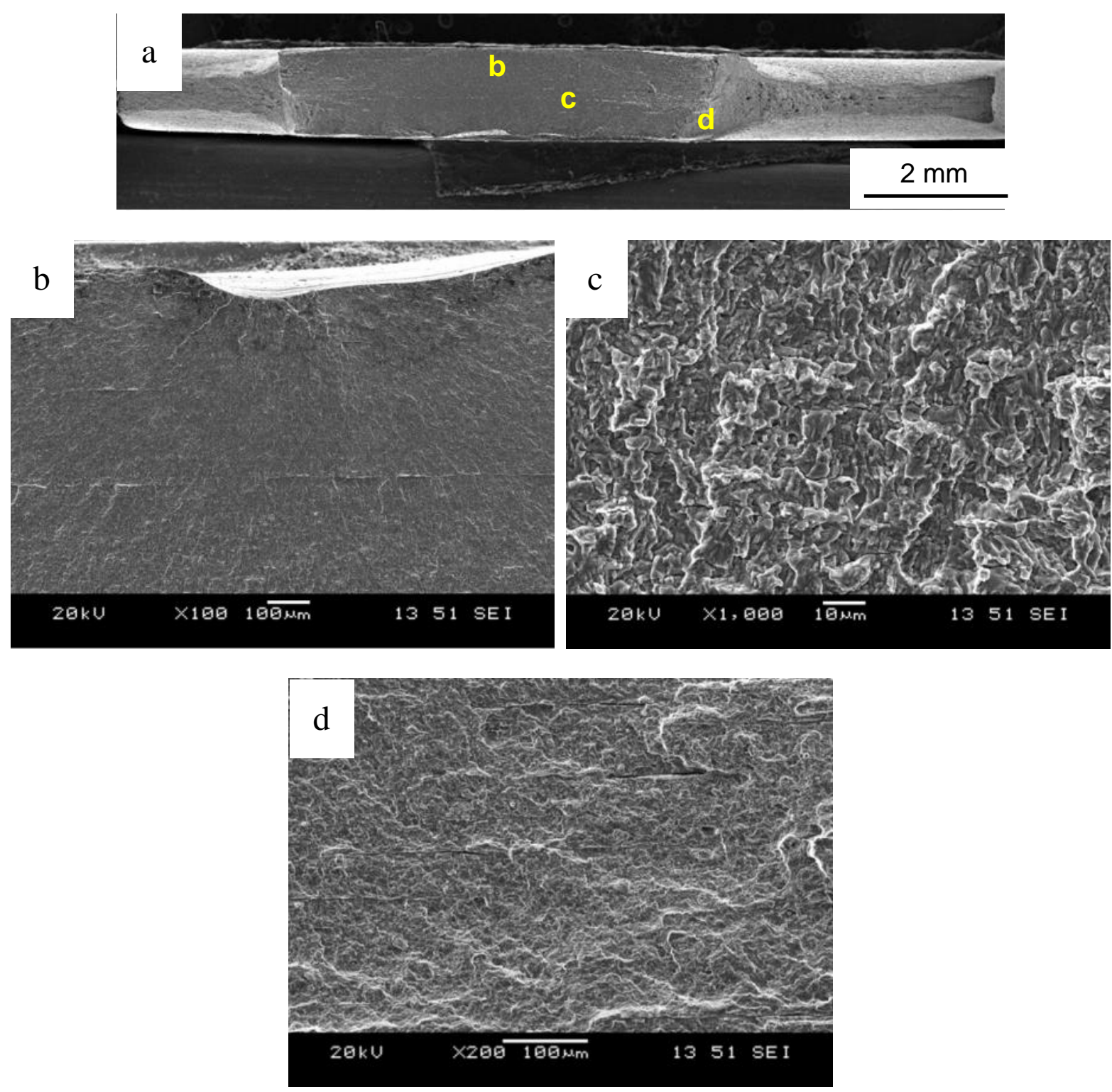

Fig. 5.7 SEM micrographs depicting the fatigue fracture surface in a dissimilar HSLA-DP980 welded joint tested at a stress amplitude of $200 \mathrm{MPa}$ (a) overall view, (b) fatigue crack initiation region, (c) crack propagation region, and (d) final fast fracture interface. 

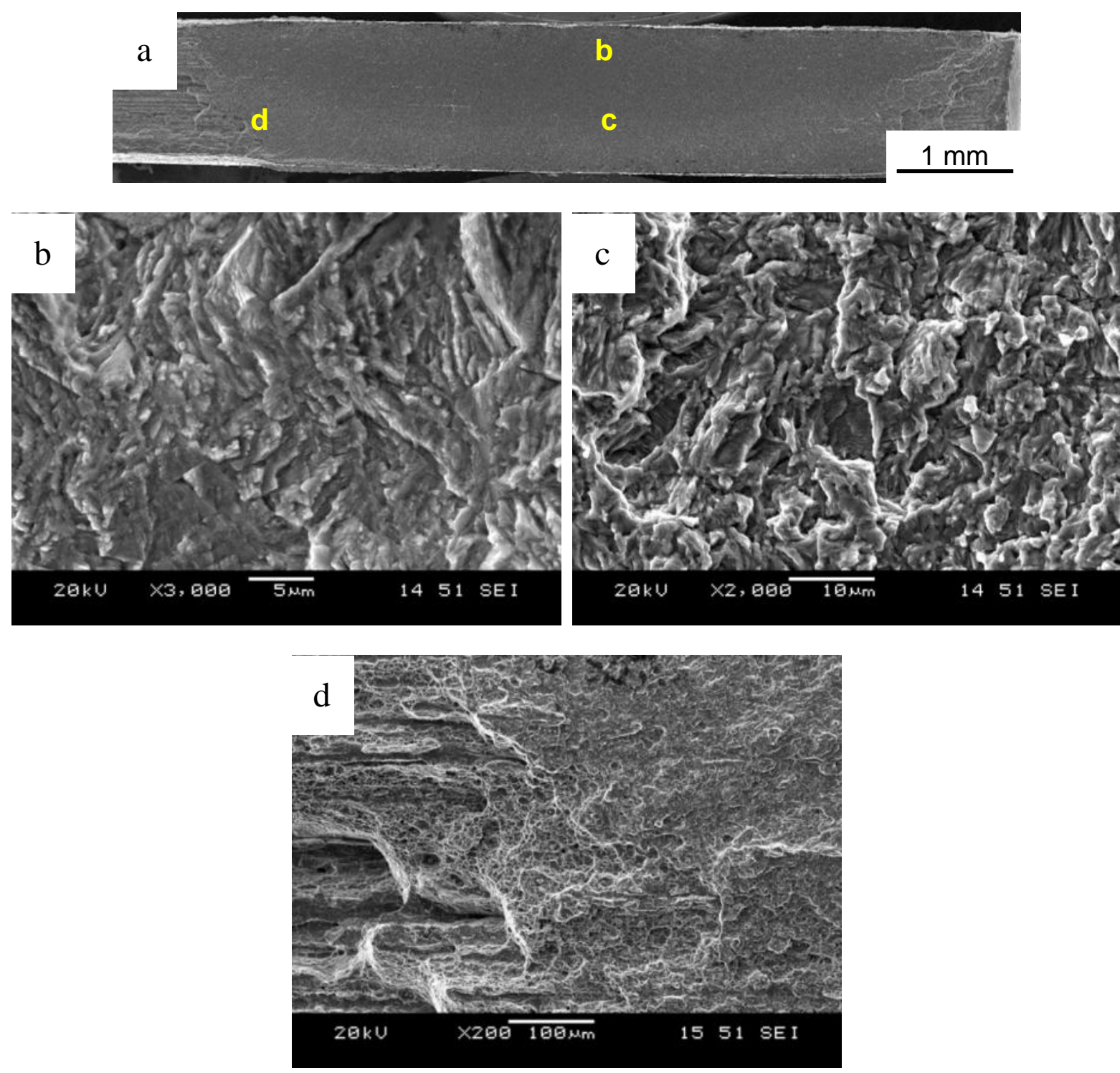

Fig. 5.8 SEM micrographs of the fatigue fracture surface in a dissimilar HSLA-DP980 welded joint tested at a stress amplitude of $150 \mathrm{MPa}$ (a) overall view, (b) fatigue crack initiation region, (c) crack propagation region, and (d) final fast fracture interface.

\subsection{Summary}

From the analysis done of the microstructure, hardness profile, tensile properties, and fatigue performance of HSLA-DP980 dissimilar welded joints, the following conclusions were drawn: 
1) The fiber laser welded dissimilar HSLA-DP980 joints consisted of a microstructure lying in-between those of similar HSLA-HSLA and DP980-DP980 welded joints. Due to the fast cooling during FLW, the narrow FZ was composed of a highly martensitic structure. The HAZ on the DP980 side of the weld contained some newly formed martensite and partially tempered martensite.

2) A characteristic asymmetric hardness profile was observed across the dissimilar HSLADP980 welded joint with a higher hardness on the DP980 side and a lower hardness on the HSLA side. While a soft zone appeared on the DP980 side, it was absent on the HSLA side. Inside the FZ, two distinct hardness sub-regions (i.e., 390 HV on the HSLA side and $\sim 410 \mathrm{HV}$ on the DP980 side) were observed due to the difference in the carbon and manganese contents between HSLA and DP980 along with the fast cooling during FLW.

3) The presence of soft zone on the DP980 side of the dissimilar welded joints was observed to have no effect on the tensile properties, since the lowest hardness value at the valley of soft zone $(255 \mathrm{HV})$ was still higher than that of the HSLA BM (167 HV). A joint efficiency of 97 100\% was achieved with respect to the HSLA. While the strain to failure was lower in the similar DP980-DP980 welded joints, it had a remarkable ( three-fold) increase in the dissimilar HSLA-DP980 welded joints.

4) While the fatigue strength of the dissimilar HSLA-DP980 welded joints was lower than that of similar DP980-DP980 welded joints, it was equivalent to the similar HSLA-HSLA welded joints.

5) Failure occurred in the BM on the HSLA side in the tensile tests as well as in the fatigue tests at high cyclic stress levels, where yielding was a dominant form of failure. At the intermediate and lower cyclic stress levels, fatigue failure occurred in the weld area due to the higher degree of sensitivity to the weld concavity. 
6) Fatigue crack initiation occurred from the specimen surface due to the stress concentration arising from the presence of concavity. 


\section{Chapter 6 Tensile Properties of Fiber Laser Welded Dissimilar Joints of High Strength Low Alloy and Dual-Phase Steels at Warm and Low}

\section{Temperatures}

Although DP steels are emerging candidates, the major parts of the cab body are still dominated by HSLA steel. However, there has been no work on the mechanical behavior of the dissimilar welded joints of HSLA and DP980 steels at low and warm temperatures, which is important to investigate considering the environmental conditions to which vehicles are exposed. This chapter aims to fill the gap in the literature and reports the mechanical properties of the fiber laser welded joints of DP980 and HSLA steels in similar and dissimilar materials combinations evaluated at cryogenic, room and elevated temperatures.

\subsection{Microhardness}

The microhardness profile of the dissimilar HSLA-DP980 welded joint clearly showed the different regions and sub-regions formed after FLW (Fig. 6.1). Similar materials made under the same conditions have also been shown in Parkes et al. [48]. The HSLA BM, due to its soft and ductile matrix, has a lower mean hardness of 168 VHN. In the HAZ on the HSLA side, no softening was observed and a sharp increase in hardness was observed due to formation of harder phases e.g. martensite and bainite the fraction of which increases with distance from the BM toward the FZ. Interestingly, two sub-regions within the FZ were observed as indicated by the two different peaks in the hardness profile. This is attributed to the rapid cooling rate achieved in the FZ because of the high welding speed $(16 \mathrm{~m} / \mathrm{min})$. The process was so fast that there was no time for the diffusion to occur during cooling, which led to chemical inhomogeneity within the FZ resulting in different hardness i.e. two distinct peaks, which was also seen in Parkes et al. [48]. The upper critical HAZ on the DP980 side 
of the welded joint was found to be similar to that on the HSLA side and the inter-critical HAZ on the DP980 side contains newly formed martensite and ferrite like its BM contributing to higher hardness compared to HSLA. A significant drop in the hardness was observed at the outer HAZ (251 VHN) compared to the BM (326 VHN), which is due to the decomposition of martensite to form soft ferrite phase along with precipitated carbides [10, $11,12,13,15,48]$.

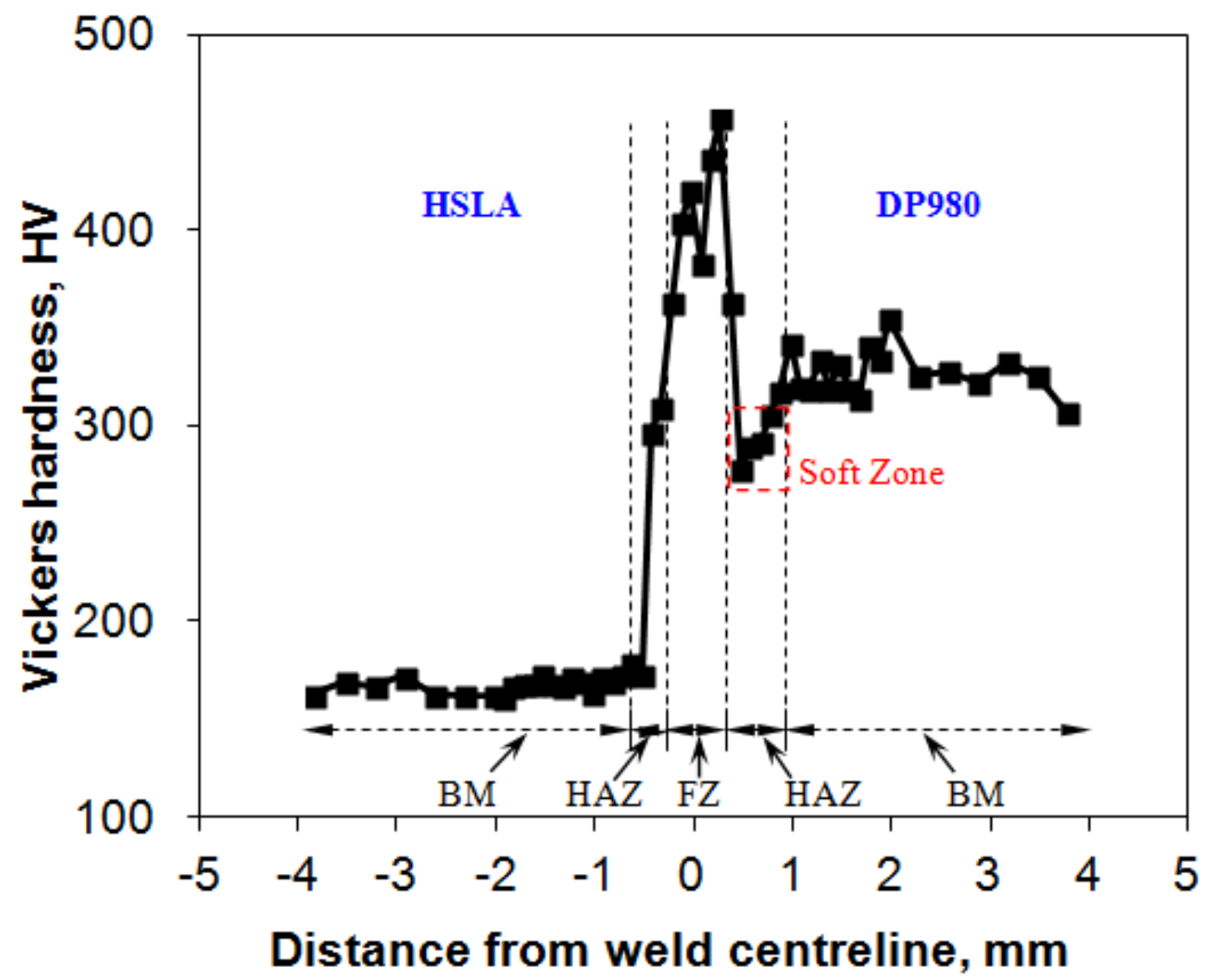

Fig. 6.1 Microhardness profile of FLWed HSLA-DP980 sample. 


\subsection{Tensile properties}

The comparison of the YS, UTS, elongation, energy absorption (EA), and the work hardening coefficient obtained at different test temperature for the HSLA BM, HSLA-DP980 and HSLA-HSLA welded joints are shown in Fig 6.2. It should be noted that the EA was obtained by calculating the area under the load-displacement curves obtained from the tensile tests. Tensile properties were found to decrease with increasing temperature in all the specimens (Fig. 6.2). Corollary to Parkes et al. [48], only the HSLA side of the HSLA-DP980 welded joint is deformed during loading because of the lower strength HSLA side compared to even the soft zone present on the DP980 side of the welded joint (Fig. 6.1). Chen et al. [49] also showed the decrease in the mechanical properties of HSLA steels at higher temperatures and those results fell closely with this study; the UTS and YS decreased with temperature which in turn decreased the EA since the elongation of the samples remained relatively constant at all temperature (Fig. 6.2(c)) [46, 50]. The Holloman equation, Eq. 6.1 [51], models the plastic behaviour on a true stress-true strain tensile curve up to the UTS, where $\sigma_{T}$ is the true stress, $K$ is the strength coefficient, $\varepsilon_{T}$ is the true strain, and $n$ is the work hardening coefficient. The higher the work hardening coefficient, the more hardening that occurs; for the HSLA containing samples, the work hardening coefficient remained relatively constant over the different temperatures which was reflected from the stress-strain curve showing little alteration in the shape of the plastic region (Figs. 6.3 and 6.4). The trend in the change of properties of the HSLA BM and the welds (HSLA-HSLA and HSLA-DP980) was observed as a function of temperature within normal scatter. 

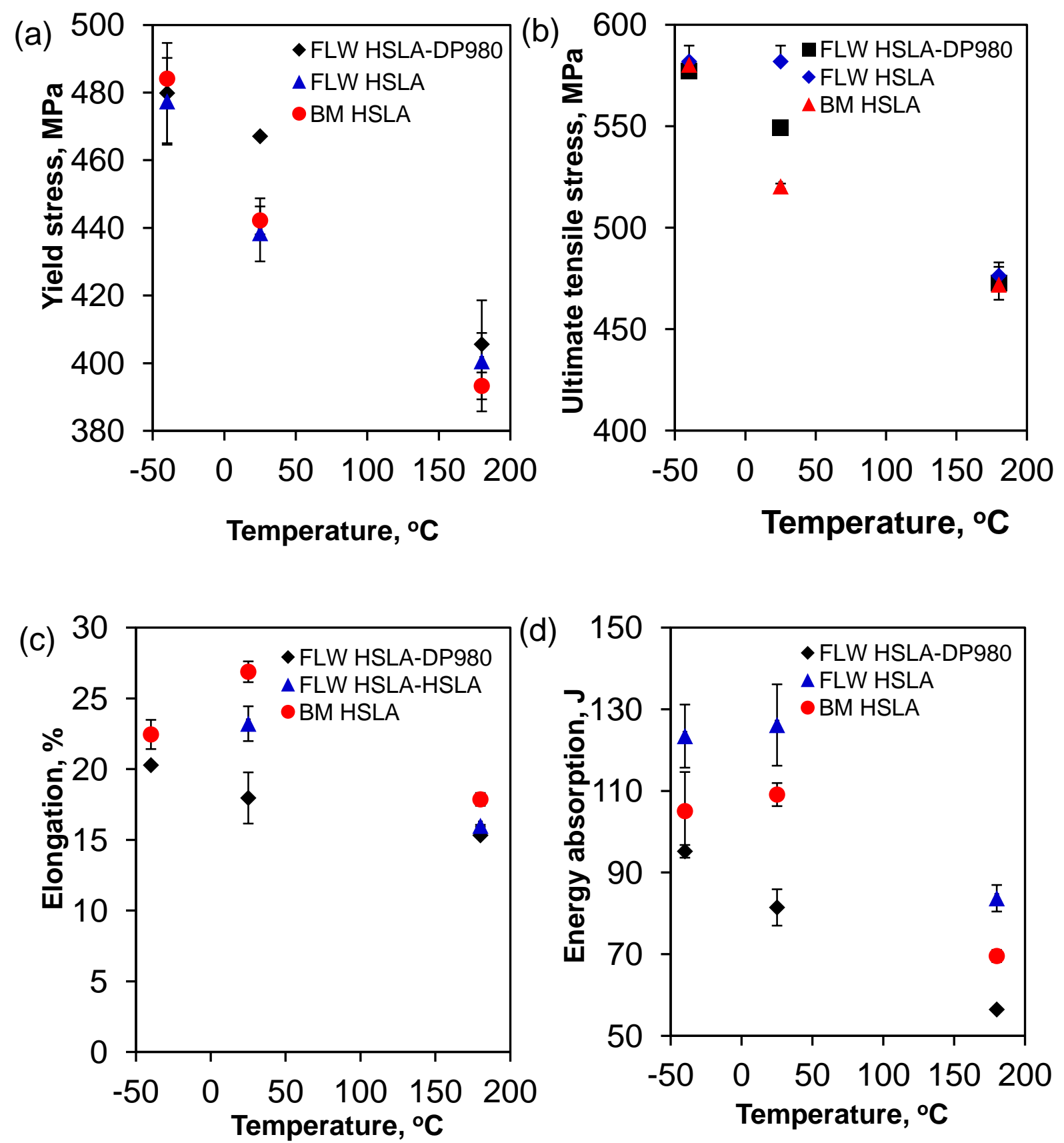
(e)

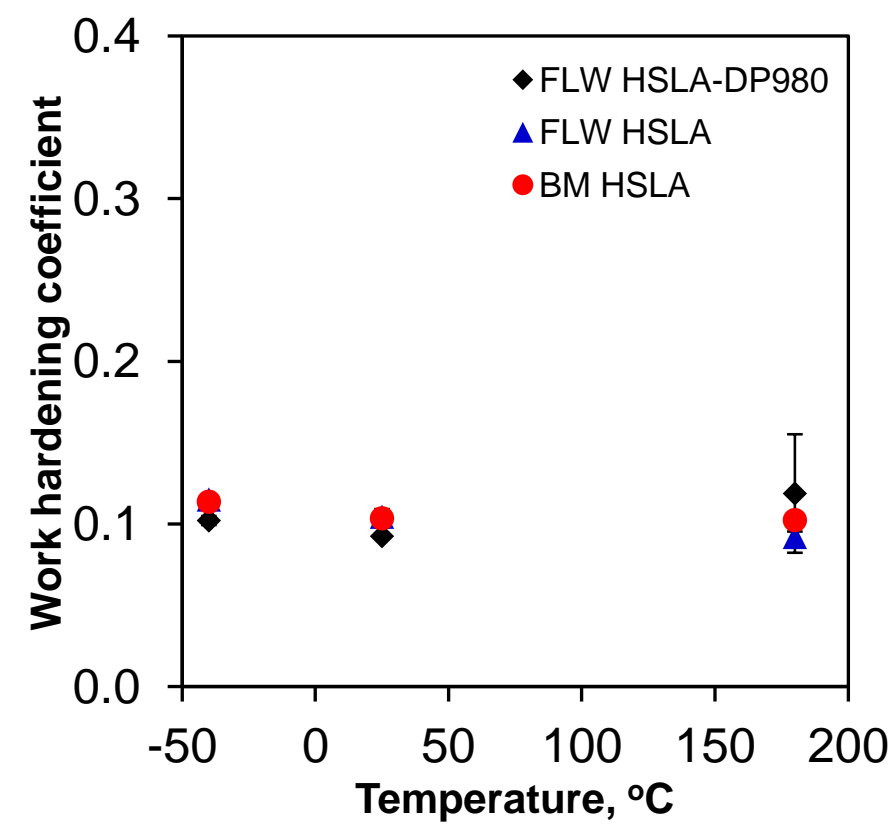

Fig. 6.2 Comparison of tensile properties of the HSLA BM, HSLA-DP980 and HSLA-HSLA welded jointsat different temperatures: (a) YS, (b) UTS, (c) elongation, (d) EA, (e) work hardening coefficient.

$$
\sigma_{\mathrm{T}}=K \varepsilon_{T}^{n}
$$

The tensile results of DP980 BM and the DP980-DP980 welded joints at different test temperatures are summarized in Fig 6.5. Examining the trends reveals interesting information about the properties of the DP980 welded joints in comparison to the BM properties; the most obvious difference is in the UTS. It was found that in the DP980 welded joint there is a consistent decrease in the strength with increasing temperature, which could be attributed to the higher mobility of dislocations allowing for dislocation climb [46, 50]. This increased deformation caused the soft zone in the HAZ to have a greater effect and to fail at a lower stress. However, in the DP980 BM, there was a decrease in UTS from $-40^{\circ} \mathrm{C}$ to $25^{\circ} \mathrm{C}$ with an increase in the UTS from $25^{\circ} \mathrm{C}$ to $180^{\circ} \mathrm{C}$. This increase in strength with temperature above room temperature has been reported in literature $[49,52,53,54]$ as dynamic strain aging (DSA), which occurs when the dislocations are temporarily arrested by solute carbon and 
nitrogen atoms, which inhibit further movement of the dislocation and subsequently require more stress to overcome the obstacles thus increasing the strength $[52,53,55,56,57,58]$. The YS of both the DP980 BM and the welded joint showed a decreasing trend with increasing temperature, which can be related to the kinetic vibrations in the lattice and how easily the dislocations can move in it $[46,50]$. Both elongation and EA remained relatively consistent over all temperatures for the DP980 BM due to the high strength of the material; however, the elongation of the DP980-DP980 welded joint was found to be much less in comparison to the BM at all temperatures (Figs. 6.3 and 6.5(c)) which is why the EA of the welded joint is significantly less than that of the BM (Fig. 6.5(d)). Lastly, the work hardening coefficient was not observed to change with temperature for the DP980 BM since the shape of the stress-strain curve did not undergo significant changes in shape (Fig. 6.3(a)); however, the DP980-DP980 welded joint at $180^{\circ} \mathrm{C}$ showed an apparent increase in the work hardening coefficient caused by a change in shape of its stress-strain curve (Fig. 6.3(b)) where there is a decrease in both the elongation and strength. This shortening and lowering of the stress-strain curve (lower strength and ductility) causes this apparent increase of the work hardening coefficient. 

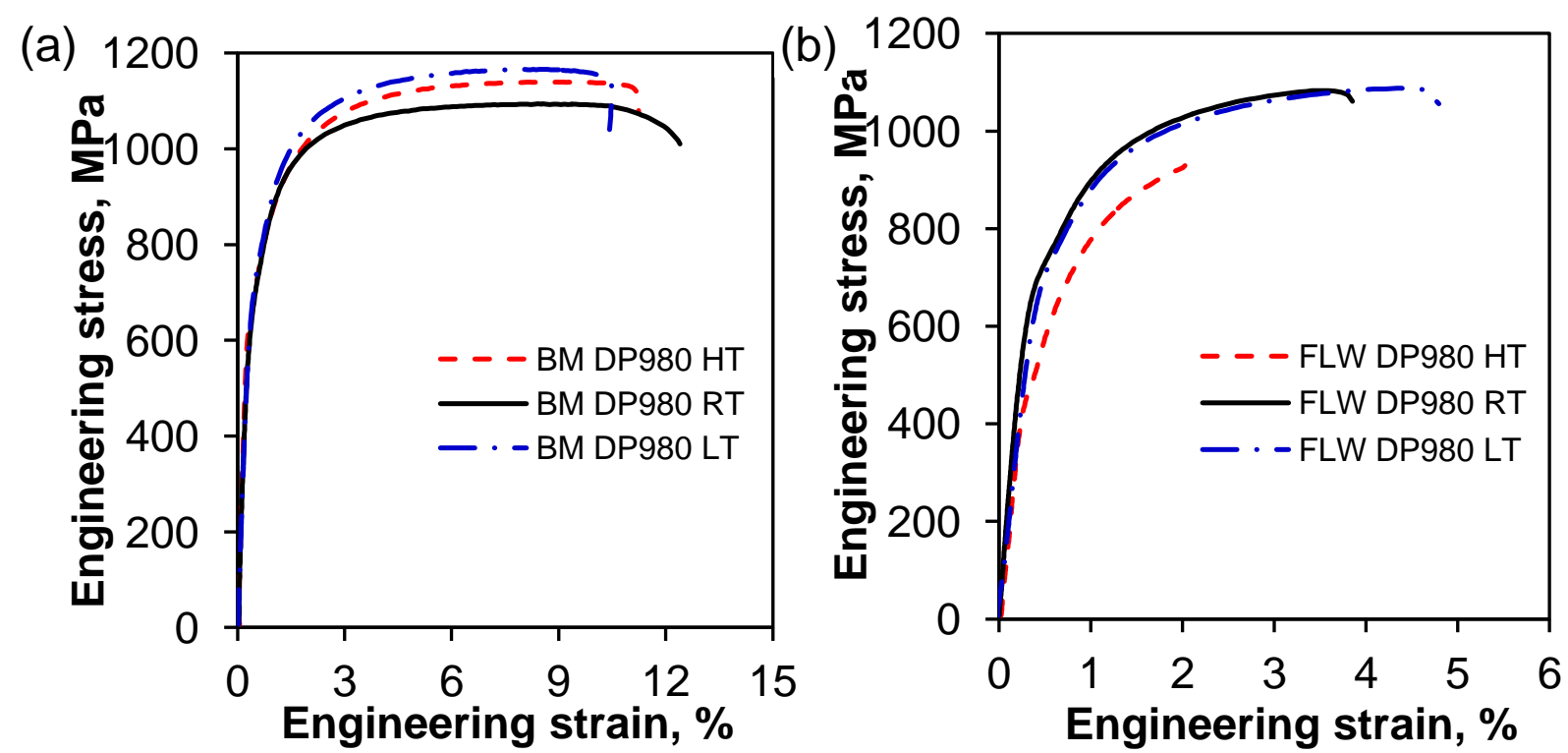

Fig. 6.3 Typical tensile curves of a) DP980 BM, b) DP980-DP980. 

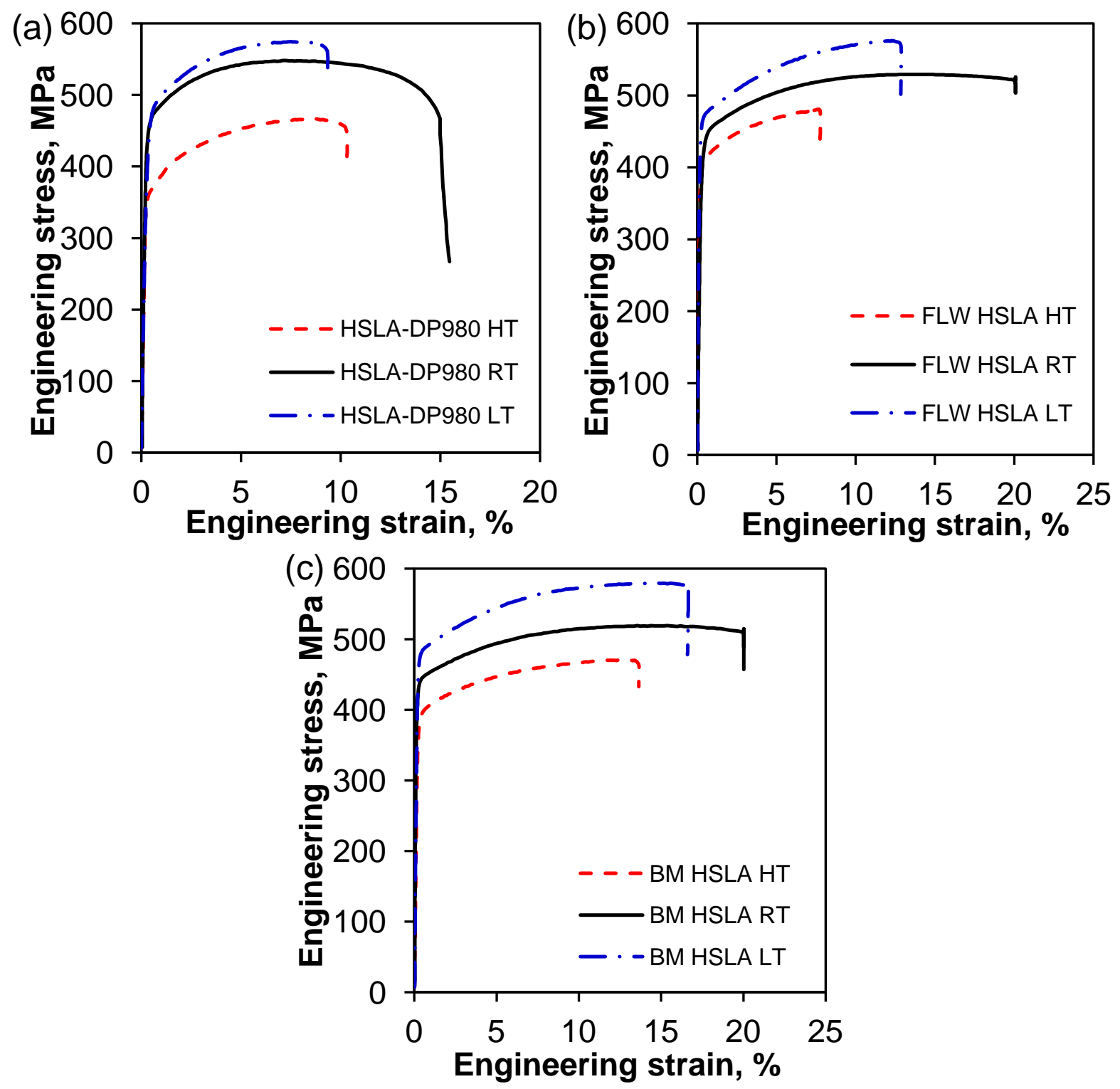

Fig. 6.4 Typical tensile curves of a) HSLA-DP980, b) HSLA-HSLA, c) HSLA BM. 

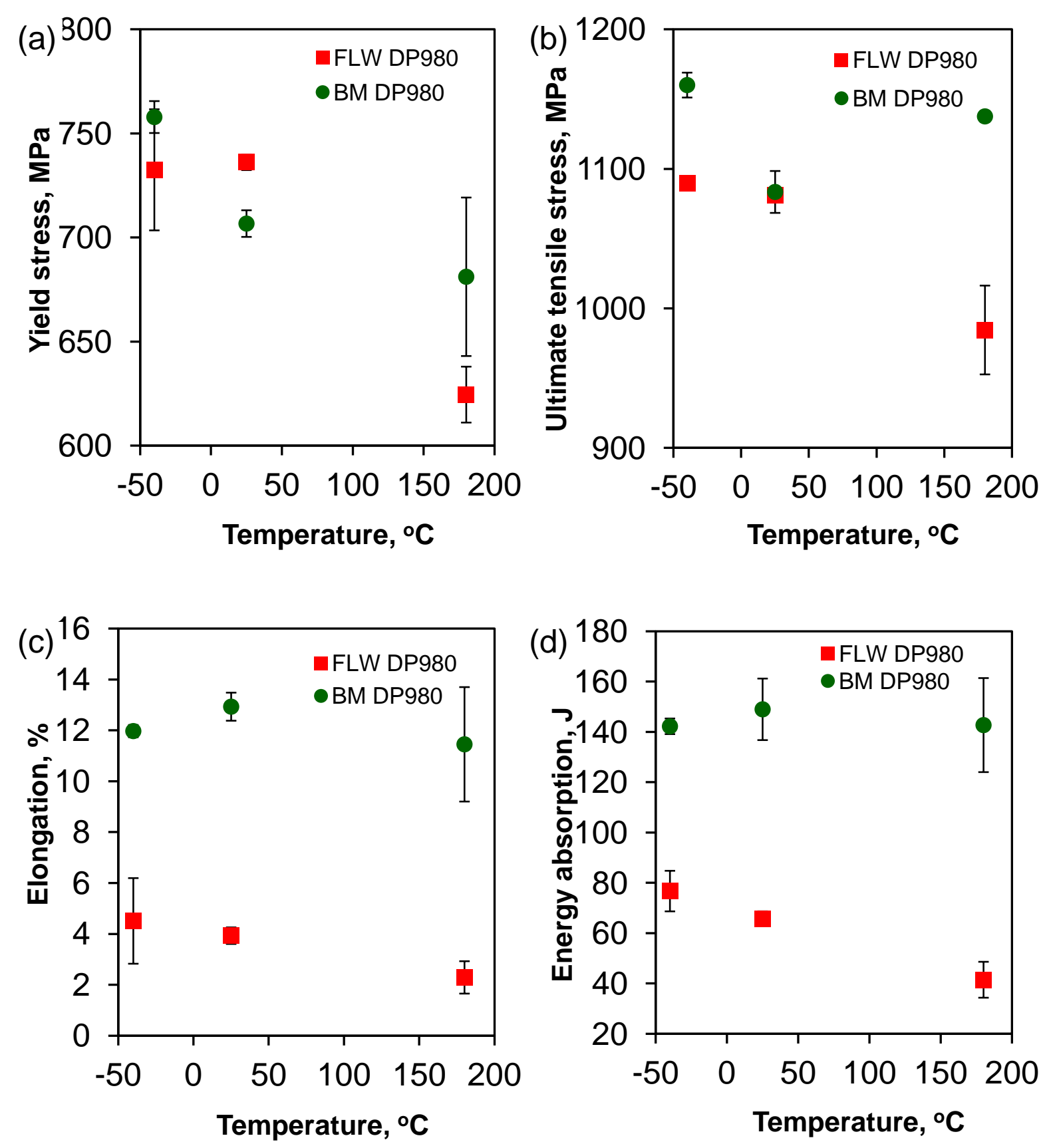


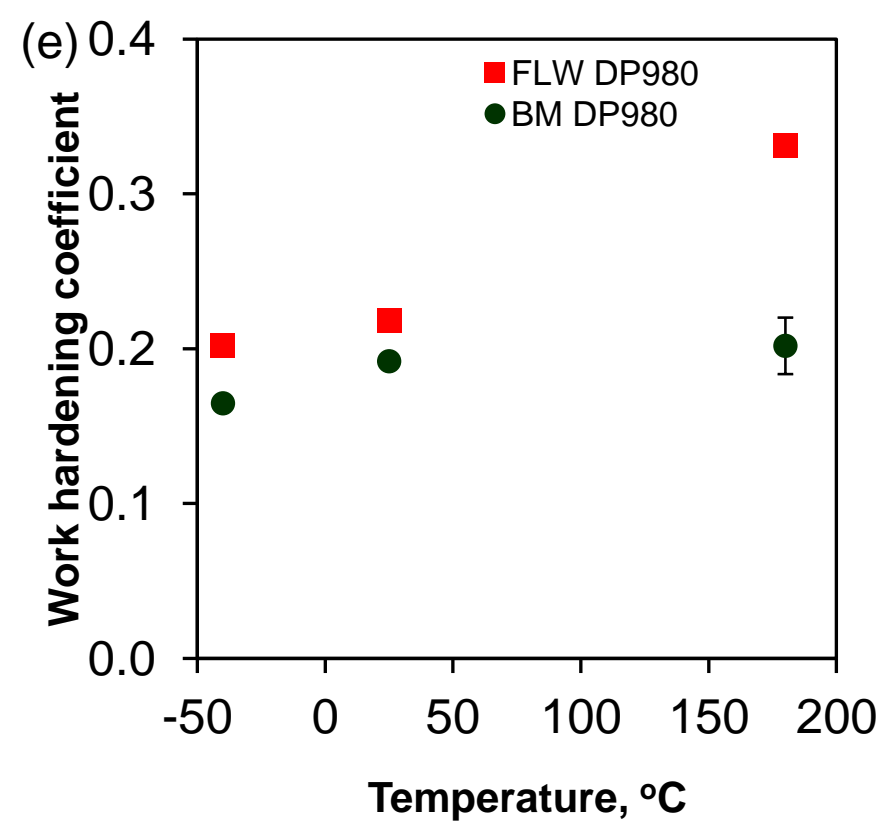

Fig. 6.5 Comparison of tensile properties of the DP980 FLWed joints and the BM tested at different temperatures: (a) YS, (b) UTS, (c) elongation, (d) EA, (e) work hardening coefficient.

\subsection{Summary}

From the analysis done of the microstructure, hardness profile, tensile properties, and fatigue performance of HSLA-DP980 dissimilar welded joints, the following conclusions were drawn:

1) The fiber laser welded dissimilar HSLA-DP980 joints consisted of a microstructure lying in-between those of similar HSLA-HSLA and DP980-DP980 welded joints. Due to the fast cooling during FLW, the narrow FZ was composed of a highly martensitic structure. The HAZ on the DP980 side of the weld contained some newly formed martensite and partially tempered martensite.

2) A characteristic asymmetric hardness profile was observed across the dissimilar HSLADP980 welded joint with a higher hardness on the DP980 side and a lower hardness on the HSLA side. While a soft zone appeared on the DP980 side, it was absent on the HSLA side. Inside the FZ, two distinct hardness sub-regions (i.e., 390 HV on the HSLA 
side and $\sim 410 \mathrm{HV}$ on the DP980 side) were observed due to the difference in the carbon and manganese contents between HSLA and DP980 along with the fast cooling during FLW.

3) The presence of soft zone on the DP980 side of the dissimilar welded joints was observed to have no effect on the tensile properties, since the lowest hardness value at the valley of soft zone $(255 \mathrm{HV})$ was still higher than that of the HSLA BM (167 HV). A joint efficiency of $97 \sim 100 \%$ was achieved with respect to the HSLA. While the strain to failure was lower in the similar DP980-DP980 welded joints, it had a remarkable ( three-fold) increase in the dissimilar HSLA-DP980 welded joints.

4) While the fatigue strength of the dissimilar HSLA-DP980 welded joints was lower than that of similar DP980-DP980 welded joints, it was equivalent to the similar HSLA-HSLA welded joints.

5) Failure occurred in the BM on the HSLA side in the tensile tests as well as in the fatigue tests at high cyclic stress levels, where yielding was a dominant form of failure. At the intermediate and lower cyclic stress levels, fatigue failure occurred in the weld area due to the higher degree of sensitivity to the weld concavity.

6) Fatigue crack initiation basically occurred from the specimen surface due to the stress concentration arising from the presence of concavity. 


\section{Chapter 7 Effect of Fiber Laser Welding Parameters on the Fatigue Properties of Dissimilar Welded Joints between DP980 and HSLA Steels}

Previous work has looked at the FLW of DP980 and HSLA similar welded joints and how the welding parameters can affect the tensile and fatigue properties of the joint [59]. This chapter furthers the work done in the previous chapters to enhance the understanding of dissimilar welded joints between DP980 and HSLA to optimise their mechanical properties for manufacturing purposes by changing the welding parameters such as weld power and or welding speed to potentially increase vehicle output.

\subsection{Microhardness}

As can be seen from the microhardness curve in Fig. 7.1, the general shape of the hardness curves between the two heat inputs is the same, which shows the soft HSLA BM which increases in hardness as it moves into the inter-critical HAZ and upper-critical HAZ reaching the peak in the FZ. This is because of the increasing amount of very high strength martensite and the bainite that is present in these regions. A difference in the hardness on both sides of the FZ has been reported before [48] and represents the difference in carbon content between the two BMs and the lack of mixing during the fusion process because of the very high cooling rates. On the DP980 side, the presence of the soft zones can be clearly seen in relation to the $\mathrm{BM}$ due to the presence of the partially tempered martensite. However, it should be noted that the degrees of softening that occurred in both the low heat input and high heat input welds are $46 \mathrm{HV}$ and $55 \mathrm{HV}$, respectively [60]. Even though this soft zone in the DP980 soft zone is present, since it is welded to HSLA, the minimum hardness of the soft zone is still significantly stronger than that of the HSLA BM; therefore, it is expected that most if not all of the deformation should occur on the HSLA side of the welded joints [48]. 


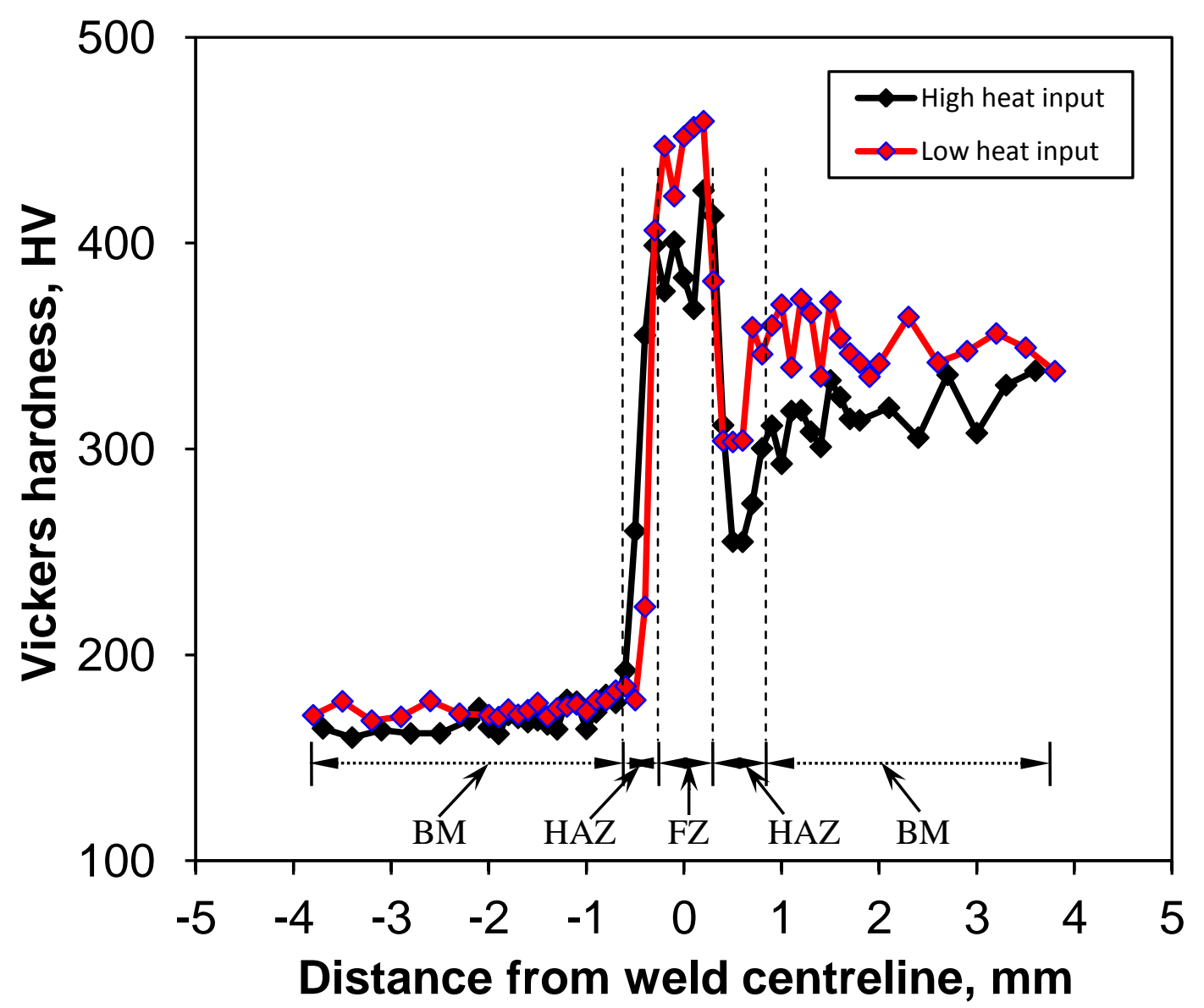

Fig. 7.1 Microhardness curves of HSLA-DP980 welded joints made with different welding conditions. [48]

\subsection{Tensile properties}

According to Haiping et al. [61], in a transverse dissimilar welded joint, the deformation is dominated by the weakest material. Since the UTS of the HSLA steel is lower than the YS of the DP980, the DP980 will only deform elastically leaving only the HSLA to yield and deform plastically. From the tensile curves in Fig. 7.2 and from Table 7.1, it can be seen that both the YS and the UTS of the two welding conditions are similar. This is due to the reason mentioned previously, that the HSLA is the material that is limiting the strength of the welded joint; the difference in the elongation between the two welding conditions is due to experimental scatter. As previously mentioned, any potential deformation that may have 
occurred in the soft zone would be negligible since it is only $\sim 200 \mu \mathrm{m}$ across and is still stronger than the HSLA BM [48].

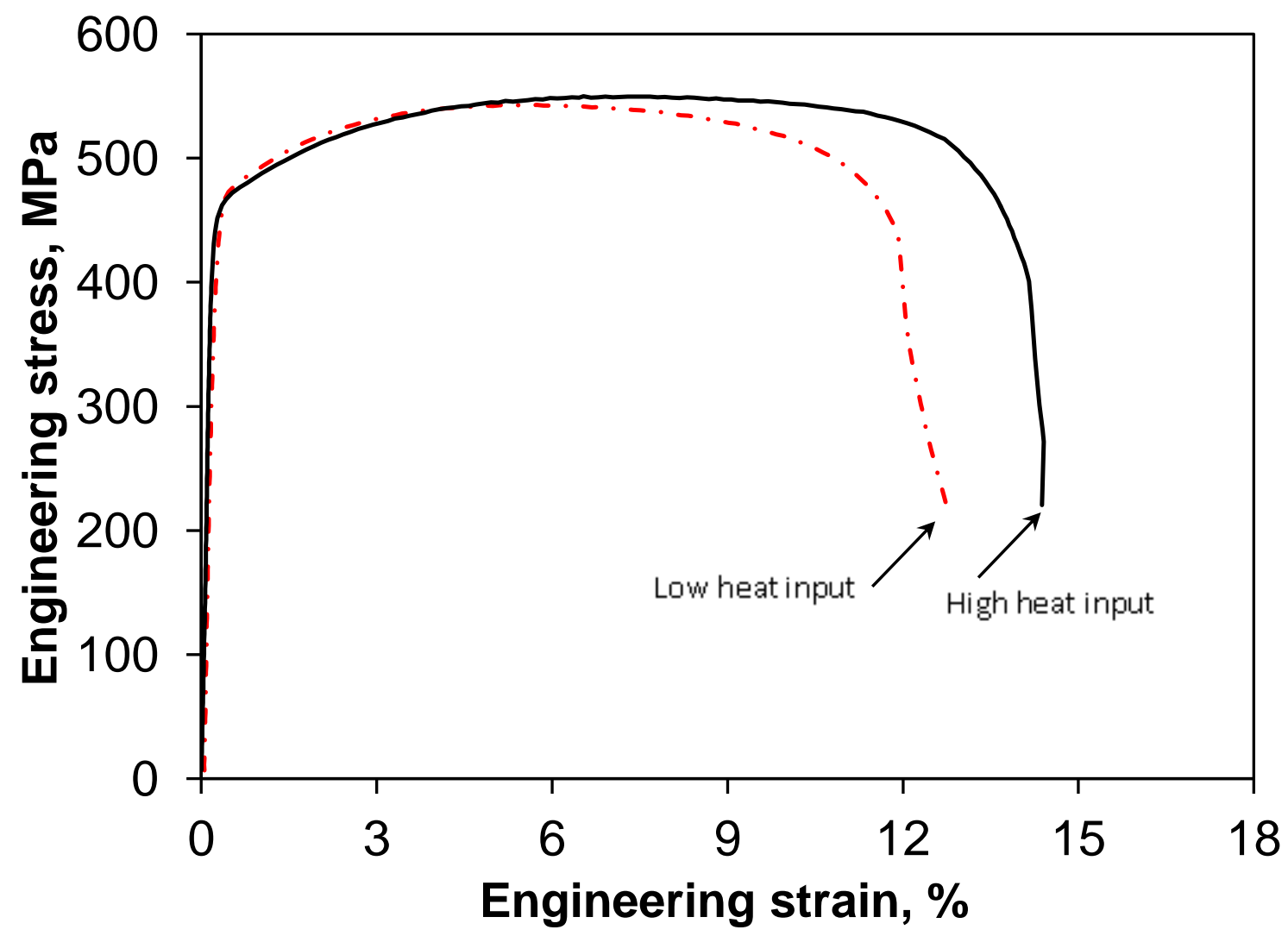

Fig. 7.2 Tensile curves of HSLA-DP980 welded joints made under different welding conditions.

\subsection{Fatigue and Fractography}

In the dissimilar HSLA-DP980 welded joints of both welding conditions, the peak stress was above the yield stress of HSLA BM at high stress amplitudes of $250 \mathrm{MPa}$ causing the yielding and failure in the BM, as shown in Fig. 7.3(b). At the lower stress amplitudes, there was more scatter in the experimental data because the samples were failing in the weld area (Fig. 7.3(a)) [48].This was partly due to the stress concentration developed by the concavity and slight sheet misalignment during welding as well as the heterogeneous microstructure 
caused during the welding procedure because they are far more sensitive under fatigue than under tensile load (Fig. 7.4) [46, 50].

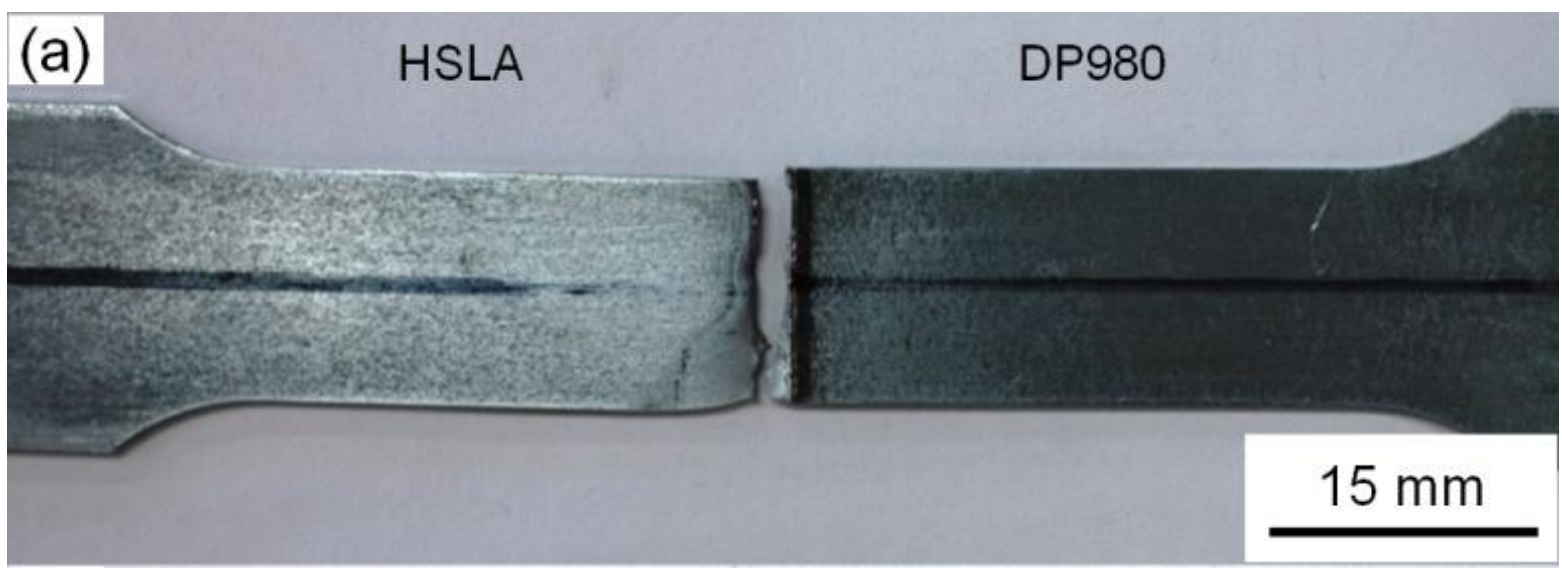

(b)

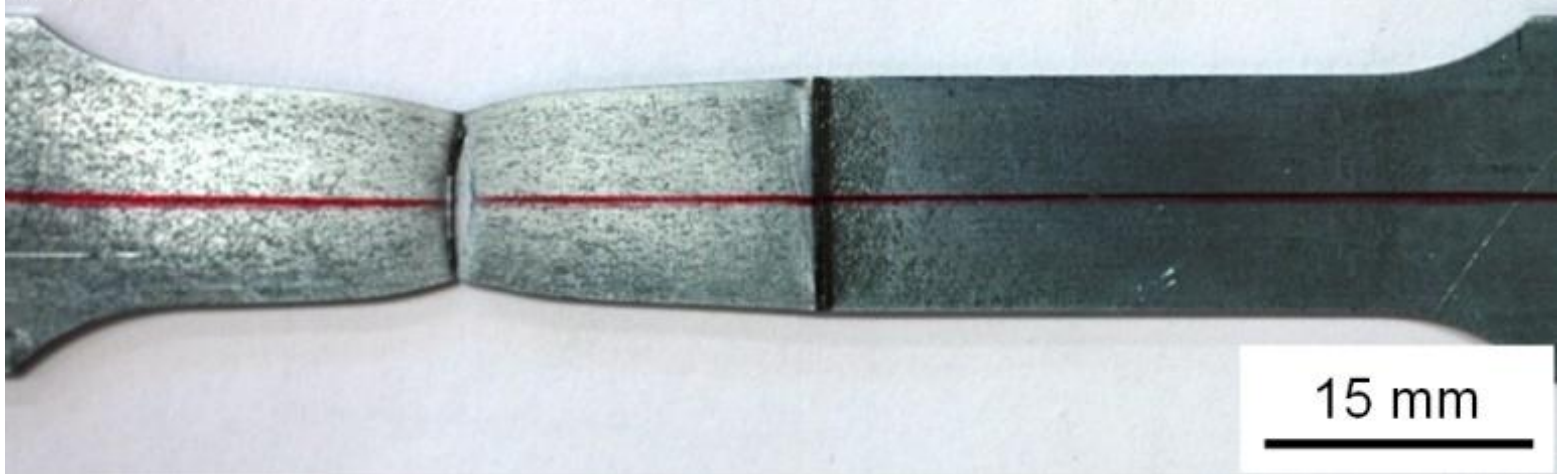

Fig. 7.3 Typical fatigue fracture locations at (a) low stress amplitude, and (b) high stress amplitude.

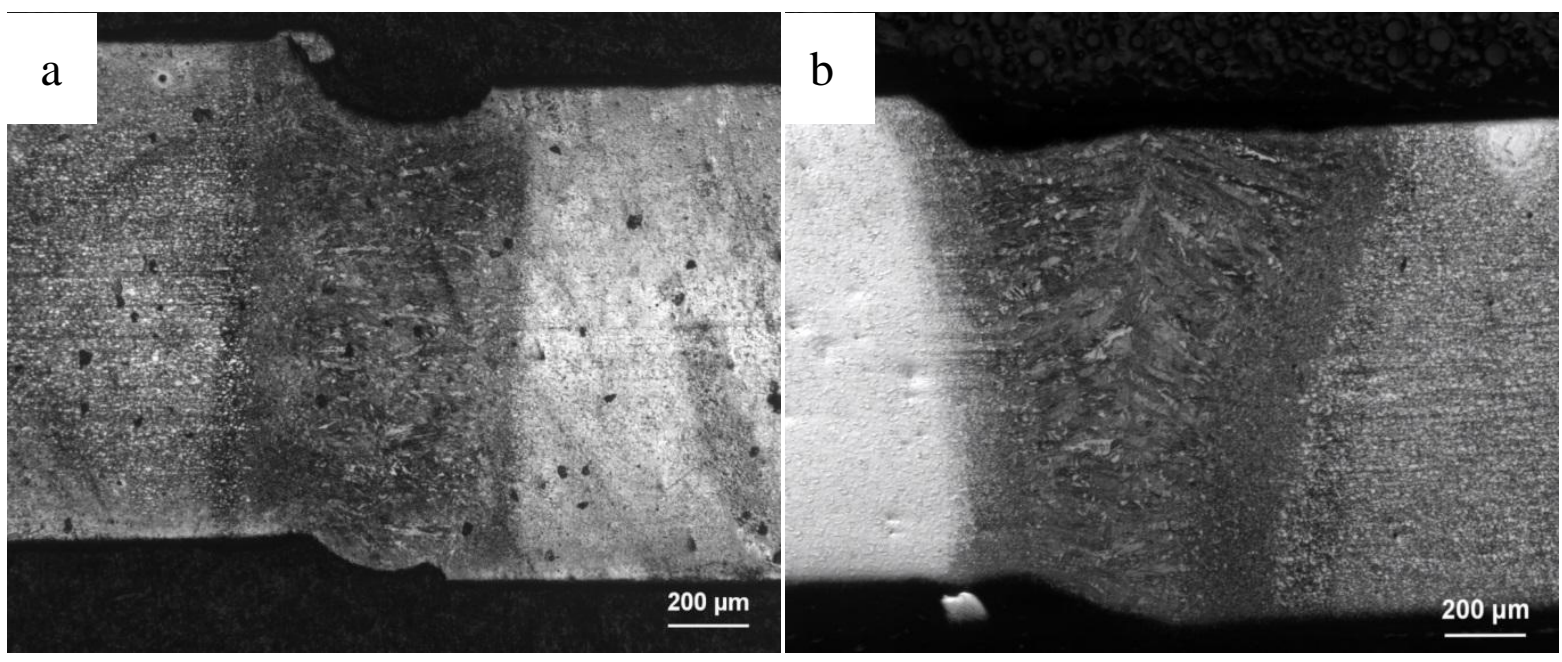

Fig. 7.4 Weld profile of (a) low heat input weld and (b) high heat input weld.

The S-N plot in Fig. 7.5 could be expressed using the Basquin equation [46, 50], 


$$
\sigma_{a}=\sigma_{f}^{\prime}\left(2 N_{f}\right)^{b}
$$

where $\sigma_{a}$ is the cyclic stress amplitude, $\sigma_{f}{ }^{\prime}$ is the fatigue strength coefficient defined by the stress intercept at $2 N_{f}=1, N_{f}$ is the number of cycles to failure $\left(2 N_{f}\right.$ is the number of reversals to failure), and $b$ is the fatigue strength exponent. The values of these parameters obtained by fitting the data points according to Eqn. (5.1) are tabulated in Table 7.1. The fatigue life of the welded joints could be estimated based on the values of $\sigma_{f}{ }^{\prime}$ and $b$. Eqn. (5.1) indicates that the higher the value of $\sigma_{f}{ }^{\prime}$ and the smaller the absolute value of $b$, which is always negative, the longer the fatigue life. From Table 7.1, it can be seen that the high heat input welds have a better $b$ value and a higher fatigue limit which means that they would have a better fatigue life in comparison to the low heat input samples. 


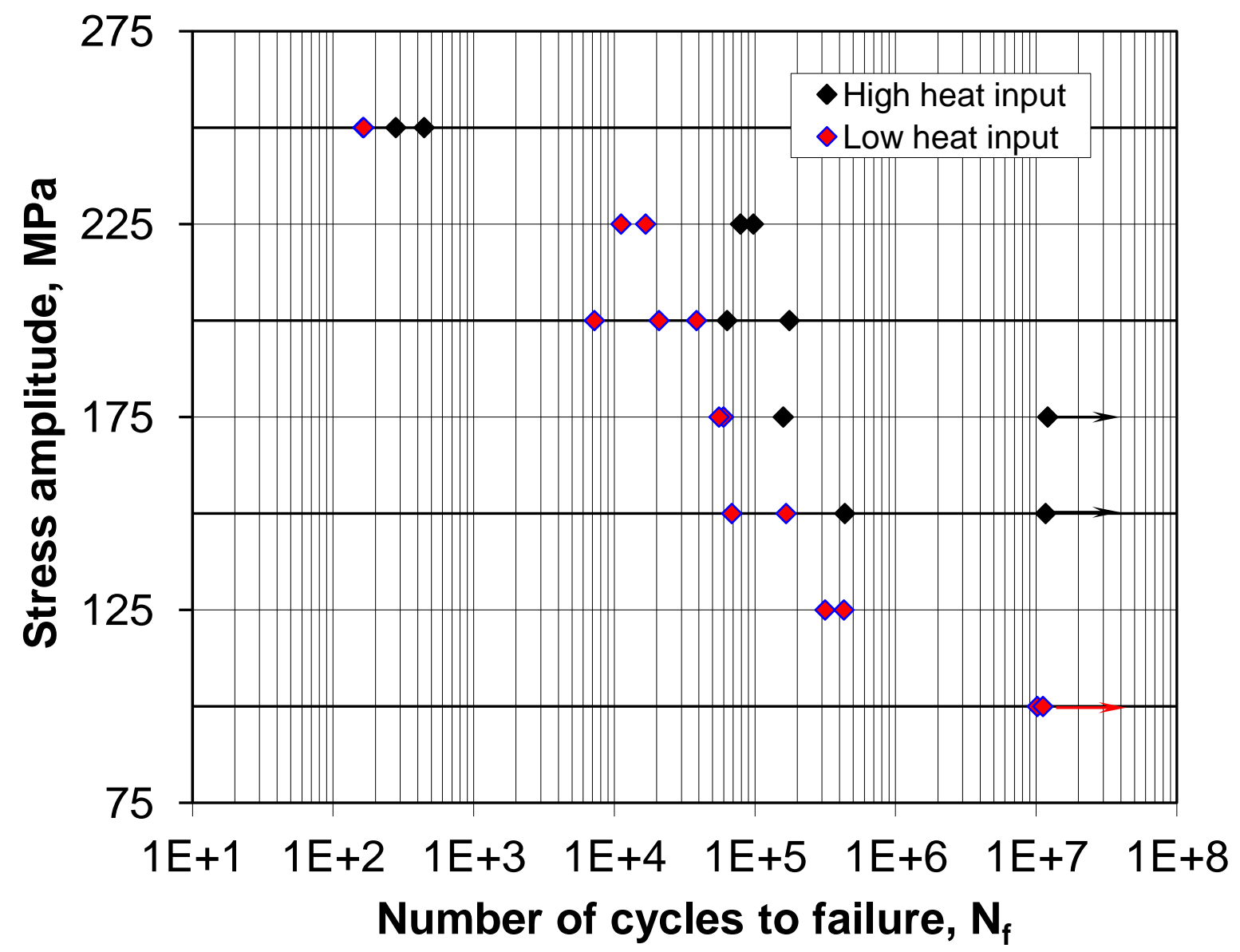

Fig. 7.5 Comparison of S-N curves of the HSLA-DP980 welded joints with different heat inputs.

Table 7.1. Summary of fatigue and tensile properties.

\begin{tabular}{|c|c|c|c|c|c|}
\hline Steel & $\sigma_{f}{ }^{\prime}$ & $b$ & Fatigue Limit & YS & UTS \\
& $(\mathrm{MPa})$ & & $(\mathrm{MPa})$ & $(\mathrm{MPa})$ & $(\mathrm{MPa})$ \\
\hline Low Heat Input & 450 & -0.084 & 100 & 478 & 543 \\
\hline High Heat Input & 355 & -0.049 & 150 & 467 & 548 \\
\hline
\end{tabular}

The typical fatigue fracture surface of the dissimilar HSLA-DP980 welded joints that failed at the lowest stress amplitudes (150 MPa for high heat input and 125 for low heat input) can be seen in Fig. 7.3(a). It can also be seen that crack initiation occurred at the specimen 
surface due to the stress concentration arising from the presence of concavity and misalignment. The fatigue striations can be seen to be propagating in multiple directions, which is characteristic of this region. In the propagation region, fatigue striations can be seen in Figs. 7.6(c) and 7.6(d), where fatigue damage accumulated as the propagation approached the final fracture. Final fast fracture area consisted of characteristic dimples Figs. 7.6(e) and 7.6(f). This is understandable since both HSLA and DP980 are quite ductile [48]. To enhance the fatigue strength of such dissimilar welded joints, further efforts are needed to get rid of the weld concavity and sheet misalignment. 

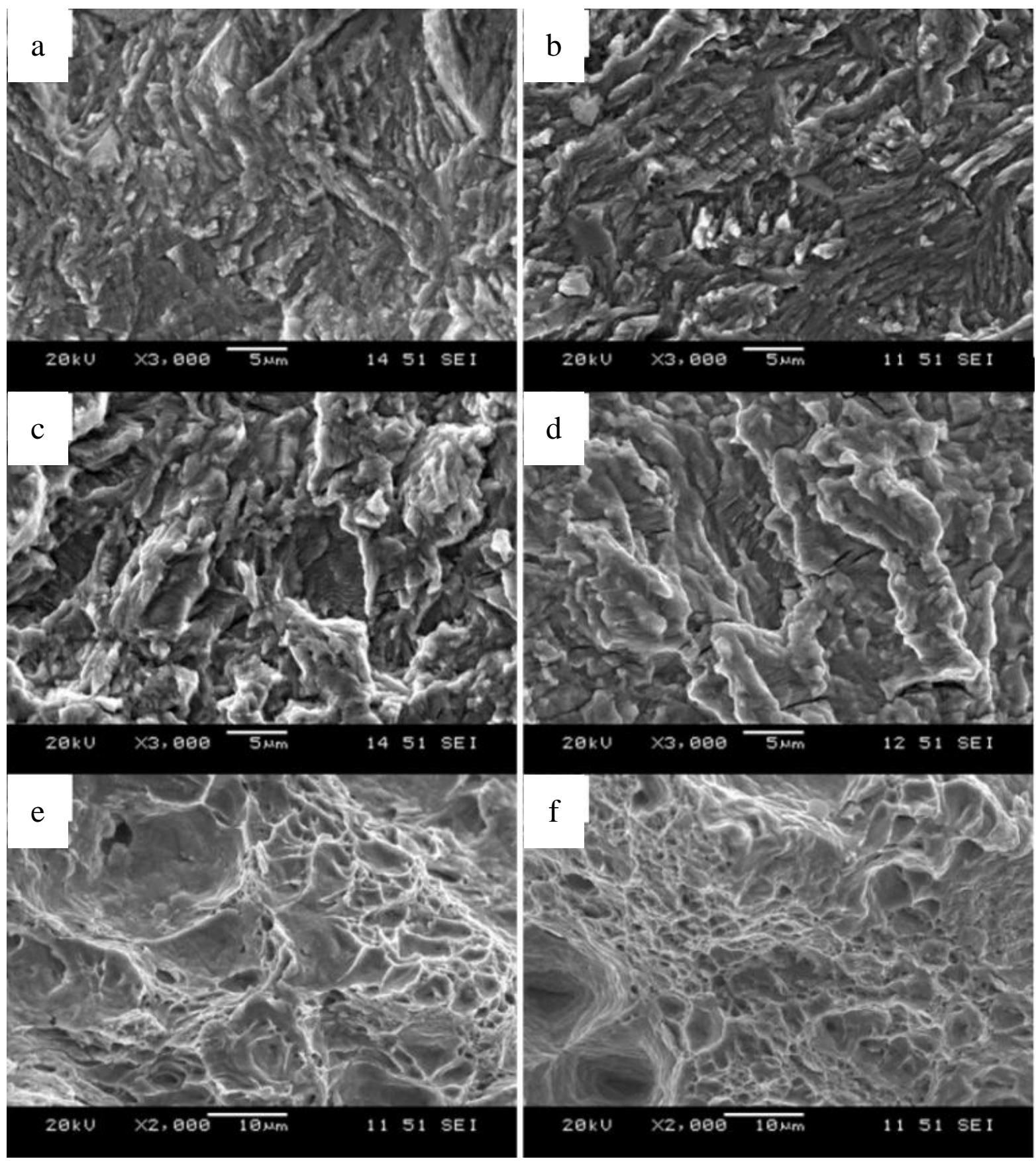

Fig. 7.6 Fatigue fracture surface features: initiation region (a) high heat input, and (b) low heat input.

Propagation region: (c) high heat input and (d) low heat input. Fast fracture: (e) high heat input and (f) low heat input.

\subsection{Summary}

The major conclusions that can be drawn from this work are as follows: 
1. The tensile properties of the two weld heat inputs were very similar even though the high heat input weld had more softening than the low heat input weld. This is because the strength of the soft zone in both cases was still much greater than the hardness of the sub-critical HAZ.

2. The low heat input welded joint had significantly more bainite in its FZ than the high heat input welded joint.

3. The low heat input weld had a lower fatigue life than the high heat input welds because of a combination of stress concentration caused by slight misalignment of the welded sheets and minor concavity made in the welding process. 


\section{Chapter 8 Fatigue and Microstructure Comparison between Galvanized and Galvannealed DP980-DP600-HSLA Triple Dissimilar Welds}

In order to ensure the widespread use of DP steels in the automotive industry, a clear understanding of the relationships between the microstructural change involved in FLW and the static and dynamic performance of the welded joints must be evaluated in order to ensure the overall safety of the passenger vehicles. However, there is no literature on the dissimilar combination of DP980, DP600, and HSLA using the FLW process and also on the effects of zinc coating type on the mechanical behaviour of welded joint. This chapter is an extension of the previous, which aimed to characterize and compare the triple dissimilar FLWed joints of GI- and GA-coated DP980, DP600, and HSLA steels with respect to the microstructure, tensile, and fatigue performance.

\subsection{Microhardness}

The microhardness profiles of the GI and GA triple dissimilar welded joints can be seen in Fig. 8.1. From left to right across the welds, a good correlation between the GI and the GA coated DP980 and DP600 BMs of the welded joints and in the HAZ and FZ on the welded joints was observed. The microstructures of the GI and GA coated DP600 were very similar giving rise to similar hardness. In the DP980 samples, there was a difference in the BM microstructure between the GI and GA coated i.e. a small amount of bainite present in GA steel, which did not reflect in the hardness. However, in the HSLA part of the weldments, a distinct difference between the hardness of the BMs and also FZ was seen (Fig. 8.1). This may be the determining factor between the strengths of the two joints since the strength of the welded joints will be limited by the strength of their weakest components. The DP980 shows the "soft zone" from the tempered martensite, but not on the DP600 sides of the weld. In 
diode laser welding, soft zone was observed in DP600 steel welds also due to the significantly higher heat input compared to FLW [13, 15, 62].

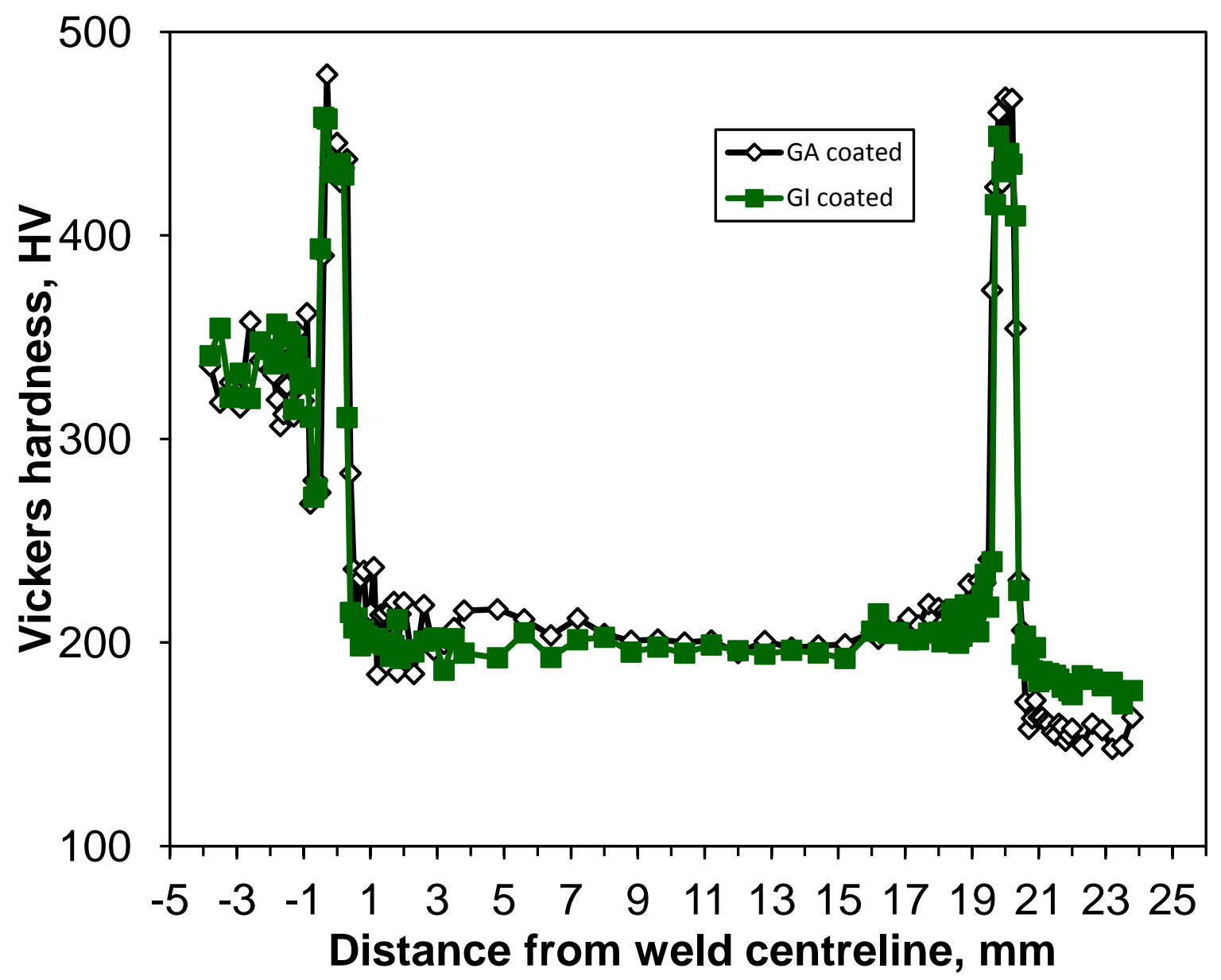

Fig. 8.1 Microhardness of GI and GA coated DP980-DP600-HSLA triple dissimilar welds.

\subsection{Tensile properties}

The representative engineering stress and strain curves for the triple dissimilar welded joints can be seen in Figs. 8.2 and 8.3. A summary of tensile properties can be found in Table 8.1. The GI coated BM samples were found to have homogeneous yield behaviour up to failure. Both the YS and the UTS of the triple dissimilar weld were found to be very similar to the values of the HSLA BM. As previously mentioned, since the HSLA was the weakest BM, it 
stands to reason that it would decide the performance of the welded joints (Fig. 8.1) [61]. There is also a significant decrease in the elongation of the welded joint in comparison to all of the individual BMs; this decrease is due to the small amount of material that actually reaches the stress required for plastic deformation to occur. Since the UTS of HSLA is greater than the YS of DP600, only a small amount of plastic deformation is contributed by the DP600. The DP980, on the other hand, has a YS that is significantly greater and, therefore, it deformed only elastically.

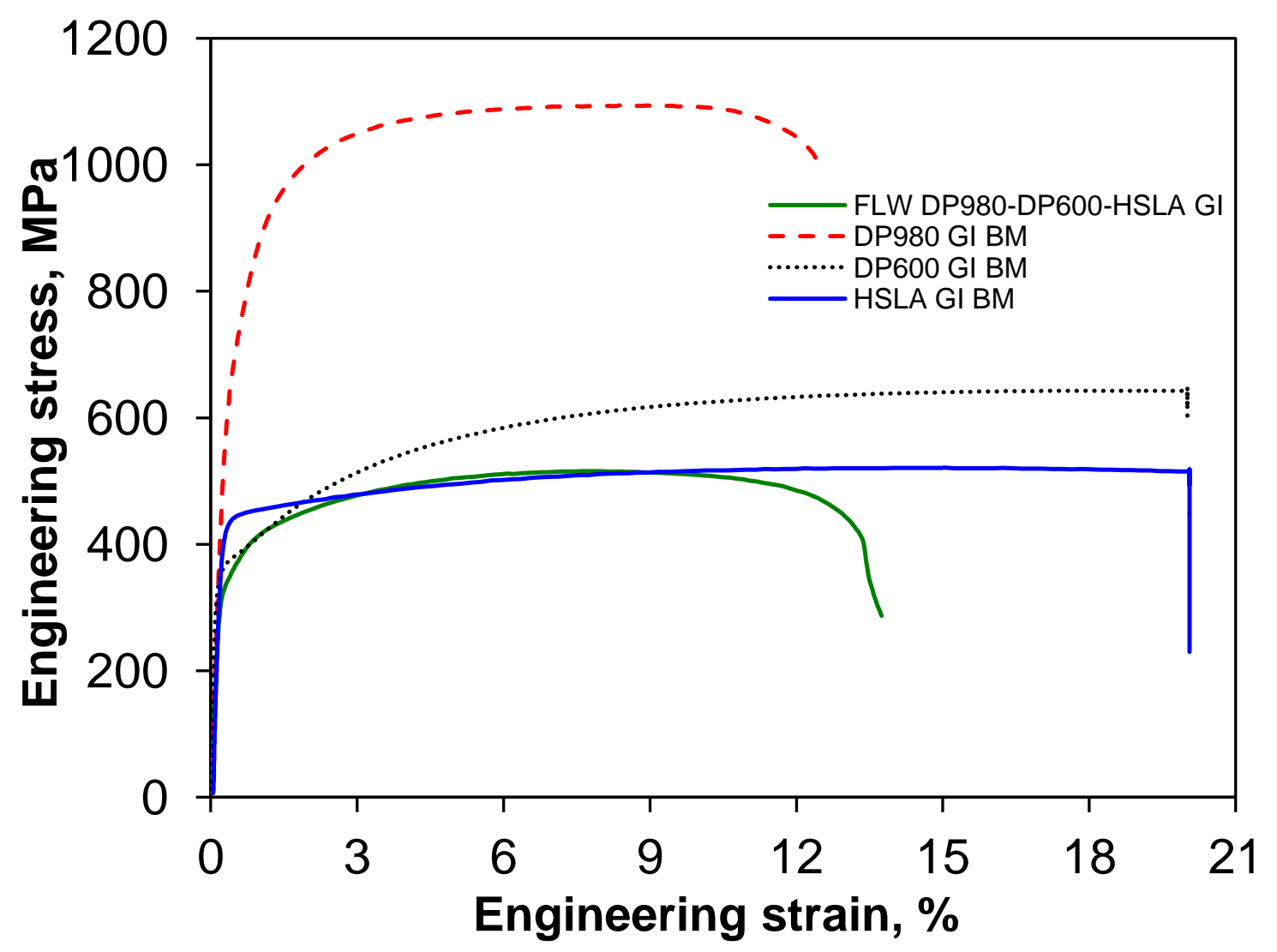

Fig. 8.2 Tensile tests of GI coated triple dissimilar weld and relevant BMs 


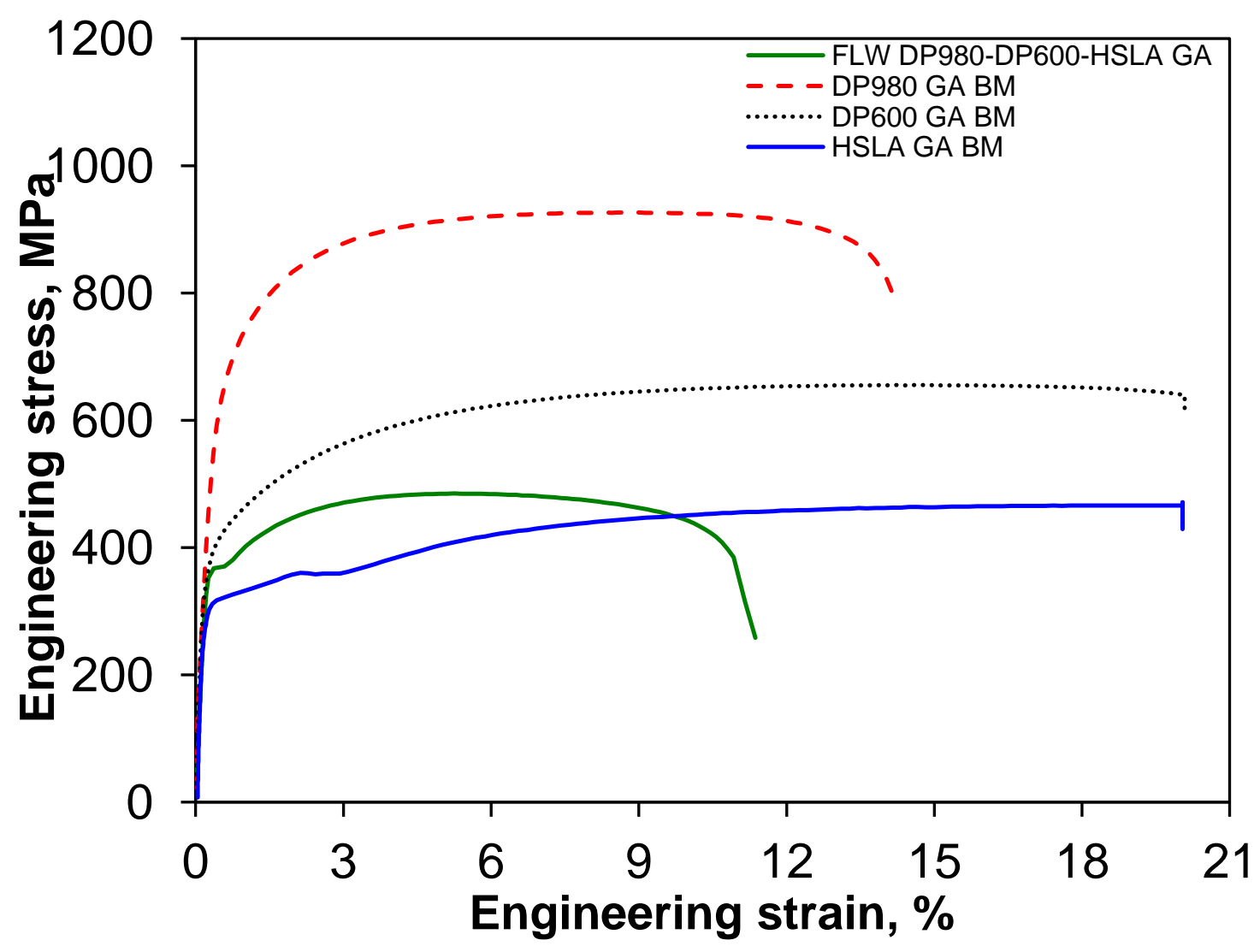

Fig. 8.3 Tensile test of GA coated triple dissimilar weld and relevant BMs.

In the GA coated samples, the DP steels exhibited a homogeneous plastic tensile behaviour like the GI coated samples. The DP980 GA sample steel had lower YS and UTS in comparison to the GI samples (Table 8.1). Due to the high temperatures of the GA process, there was a slight tempering effect of the martensite (Fig. 4.4(c)) which caused the reduction in strength. The HSLA showed yield point phenomenon (YPP) that is caused by the pinning of carbon and some nitrogen [63] which was interestingly also seen in the tensile curve of the triple dissimilar weld and causes a slight increase in the YS since the effect is much smaller than in the normal HSLA BM. 
Table 8.1 Summary of tensile and fatigue data.

\begin{tabular}{|c|c|c|c|c|c|c|}
\hline Steel & $\begin{array}{c}\text { YS } \\
(\mathrm{MPa})\end{array}$ & $\begin{array}{c}\text { UTS } \\
(\mathrm{MPa})\end{array}$ & $\begin{array}{c}\text { Elongation } \\
(\%)\end{array}$ & $\begin{array}{c}\text { Fatigue } \\
\text { life } \\
(\mathrm{MPa})\end{array}$ & $\begin{array}{c}\sigma_{f}^{\prime} \\
(\mathrm{MPa})\end{array}$ & $b$ \\
\hline HSLA-GI & 445 & 521 & $>20$ & 200 & 302 & -0.023 \\
\hline HSLA-GA & 357 & 471 & $>20$ & 175 & 267 & -0.022 \\
\hline DP600-GI & 370 & 648 & $>20$ & 150 & 414 & -0.054 \\
\hline DP600-GA & 407 & 655 & $>20$ & 175 & 395 & -0.043 \\
\hline DP980-GI & 711 & 1094 & 13.3 & 250 & 939 & -0.091 \\
\hline DP980-GA & 591 & 926 & 14.4 & 200 & 633 & -0.064 \\
\hline $\begin{array}{c}\text { Triple dissimilar } \\
\text { weld-GI }\end{array}$ & 352 & 516 & 14.5 & 100 & 603 & -0.105 \\
\hline $\begin{array}{c}\text { Triple dissimilar } \\
\text { weld-GA }\end{array}$ & 370 & 485 & 14.2 & 100 & 410 & -0.086 \\
\hline
\end{tabular}

\subsection{Fatigue and Fractography}

In the GA triple dissimilar welded joints, the maximum stress at the highest stress amplitude was above the yield stress of HSLA BM, causing the yielding and failure in the BM as shown in Fig. 8.4(a) whereas in the GI welded joint, failure occurred in the joint and yielded into the DP600 BM Fig. 8.5(a). At the lower stress amplitudes, there was more scatter in the experimental data because the samples were failing in the weld area (Figs. 8.4(b) and 8.5(b)) [48]. This was partly due to the stress concentration developed by a combination of the concavity, the slight sheet misalignment during welding process, the difference in sheet thicknesses, as well as the heterogeneous microstructure caused during the welding procedure because they are far more sensitive under fatigue than under tensile load [45, 46, 47, 48, 59]. 


\section{a}

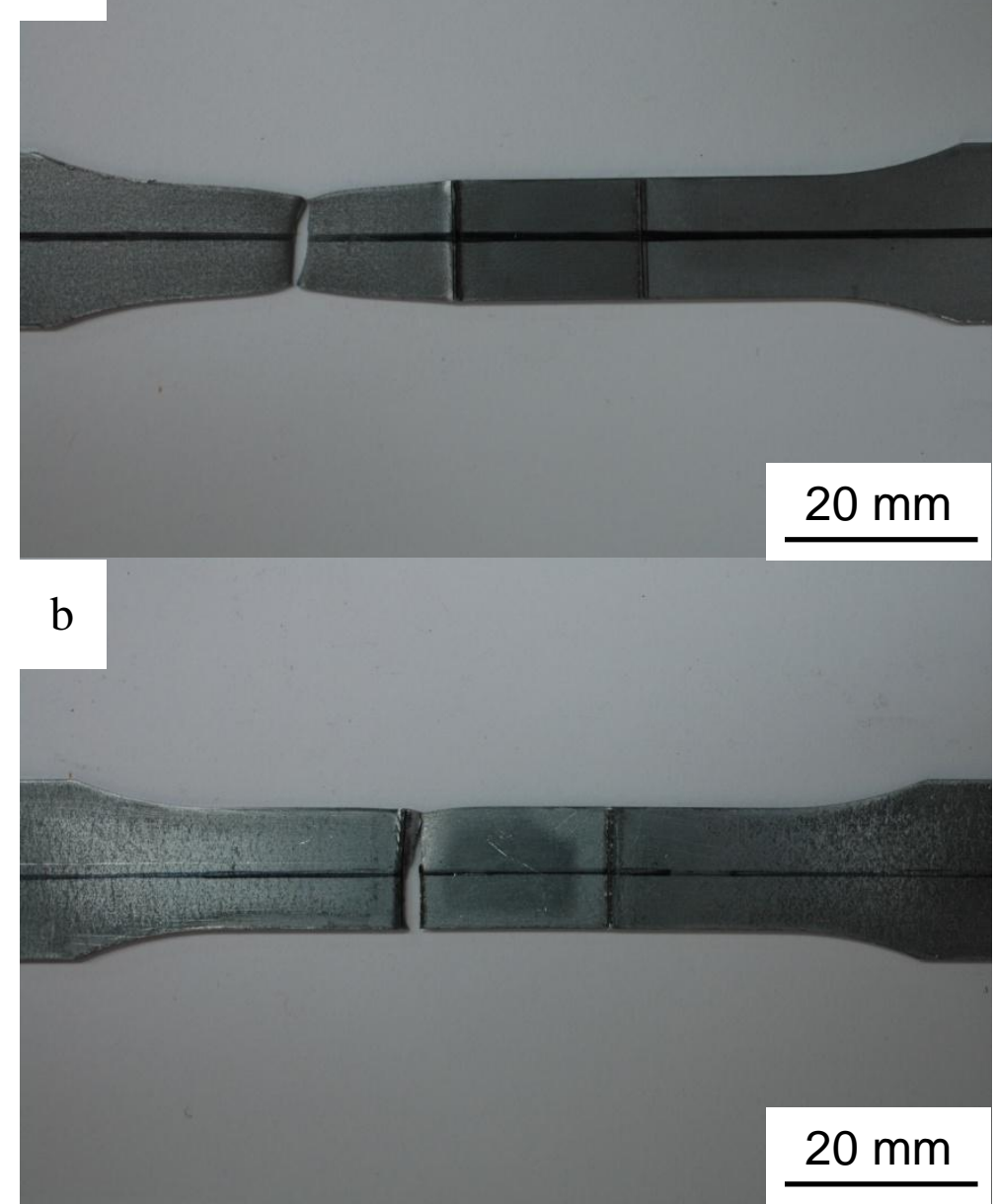

Fig. 8.4 Fatigue failure locations for GA coated triple dissimilar welds at (a) high stress amplitude, and (b) low stress amplitude. 


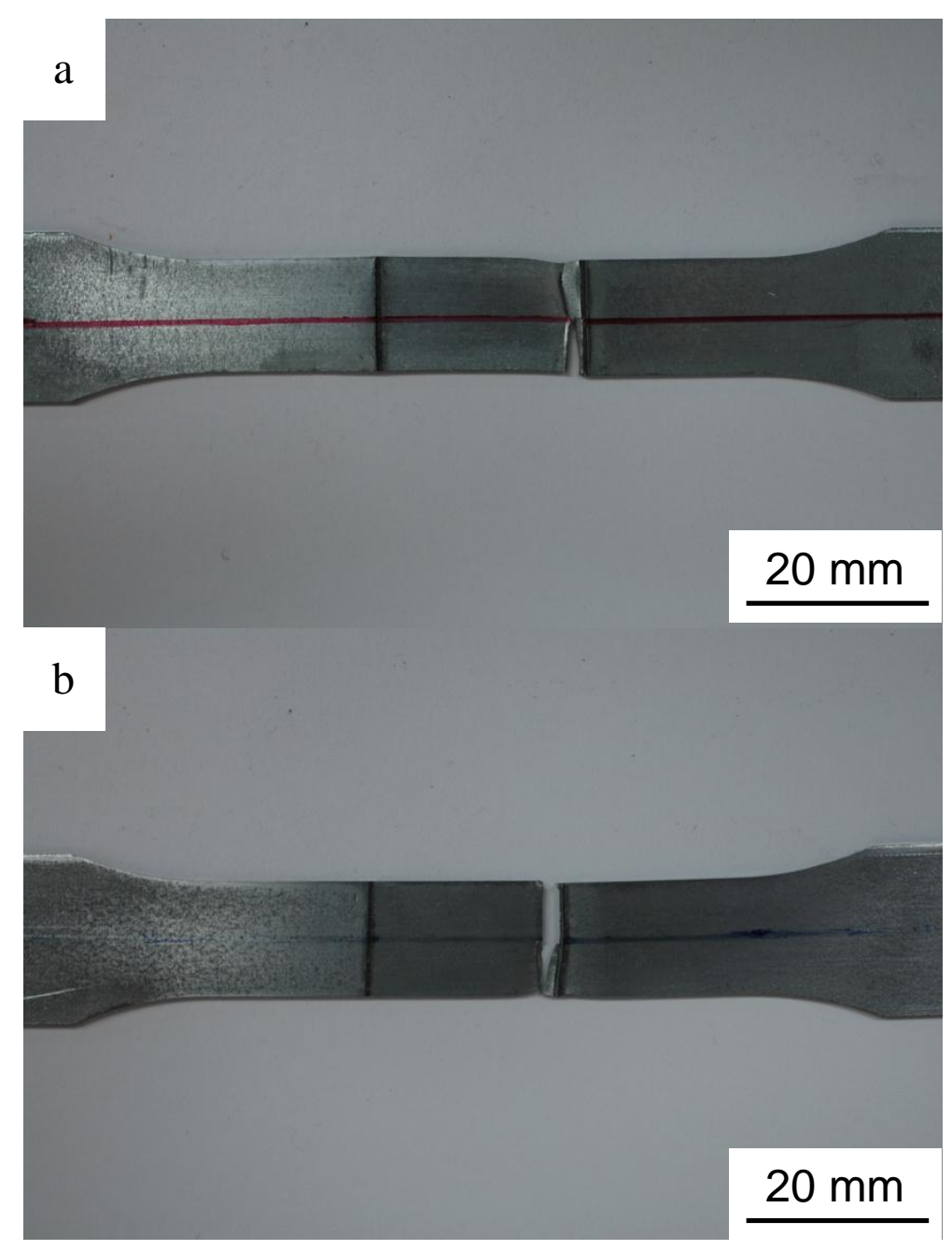

Fig. 8.5 Fatigue failure locations for GI coated triple dissimilar welds at (a) high stress amplitude, and (b) low stress amplitude.

The S-N plot in Fig. 8.6 and Fig. 8.7 could be expressed using the Basquin equation [46, 48],

$$
\sigma_{a}=\sigma_{f}^{\prime}\left(2 N_{f}\right)^{b}
$$

where $\sigma_{a}$ is the cyclic stress amplitude, $\sigma_{f}{ }^{\prime}$ is the fatigue strength coefficient defined by the stress intercept at $2 N_{f}=1, N_{f}$ is the number of cycles to failure $\left(2 N_{f}\right.$ is the number of reversals to failure), and $b$ is the fatigue strength exponent. The values of these parameters obtained by fitting the data points according to Eq. (5.1) are tabulated in Table 8.1. The fatigue life of the welded joints that could be estimated based on the values of $\sigma_{f}{ }^{\prime}$ and $b$. Eq. (5.1) indicates that the higher the value of $\sigma_{f}{ }^{\prime}$ and the smaller the absolute value of $b$, which is always 
negative, the longer the fatigue life. From Table 8.1, it can be seen that the GA coated base metals and triple dissimilar welds have lower $b$ values while the GI coated BMs and welded joints have a higher $\sigma_{f}{ }^{\prime}$. The difference in the fatigue life of the two welded joints was the same and was lower than all of the corresponding BMs. The differences in the BMs fatigue life were primarily due to the respective strengths of the BMs.

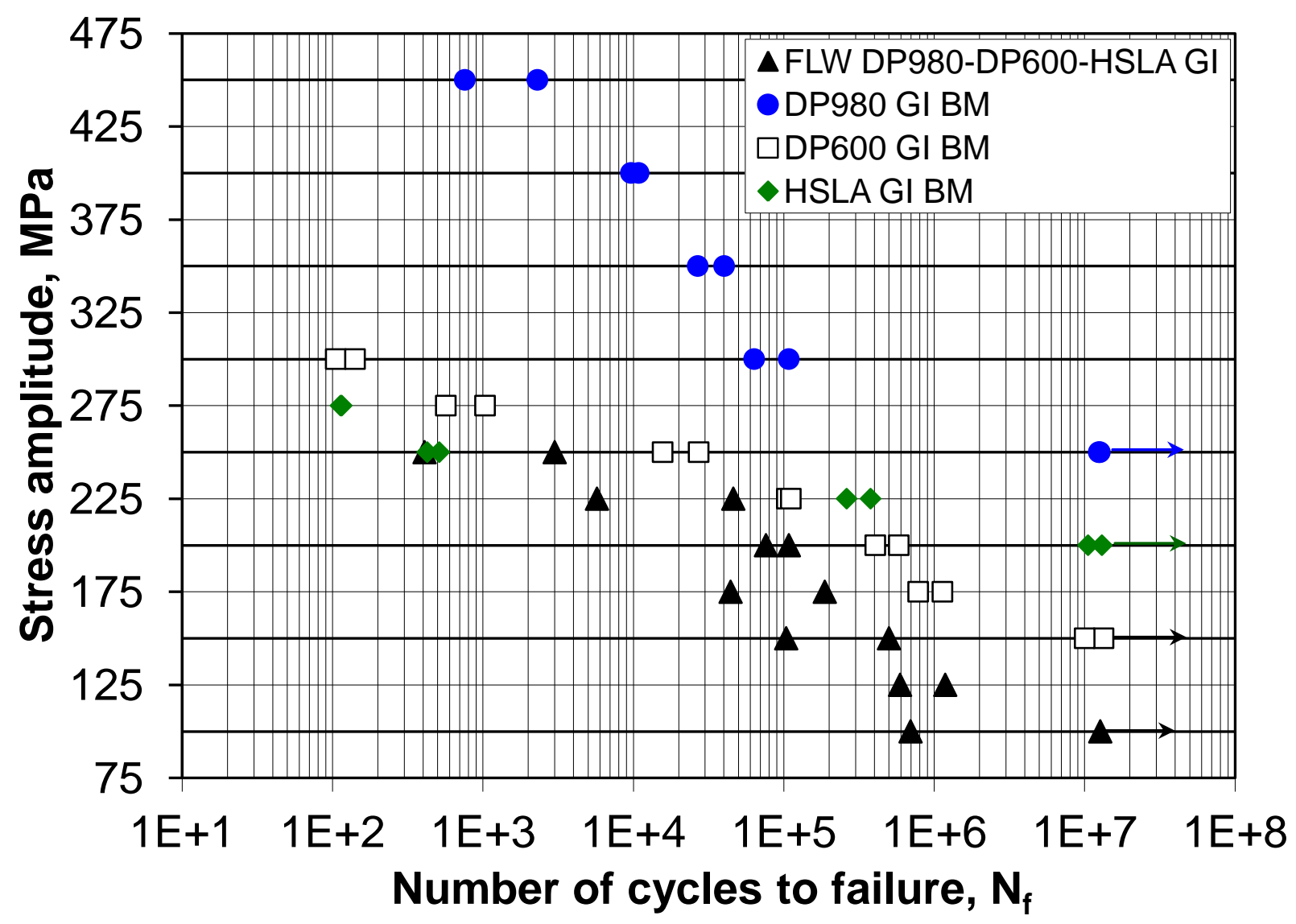

Fig. 8.6 S-N curve of GI coated triple dissimilar welds and related BMs [10]. 


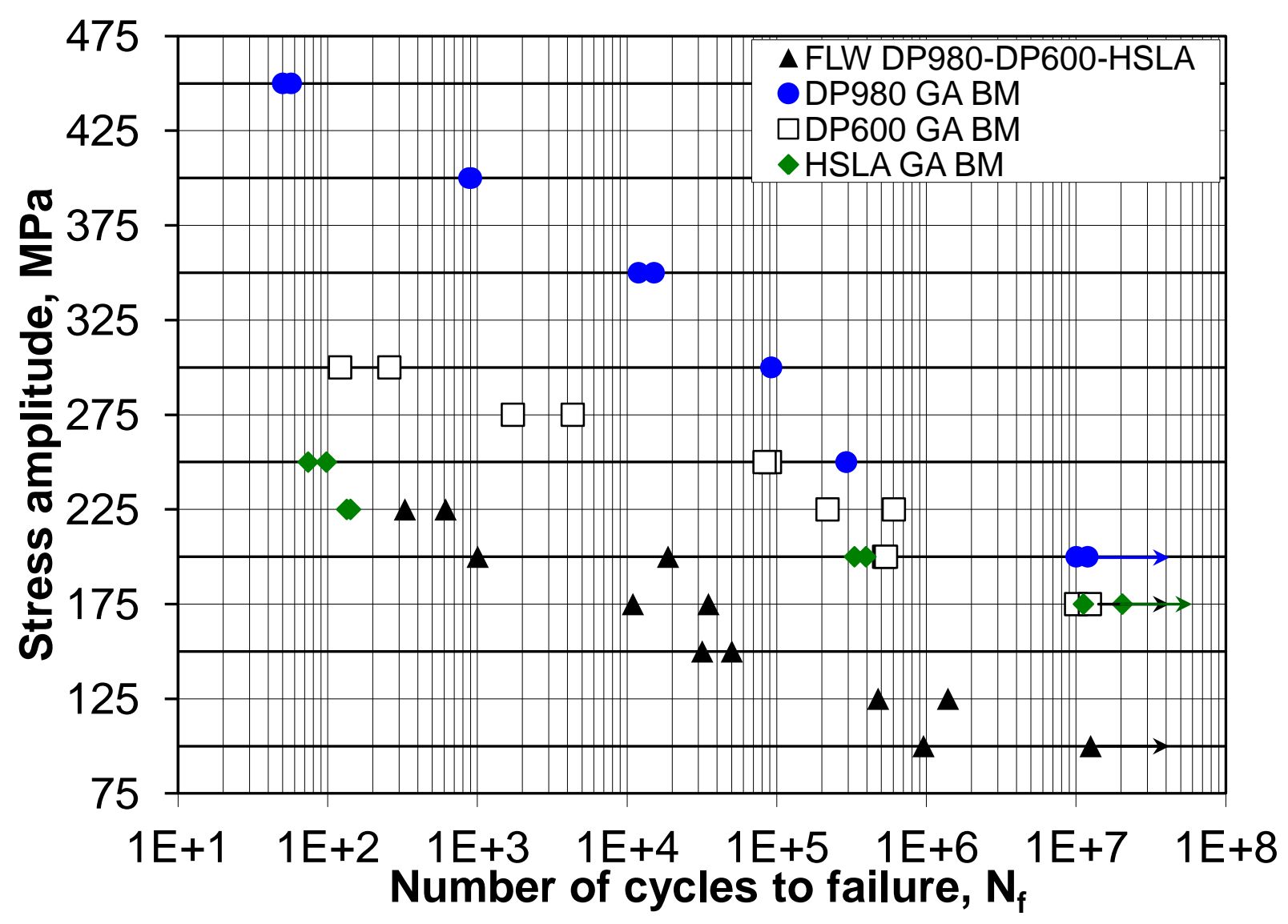

Fig. 8.7 S-N curve of GA coated triple dissimilar welds and related BMs.

The typical fatigue fracture surface of the triple dissimilar welded joints that failed at the lowest stress amplitudes (125 MPa for each) can be seen in Figs. 8.4(b) and 8.5(b). The failure of the joints at low stress amplitudes exhibited typical fatigue failure traits. The overall fracture surfaces can be seen in Figs. 8.8(a) and 8.9(a). In the crack initiation region, characteristic fatigue striations can be seen to be propagating in multiple directions Figs. 8.8(b) and 8.9(b). Moving farther into the sample, the propagation region is reached where the fatigue striations can be seen again, but all the propagation is radiating away from the initiation region (Figs. 8.8(c) and 8.9(c)). This is where fatigue damage accumulated until the crack grew large enough for final fracture. The final fast fracture area consisted of dimple fracture (Figs. 8.8(c) and 8.9(c)) characteristic of microvoid formation in ductile materials such as DP and HSLA steels (Table 8.1) [33, 48]. To enhance the fatigue strength of such 
dissimilar welded joints, further efforts are needed to reduce weld concavity, sheet misalignment, and size mismatch [45, 59].

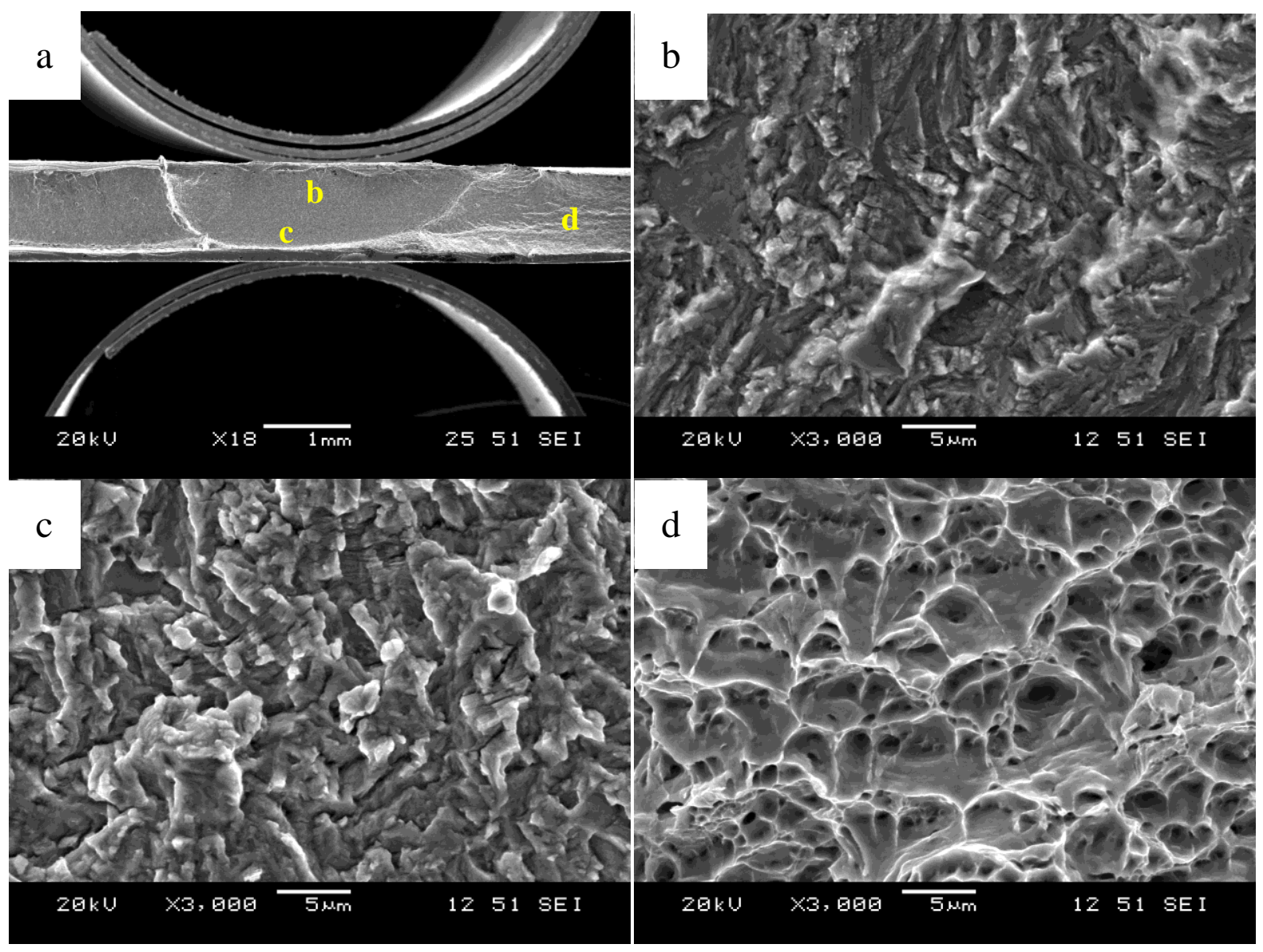

Fig. 8.8 Fracture surface of GI coated triple dissimilar weld, (a) Overall fracture surface, (b) initiation region, (c) propagation region, (d) fast fracture region. 


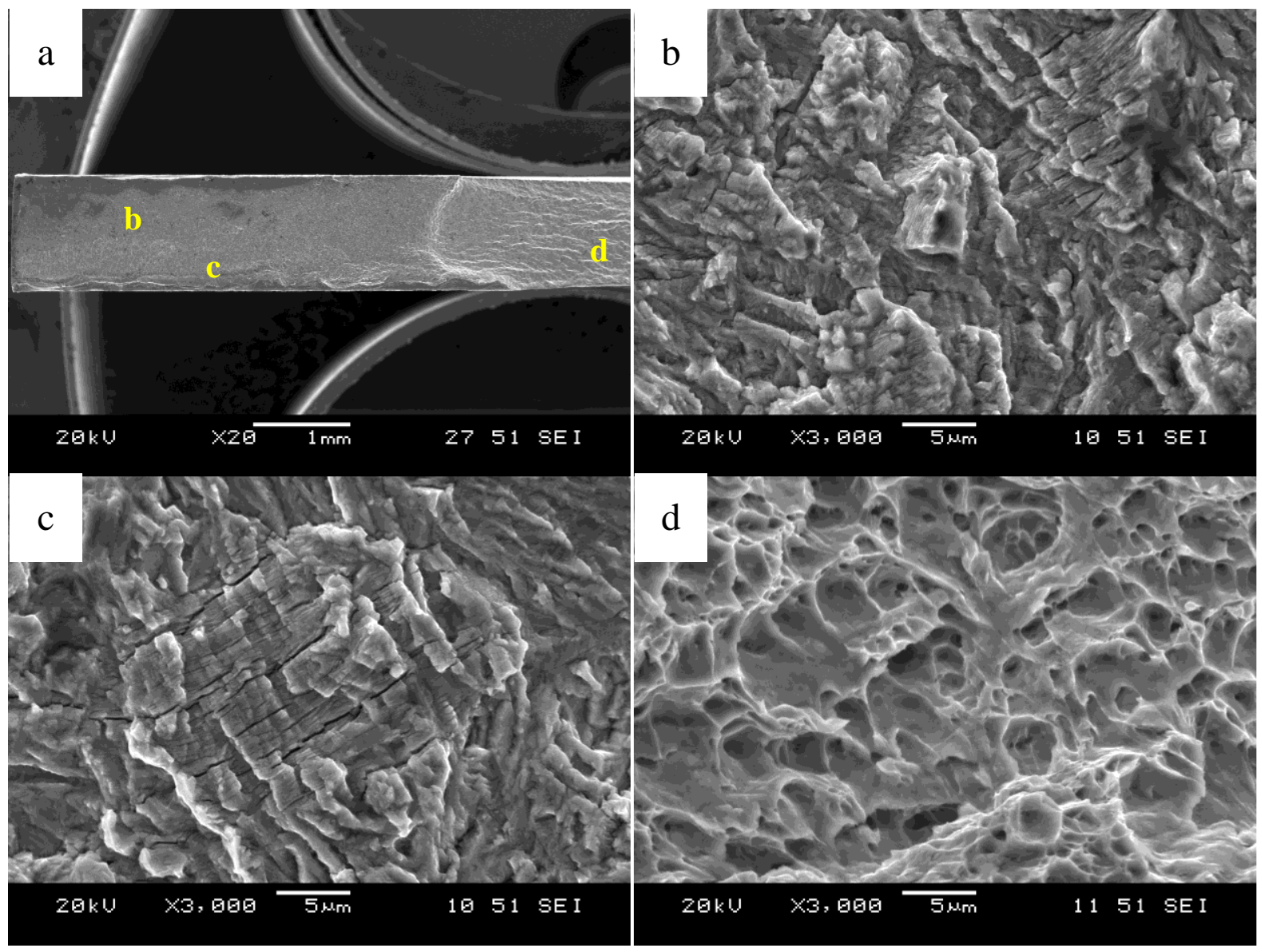

Fig. 8.9 Fracture surface of GA coated triple dissimilar weld, (a) Overall fracture surface, (b) initiation region, (c) propagation region, (d) fast fracture region.

\subsection{Summary}

The following conclusions could be drawn from the analysis of the microstructure, microhardness, tensile, and fatigue properties of the dissimilar welded joints:

1. The GA coated HSLA BM exhibited YPP which was seen in the GA coated triple dissimilar weld, causing an apparent increase in the YS using the normal method of measuring YS.

2. According to both the tensile and the fatigue data, GI coated samples were found to have higher strength values in general. The GA coated samples had better $b$ values 
indicating better overall fatigue life, but the GI coated samples had higher $\sigma_{f}^{\prime}$ values meaning that they were stronger under low cycle fatigue.

3. Coating type was not observed to affect the tensile and fatigue properties of the welded joints, which was rather dominated by BM strength, concavity, sheet alignment and difference in sheet thickness. 


\section{Chapter 9 Fiber Laser Welding of dual-phase DP980 steel: Effects of Heat Input and Chemistry on Softening and Performance}

The previous chapters have examined the effect of dissimilar welding between DP980 and HSLA using FLW. This chapter examines the effects of different heat inputs on the mechanical properties of different similarly FLWed DP980 joints of different chemistry.

\subsection{Microhardness}

The hardness profiles of the steels are given in Figs. 9.1 and 9.2 for the welds made with low and high heat input, respectively. The metallurgical changes caused by FLW resulted in a large variation in the hardness across the weldments. For both steels, the FZ greatly increased in hardness compared to the BM. The width of the fusion zone in both steels was found to be in the range of 450 to $550 \mu \mathrm{m}$.. The DP980 Lean weld possessed a higher average hardness in the FZ, while the DP980 Rich steel weld showed a lower average hardness (Table 9.1); this difference in hardness is attributed to the difference in carbon content of the steels, see Table 3.1 . 


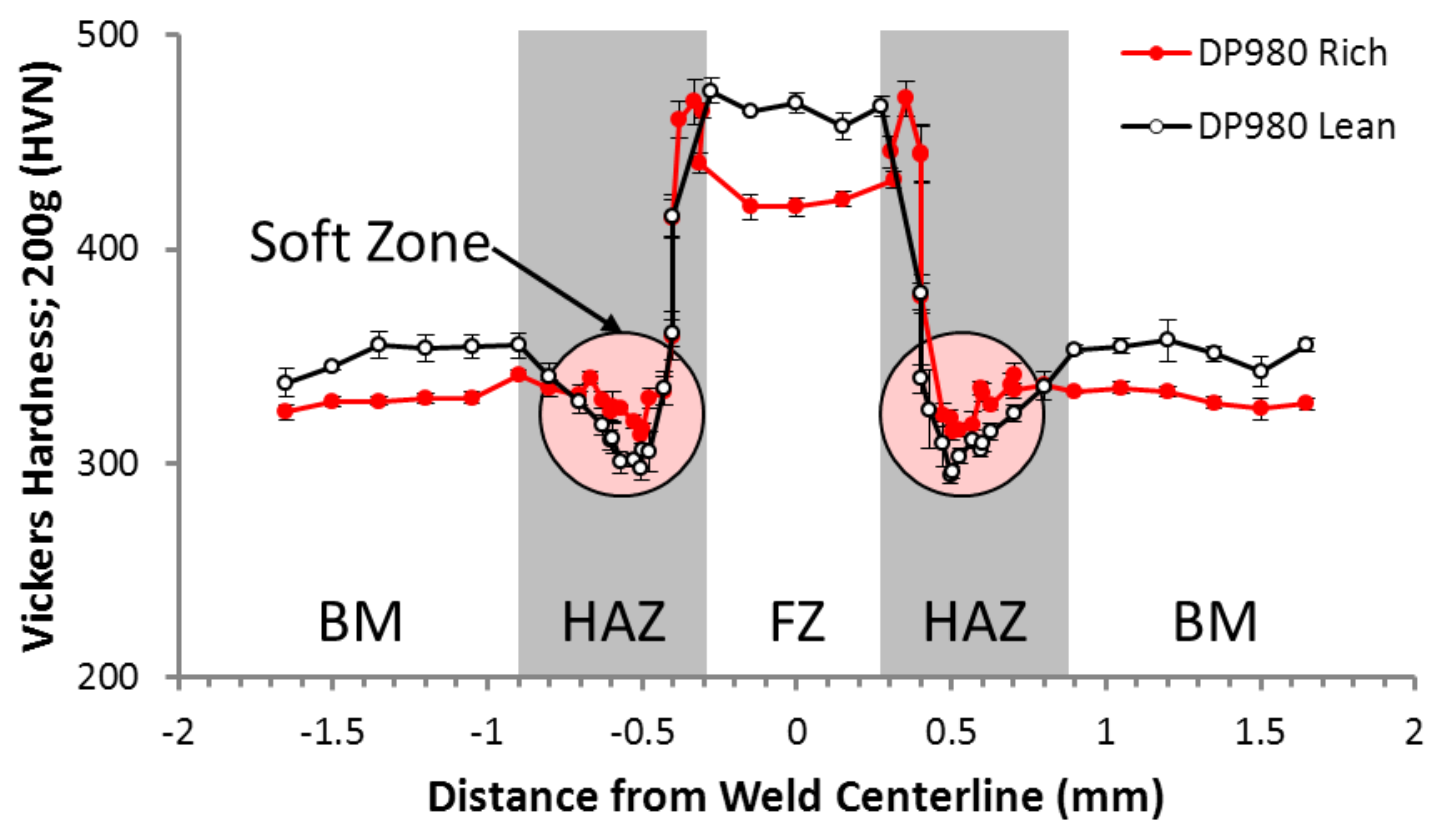

Fig. 9.1 Vickers hardness profiles for low heat input welds; error bars show one standard deviation.

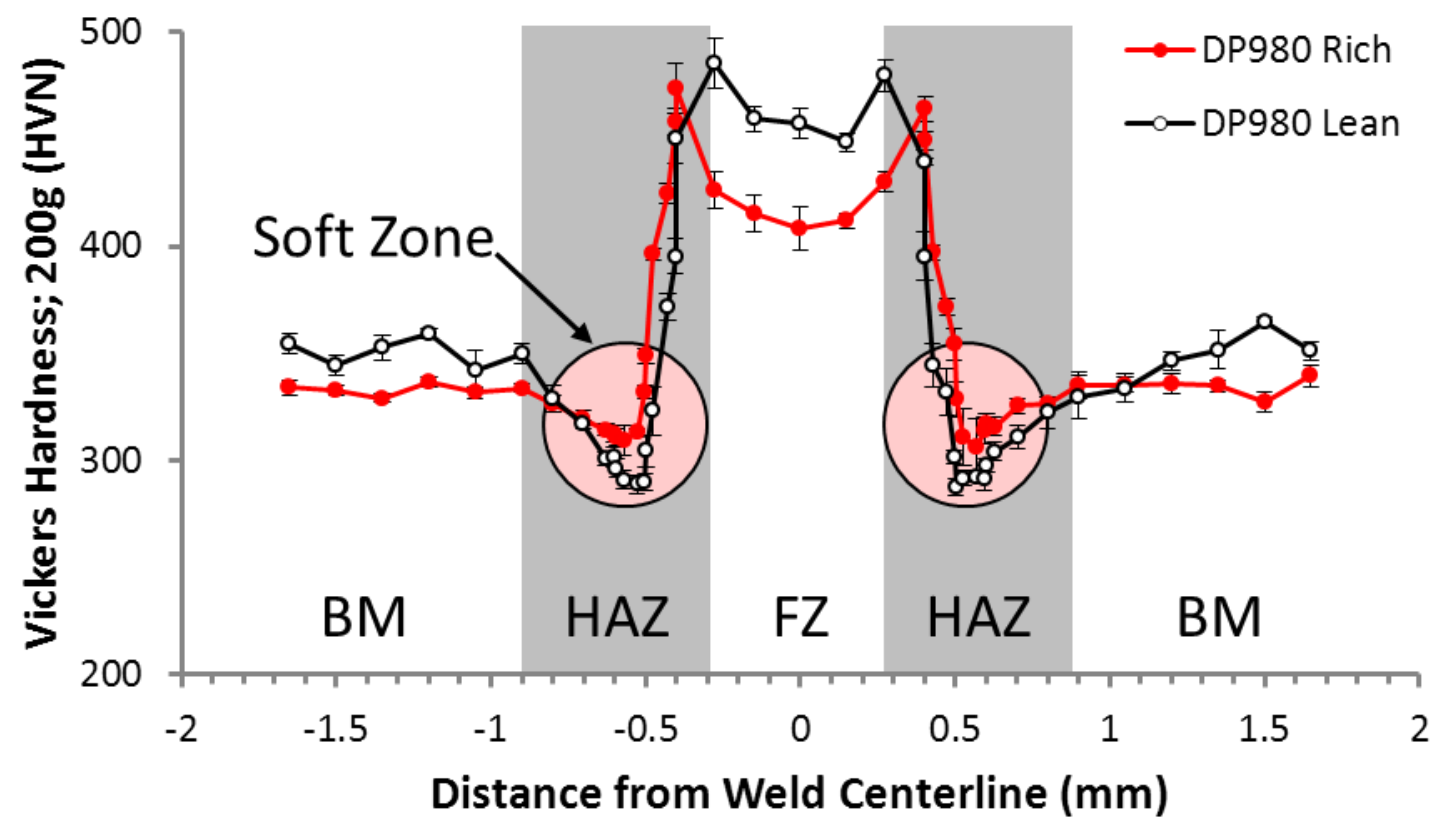

Fig. 9.2 Vickers hardness profiles for low heat input welds; error bars show one standard deviation. 
Table 9.1 Soft zone properties of welded DP980 Rich and Lean steels

\begin{tabular}{|l|c|c|c|c|c|c|}
\hline Steel & $\begin{array}{c}\text { Welding } \\
\text { Speed } \\
(\mathrm{m} / \mathrm{min})\end{array}$ & $\begin{array}{c}\text { Laser } \\
\text { Power } \\
(\mathrm{kW})\end{array}$ & $\begin{array}{c}\text { Heat } \\
\text { Input } \\
\left(\mathrm{J} / \mathrm{mm}^{2}\right)\end{array}$ & $\begin{array}{c}\text { FZ } \\
\text { Hardness } \\
(\mathrm{HV})\end{array}$ & $\begin{array}{c}\text { Softening } \\
(\%)\end{array}$ & $\begin{array}{c}\text { Soft Zone } \\
\text { Width }(\mu \mathrm{m})\end{array}$ \\
\hline DP980 Lean & 20.5 & 4 & 9.76 & 468 & 17.2 & 400 \\
\hline DP980 Lean & 10 & 2 & 10 & 452 & 18.8 & 650 \\
\hline DP980 Rich & 20.5 & 4 & 9.76 & 420 & 4.5 & 100 \\
\hline DP980 Rich & 10 & 2 & 10 & 408 & 6.1 & 200 \\
\hline
\end{tabular}

Yurioka et al. [64] showed that the hardness of martensite could be predicted by the carbon content of the steel using Eqn. (9.1):

$$
H_{M}=884 C\left(1-0.3 C^{2}\right)+294
$$

From Eqn. 9.1 it is clear that higher bulk carbon content leads to a harder martensite phase, as was also observed in the literature [64]. For DP980 Rich welded at the low heat input, the predicted and measured values of the maximum hardness were $373 \mathrm{HV}$ and $420 \mathrm{HV}$, respectively, while DP980 Lean resulted in a predicted hardness of $426 \mathrm{HV}$ and measured hardness of $468 \mathrm{HV}$ (Table 9.1). This difference in hardness is corroborated by similar study on arc welding conducted by Yurioka et al. [64], which reported that higher cooling rates resulted in higher hardness values than predicted. Laser welding possesses a much higher cooling rate than arc welding due to its higher speed $[20,39,65]$. This high cooling rate leads to finer grain size in the FZ, which would cause an increase in hardness [40,66, 67]. Therefore, as both the steels were welded with similar welding speed (cooling rate), the higher FZ hardness in the DP980 Lean was determined to be only a result of the higher carbon content of the steel compared to DP980 Rich.

The hardness profiles of all the welds (high speed; Fig. 9.1 and low speed; Fig. 9.2) showed a steep gradient in the HAZ in which the hardness of the material rapidly increased as the FZ was approached. In addition, the hardness was observed to drop significantly below the BM 
hardness in both the steels at the subcritical HAZ (marked as soft zone in Fig. 9.1 and Fig. 9.2), which is well known as HAZ softening [60, 42, 68, 69]. The width of the soft zone for DP980 Rich and DP980 Lean was measured to be about $100 \mu \mathrm{m}$ and $400 \mu \mathrm{m}$, respectively. The soft zone width was also found to decrease with increases in the welding speed (Table 9.1), which has been seen in earlier studies [12]. Furthermore the reduction in the BM hardness i.e. severity of softening was also observed to decrease with increasing welding speed (Table 9.1); where softening is defined as:

$$
\text { Percent Softening }=\left(1-\frac{H_{H A Z}}{H_{B M}}\right) \times 100
$$

Where $H_{B M}$ is the BM hardness and $H_{H A Z}$ is the minimum hardness observed in the HAZ.

In addition to the heat input, softening was observed to be dependent on the chemistry of the steel. For instance, DP980 Rich softened to a lower extent when compared to DP980 Lean, when both are welded with similar welding parameters (Table 9.1). The reason for increasing resistance to softening has been reported to be the substitutional alloying elements $(\mathrm{Mn}, \mathrm{Cr}$, Mo), which restrict the diffusion of carbon to form cementite and thus stabilize the martensite phase [42].

\subsection{Tensile properties}

The stress strain plots for the BM and welded joints of DP980 Rich and DP980 Lean are shown in Figs. 9.3 and 9.4, respectively. It is clearly seen that the DP980 Lean welded joints showed reduction in the elongation of the samples when compared to BM (Fig. 9.4) while DP980 Rich showed similar tensile properties as its BM (Fig. 9.3). Interestingly, the strength of both the steels did not change after welding at different heat inputs. The difference in the hardness values between the two steels (Figs. 9.1 and 9.2) was reflected in the tensile curves 
(Figs. 9.3 and 9.4). For example, the ultimate tensile strengths for high and low heat inputs of the DP980 Lean chemistry were $1065 \mathrm{MPa}$ and $1067 \mathrm{MPa}$, respectively, and for DP980 Rich were $1020 \mathrm{MPa}$ and $1017 \mathrm{MPa}$, respectively. It can also be noted that there was insignificant difference between the two different heat inputs on the final tensile performance of the welded joints. This is likely due to the fact that the different amount of HAZ softening that each of the two DP980 samples experienced from the welding process was minimal between the heat inputs. From Table 9.1, the degree of softening in the DP980 Lean is much greater than that of the DP980 Rich, which would lead to a greater effect of the sub-critical HAZ during the tensile test. In previous studies $[10,12,69,70]$ it has been seen that the degree of softening and the size of the HAZ have had a strong influence over tensile behaviour, with the decrease in the size of the sub-critical HAZ (Table 9.1) in FLW compared to other laser welding, the effect of softening on determining the overall specimens until the UTS is reached was reduced. Because of this, the failure in the tensile testing consistently occurred in the tempered region of the specimens for the DP980 Lean samples whereas DP980 Rich steel welds failed in the BM. 


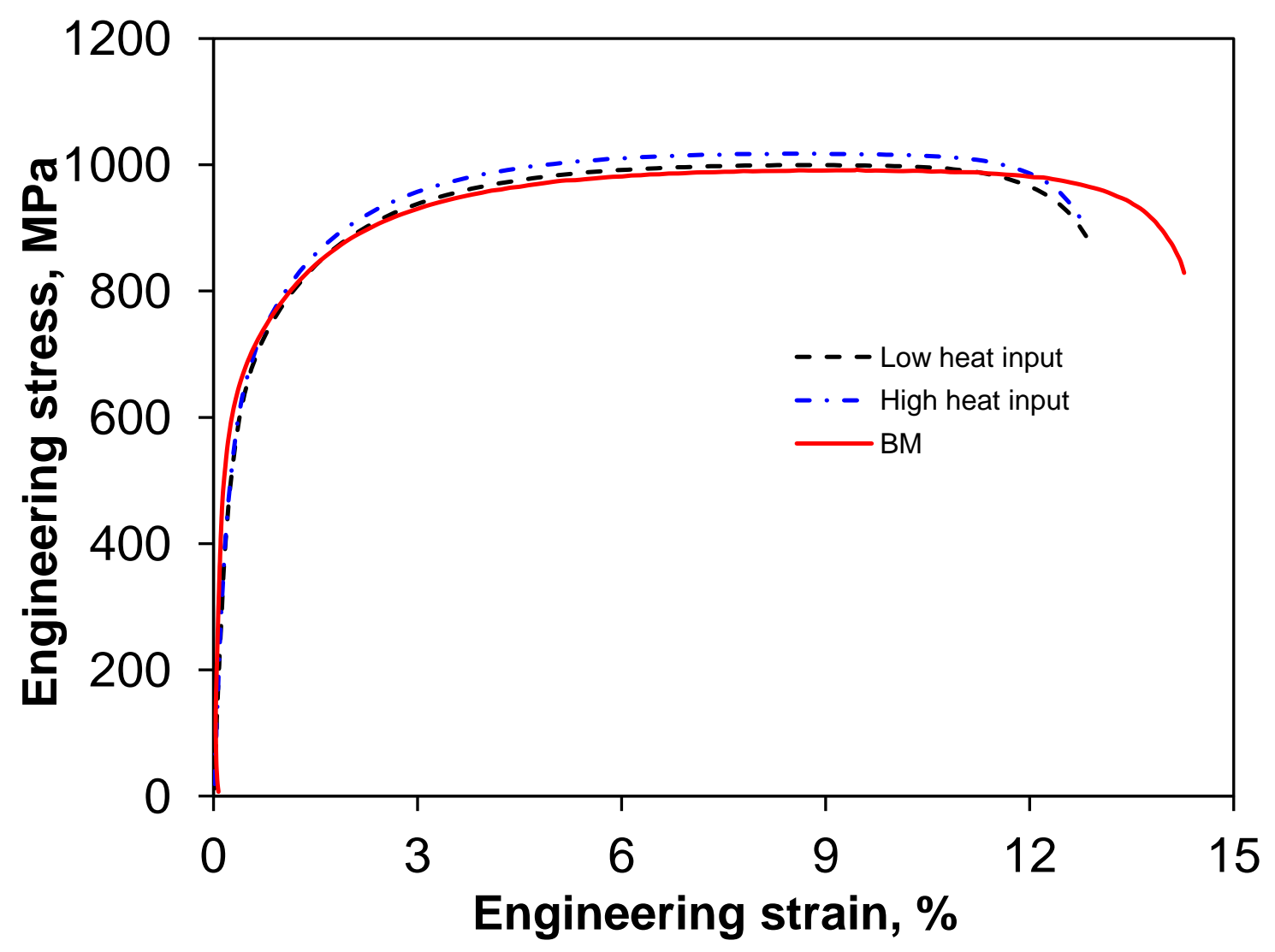

Fig. 9.3 Tensile curve for DP980 Rich at high and low heat inputs. 


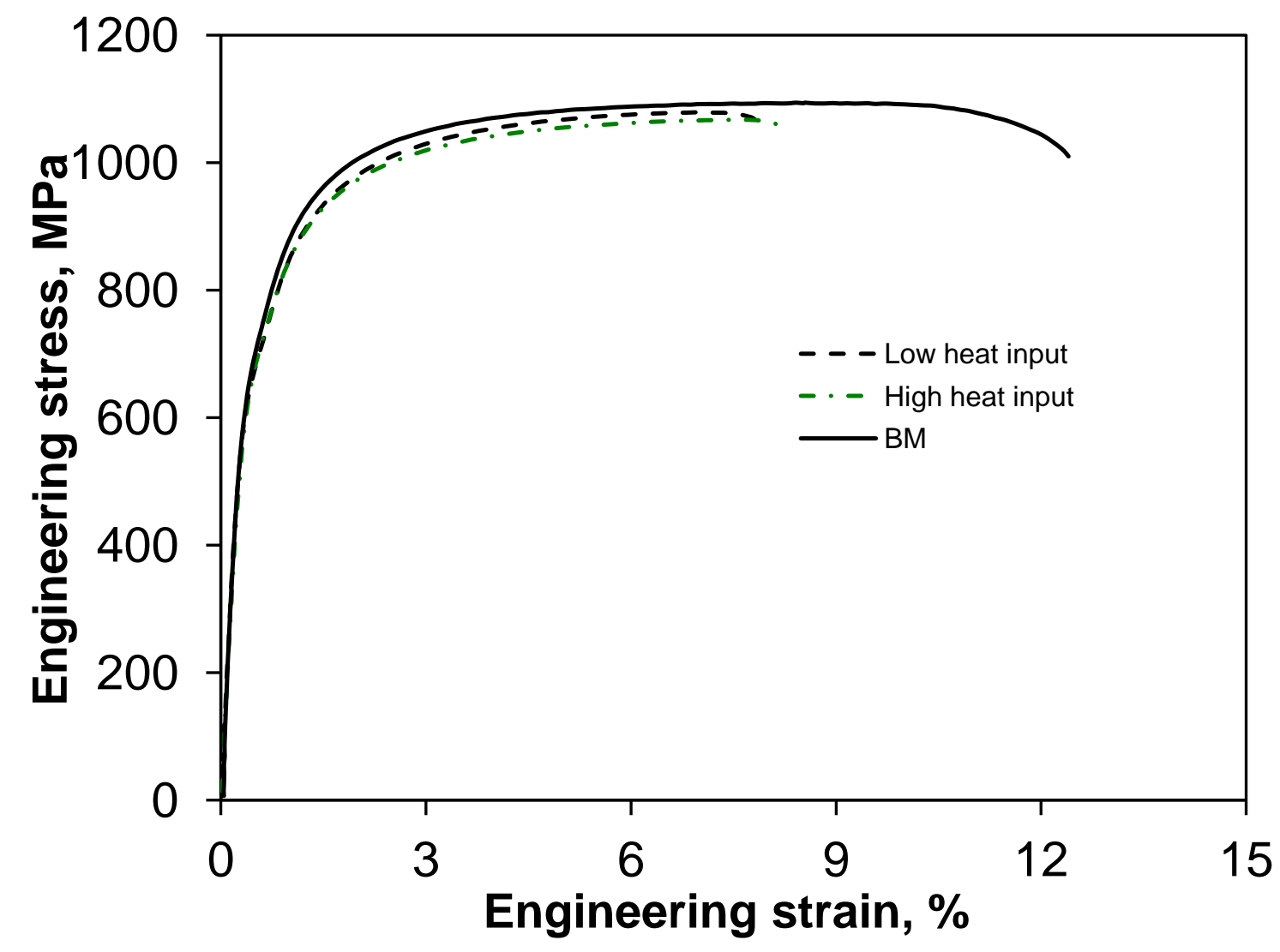

Fig. 9.4 Tensile curve for DP980 Lean at high and low heat inputs.

\subsection{Formability}

Limiting dome height (LDH) testing indicated that the DP980 Rich and DP980 Lean BM exhibited similar formability (Table 9.2) as demonstrated by the insignificant difference in their $\mathrm{LDH}$ values. Both the BMs failed with the crack growing parallel to the rolling direction as shown in Fig. 9.5. As expected, the higher softening in the DP980 Lean steel yielded a larger reduction $(7-9 \mathrm{~mm})$ in the LDH value of welded blank (Table 9.2) whereas for the DP980 Rich welds, which showed better resistance to softening, the reduction in LDH values was very low $(\sim 0.5 \mathrm{~mm})$, irrespective of the heat input. Interestingly, the welded DP980 Lean steel demonstrated failure parallel to the weld line while the DP980 Rich steel welded blanks failed across the weld line and parallel to the rolling direction similar to its BM (Fig. 9.5). It 
may be recalled that during tensile testing, DP980 Rich attained properties similar to its BM. Panda et al. [44] have reported that the ductility in the single axial tensile testing was not always representative of the stretchability in bi-axial stretch forming due to the difference in the loading condition. However, previous studies predicted that as heat input was reduced, the welded blanks attained properties closer to that of the BM $[69,70]$. Laser welded blanks made by FLW, due to its low heat input, were able to attain BM like properties for the DP980 Rich steel, but not the DP980 Lean. The low heat input of FLW and higher alloying content of DP980 Rich formed a weld in which the influence of softening was negligible on tensile properties and formability.

Table 9.2 Limiting dome height and dome force of welded DP steels

\begin{tabular}{|l|c|c|c|c|}
\hline Steel & $\begin{array}{c}\text { Welding Speed } \\
(\mathrm{m} / \mathrm{min})\end{array}$ & $\begin{array}{c}\text { Laser Power } \\
(\mathrm{kW})\end{array}$ & $\begin{array}{c}\text { Max. Dome } \\
\text { Force }(\mathrm{kN})\end{array}$ & $\begin{array}{c}\text { LDH } \\
(\mathrm{mm})\end{array}$ \\
\hline DP980 Rich & $\ldots$ & $\ldots$ & 142 & 29.5 \\
\hline DP980 Rich & 20.5 & 4 & 155 & 29.2 \\
\hline DP980 Rich & 10 & 2 & 157 & 29.0 \\
\hline DP980 Lean & $\ldots$ & $\ldots$ & 155 & 29.4 \\
\hline DP980 Lean & 20.5 & 4 & 107 & 21.6 \\
\hline DP980 Lean & 10 & 2 & 105 & 20.4 \\
\hline
\end{tabular}



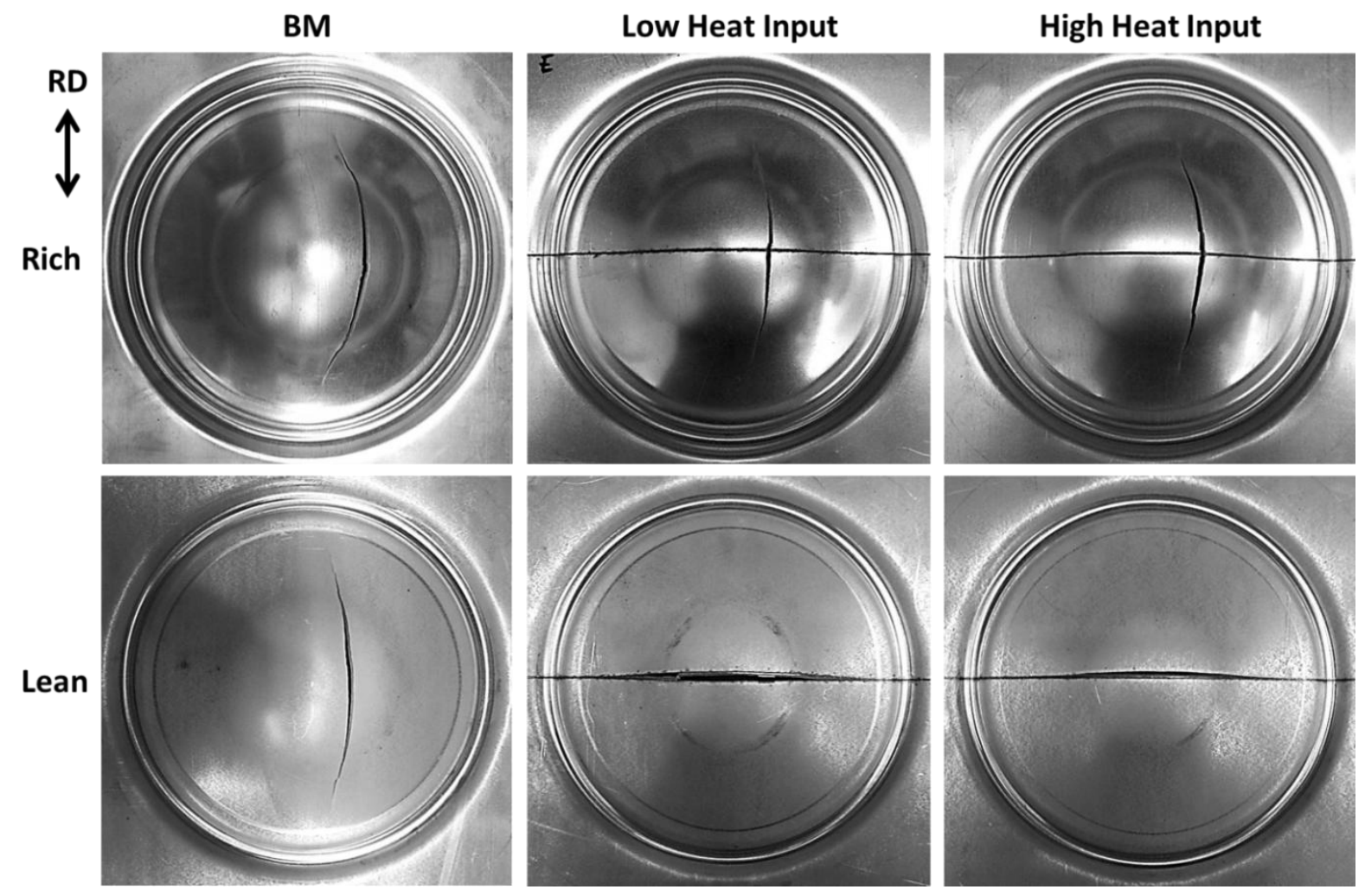

Fig. 9.5 Fracture location of Formed Domes.

\subsection{Fatigue and Fracture}

Fatigue results (Fig. 9.6) indicated distinct difference in the durability of the DP980 Rich and DP980 Lean steels when welded using low heat inputs, and there was a difference between the different heat inputs for each sample chemistry. The S-N curves that were generated by the fatigue tests were fitted using the Basquin equation [46]:

$$
\sigma_{a}=\sigma_{f}{ }^{\prime}\left(2 N_{f}\right)^{b}
$$

Where $\sigma_{a}$ is the cyclic stress amplitude, $\sigma_{f}{ }^{\prime}$ is the fatigue strength coefficient defined by the stress intercept at $2 N_{f}=1, N_{f}$ is the number of cycles to failure $\left(2 N_{f}\right.$ is the number of reversals to failure), and $b$ is the fatigue strength exponent $[33,34,46]$. The information from the 
Basquin equation is summarized in Table 9.3. From this it can be seen that there is a difference between the DP980 Rich and DP980 Lean as well as between the different heat inputs. Examination of the tensile properties and formability showed very little difference between the two welding conditions because these tests are not as sensitive to notches as fatigue tests $[45,46,59]$. Welds made with both the heat inputs were defect free with acceptable concavity [59]; however, the higher heat input samples had even less concavity than the lower heat input welds and caused the difference between the welding conditions for both the Lean and Rich DP980 materials.

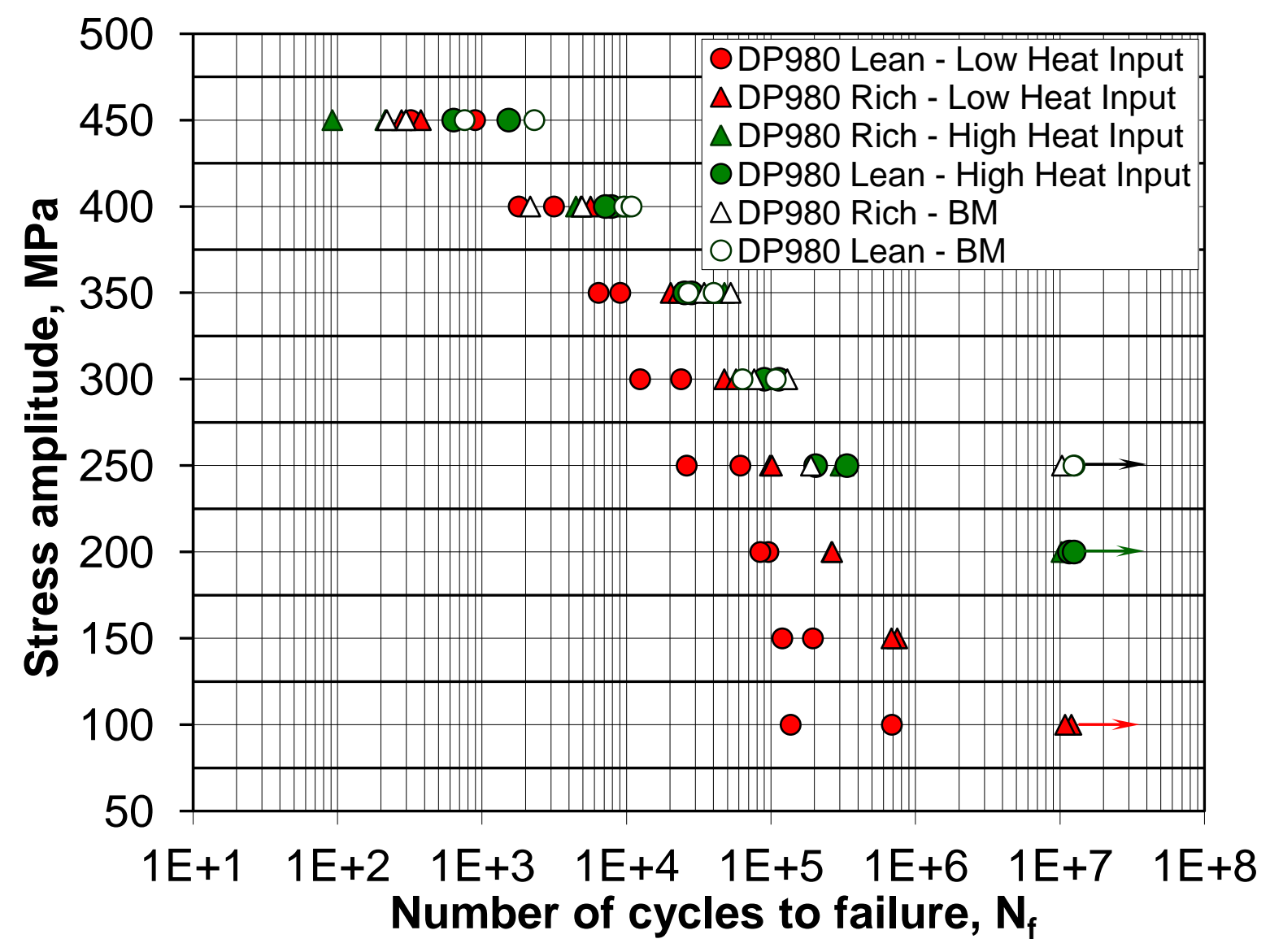

Fig. 9.6 S-N curve of DP980 Rich and Lean at the different heat inputs.

It can be seen in the summarized data of fatigue results (Table 9.3) that the DP980 Rich had better improved fatigue properties than the Lean DP980 samples. Possible reasons for this are the degree of softening that occurred in the Lean DP980 in comparison to the Rich DP980 
chemistry and the slight difference in strength between the two BMs. As it can be seen in Fig. 9.7, the DP980 Lean samples always failed in or around the HAZ due to the large difference in strength between its BM hardness and the hardness of the sub-critical HAZ; whereas at higher stress amplitudes the DP980 Rich samples failed in the BM and in the HAZ for low stress amplitude tests.
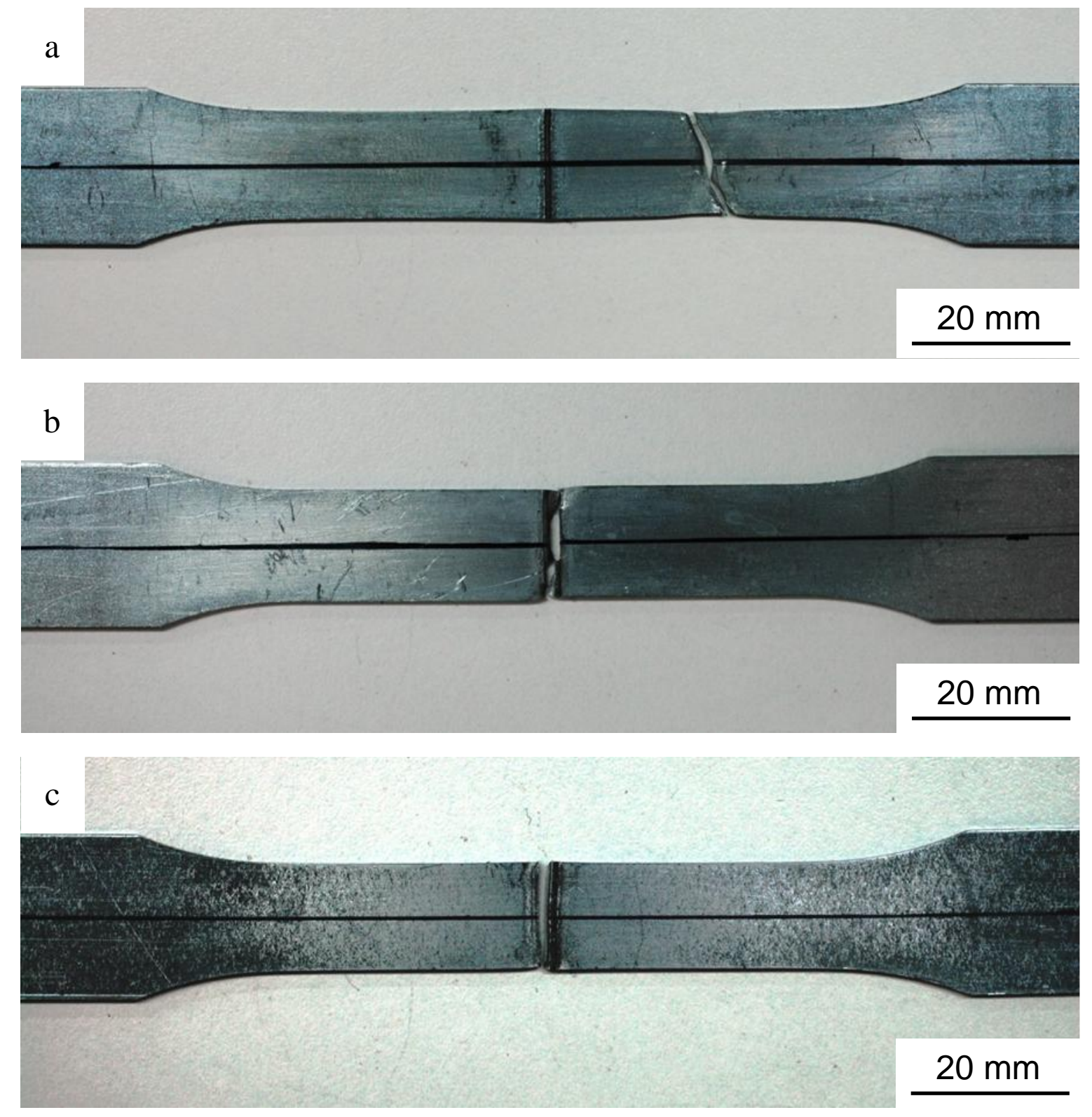


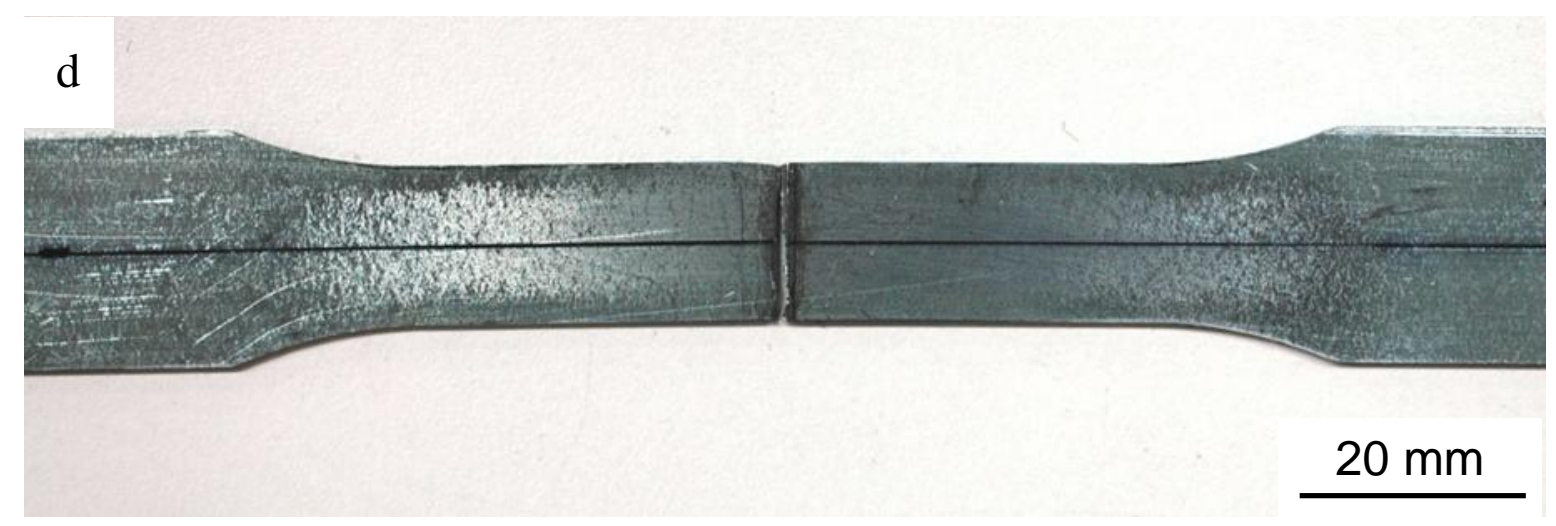

Fig. 9.7 Typical fracture locations of both heat inputs (a) high stress amplitude Rich DP980, (b) low stress amplitude Rich DP980, (c) high stress amplitude Lean DP980, (d) low stress amplitude Lean DP980.

Table 9.3 Fatigue data for the DP980 Rich and Lean base metals and the different heat inputs

\begin{tabular}{|l|c|c|c|c|c|}
\hline Steel & $\begin{array}{c}\text { Welding Speed } \\
(\mathrm{m} / \mathrm{min})\end{array}$ & $\begin{array}{c}\text { Laser Power } \\
(\mathrm{kW})\end{array}$ & $\begin{array}{c}\text { Fatigue Limit } \\
(\mathrm{MPa})\end{array}$ & $\begin{array}{c}\sigma_{f}^{\prime} \\
(\mathrm{MPa})\end{array}$ & $n$ \\
\hline DP980 Rich & $\ldots$ & $\ldots$ & 250 & 730 & -0.0722 \\
\hline DP980 Rich & 20.5 & 4 & 100 & 1338 & -0.1407 \\
\hline DP980 Rich & 10 & 2 & 200 & 712 & -0.0701 \\
\hline DP980 Lean & $\ldots$ & $\ldots$ & 250 & 939 & -0.0909 \\
\hline DP980 Lean & 20.5 & 4 & $100>$ & 2410 & -0.2145 \\
\hline DP980 Lean & 10 & 2 & 200 & 1018 & -0.1019 \\
\hline
\end{tabular}

Fig. 9.8 shows the fatigue fracture surface for both the DP980 Rich and DP980 Lean samples at low stress amplitudes. Within each of the samples, three specific regions were found common to steel fatigue failure: the initiation region (Fig. 9.9), the propagation region (Fig. 9.10), and the fast fracture region (Fig. 9.11). The initiation region characteristically has fatigue striations going in different directions due to the initial forming of the fatigue crack; the propagation region where the fatigue crack growth occurred shows striations that are moving away from the crack initiation region; and in the fast fracture region the crack grew to a critical size and the sample started to fail catastrophically and showed ductile cup and cone failure on the fracture surface $[10,33,48]$. 


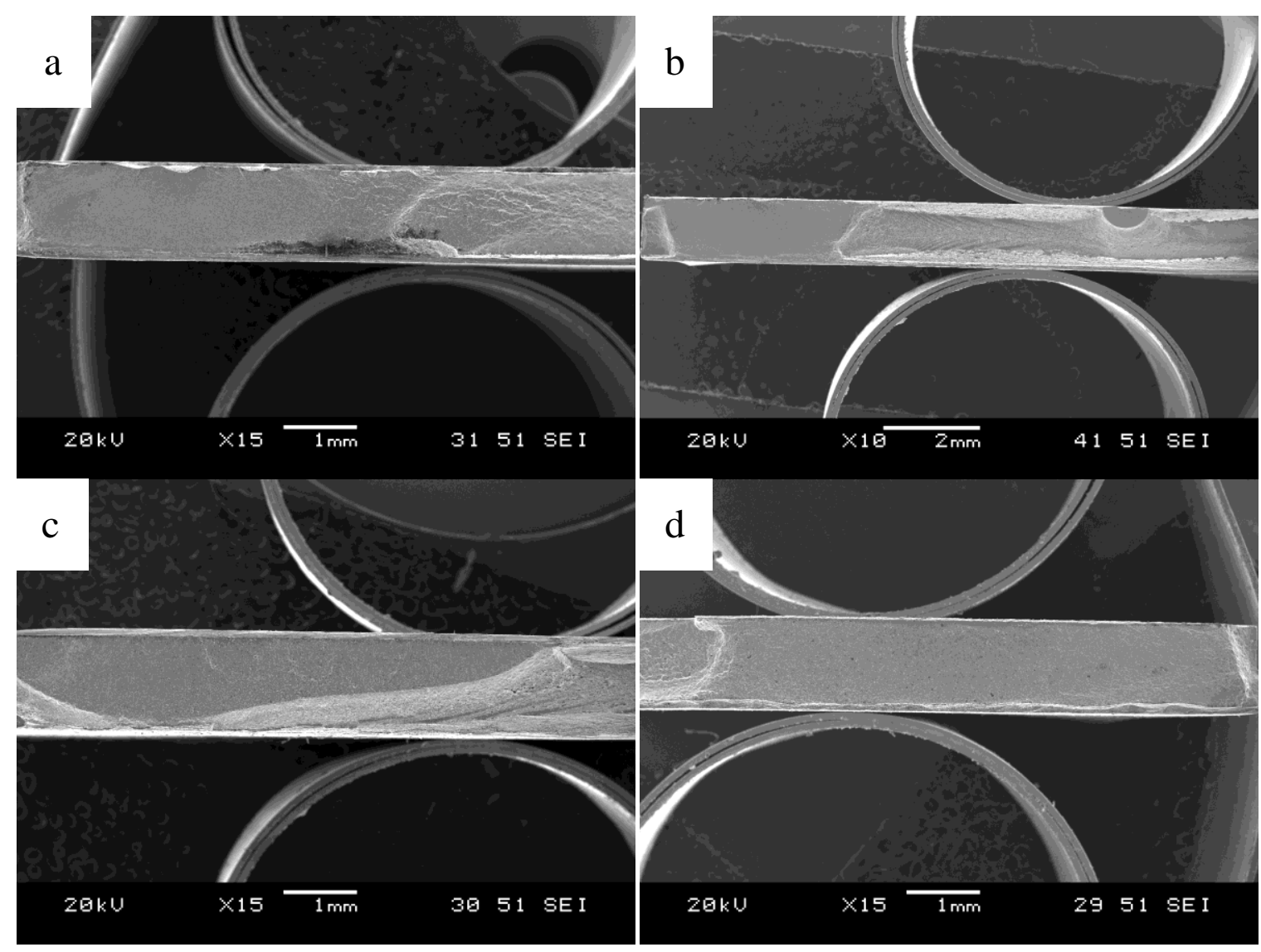

Fig. 9.8 Overall fracture surfaces of relative low stress amplitude tests for (a) high heat input DP980 Rich, (b) low heat input DP980 Rich, (c) high heat input DP980 Lean, and (d) low heat input DP980 Lean.

The low heat input DP980 Rich (Fig 9.8(b)) sample showed multiple regions of crack initiation with one dominating over the other initiation sites, whereas the DP980 lean samples only showed a single crack that grew to failure. These additional regions of crack initiation could be one of the leading causes of the difference in strength between the different heat inputs and the fact that additional crack growth occurred allowing for the sample to fail at a lower stress amplitude. 


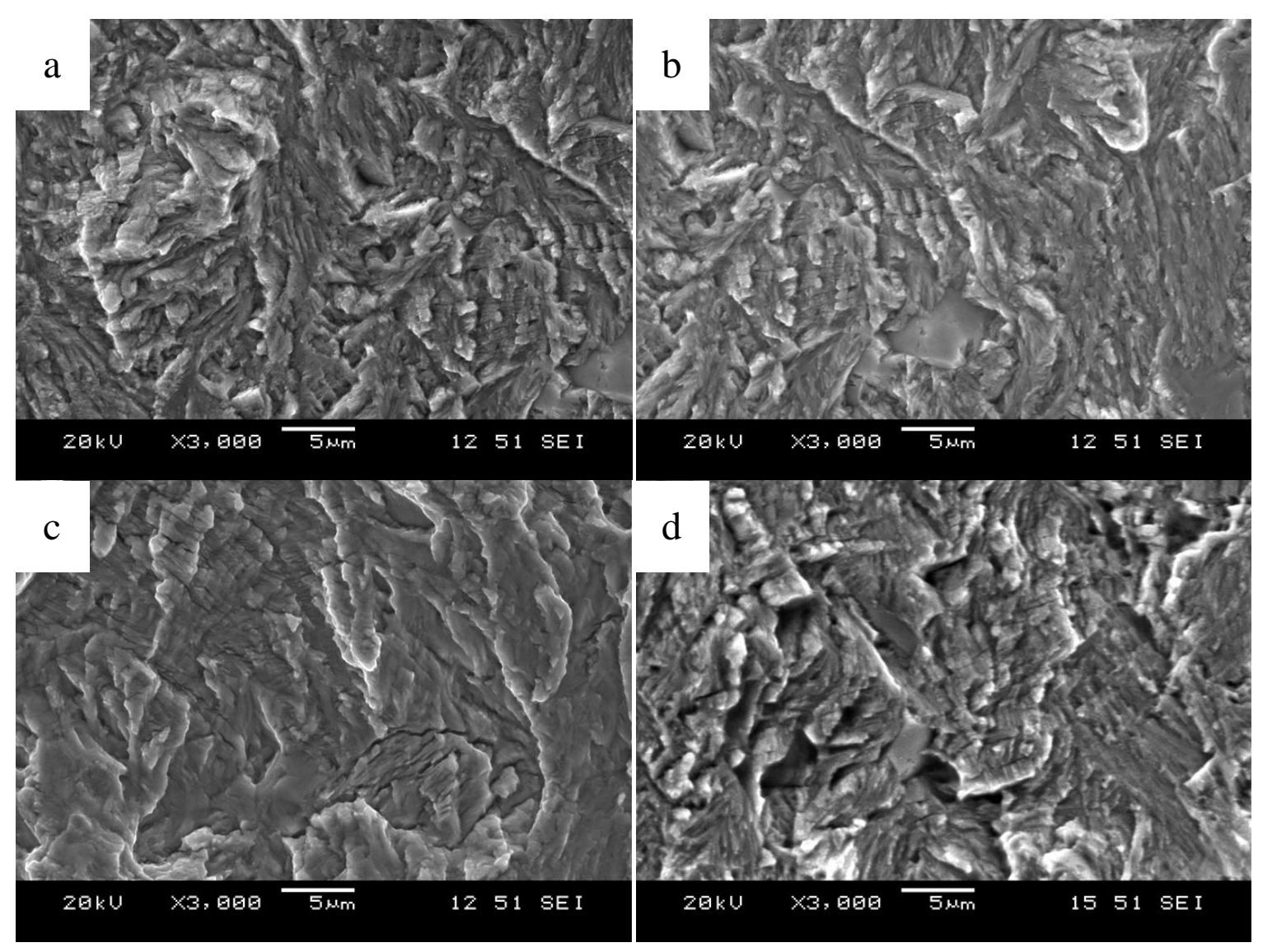

Fig. 9.9 Fracture initiation sites of (a) high heat input DP980 Rich, (b) low heat input DP980 Rich, (c) high heat input DP980 Lean, and (d) low heat input DP980 Lean. 


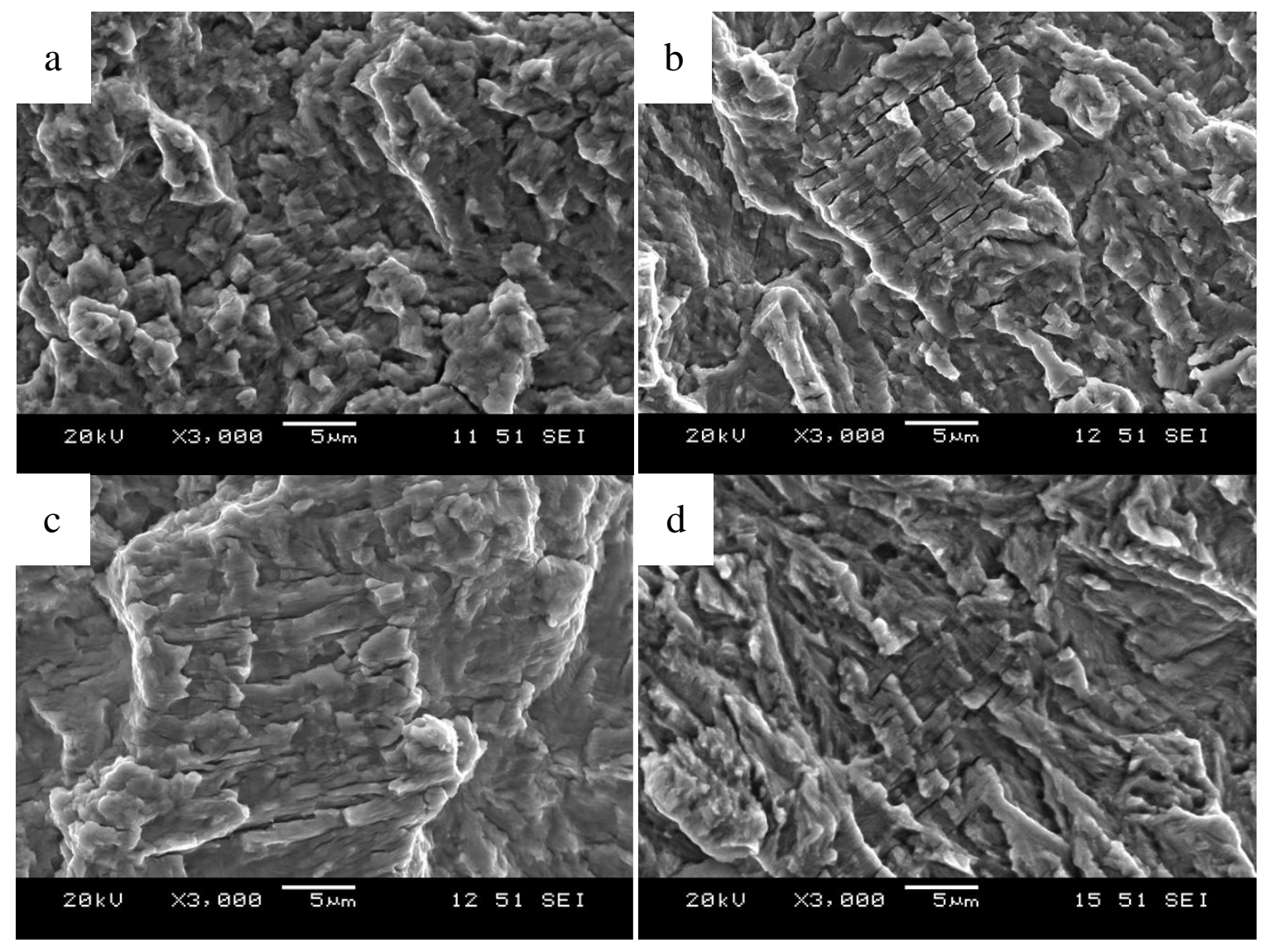

Fig. 9.10 Fracture propagation region of (a) high heat input DP980 Rich, (b) low heat input DP980 Rich, (c) high heat input DP980 Lean, and (d) low heat input DP980 Lean. 


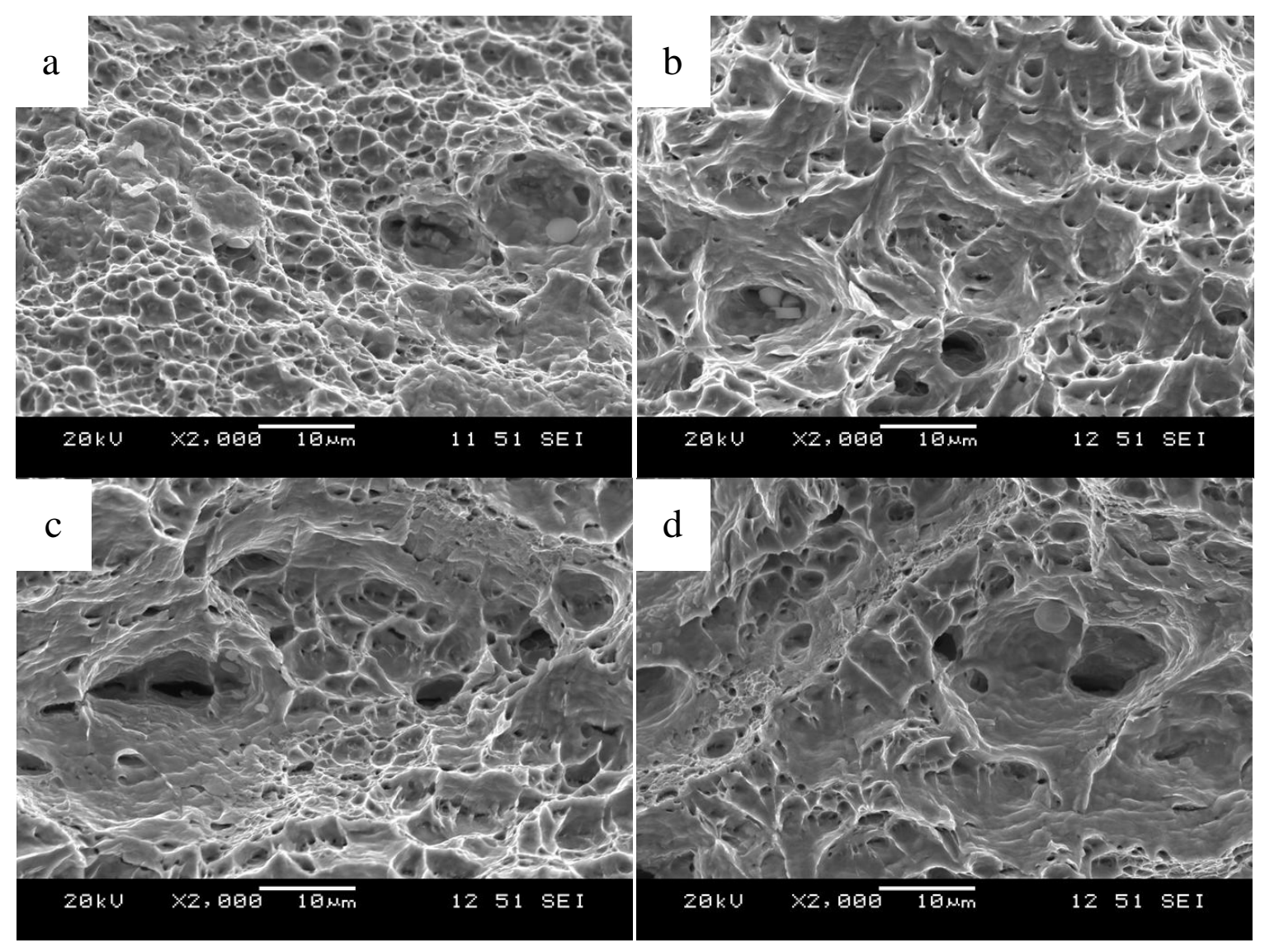

Fig. 9.11 Fast Fracture region of (a) high heat input DP980 Rich, (b) low heat input DP980 Rich, (c) high heat input DP980 Lean, and (d) low heat input DP980 Lean.

\subsection{Summary}

The higher alloying additions formed a more stable martensite phase which was resistant to softening, while the lower alloying addition of DP980 Lean led to severe tempering of the martensitic phases, which deformed locally during loading, causing premature failure in the soft zone. DP980 Lean demonstrated poor tensile strength and severe reductions in formability due to more severe softening, while DP980 Rich showed little change in the mechanical properties (tensile and formability) because of negligible softening; instead, the reduction in mechanical properties was attributed to the reduced elongation in the $\mathrm{FZ}$ of the weld. According to the S-N curve, there was a significant difference between the high and low heat inputs in both of the DP980 Rich and DP980 Lean samples. A large difference in the 
fatigue strength of the two steels was seen when compared at similar heat inputs showing that the DP980 Rich chemistry had overall better fatigue properties when welded, which was expected because of higher BM strength of the DP980 Lean steel. 


\section{Chapter 10 Conclusions}

\subsection{Conclusions}

From the work that has been accumulated by analysing the microstructure, microhardness profiles, tensile curves, formability, fatigue, and the fractography of the specimens of the different dissimilarly FLWed joints, several conclusions can be drawn from this work.

1. In all of the dissimilar welded joints, the sub-critical HAZ had little to no effect on the tensile properties since the strength of the sub-critical region in DP980 was still greater than that of HSLA BM.

2. For fatigue tests at RT and tensile tests at different temperatures of the dissimilar welded joints, the samples behaviour was dominated by the strength of the HSLA.

3. The DP980 Lean welded joints at high temperature did not exhibit the dynamic strain aging (DSA) behaviour.

4. The FLW parameters did not have a significant effect on the tensile properties, but the concavity that was generated affected the fatigue results.

5. The GA coating process had a tempering effect on the DP980 BM which lowered the mechanical properties slightly.

6. The rich chemistry of DP980 made the martensite phase more stable which decreased the degree of softening in the welded joint and increased the overall mechanical properties.

These conclusions show how DP steels could be used as a material in the manufacturing of dissimilar TWB components. It also shows that the use of FLW to join these components can produce good quality welded joints at high production rates. 


\subsection{Future Work}

Several things that can be done as a continuation of this research work are as follows:

1. An examination the effects of different combinations of dissimilar materials.

2. Further study of the effect of GI and GA coating on mechanical properties and characterizing the GA coating. Also looking into other coating methods like electrogalvanizing (EG).

3. Since it was found that there was significant difference in the mechanical properties between different DP980 joints, a deeper look into the chemistry of DP980 should be undertaken along with a look at how DP980's different microstructures change the welded joint behaviour.

4. Further work on the FLW process in order to reduce/eliminate the concavity that it created in order to increase the fatigue life of the welded joints. 


\section{References}

[1] T. N. Srinivasan, "China, India, and the World Economy," Economic and Political Weekly, pp. 3716-3727, 26 August 2006.

[2] S. Hart, "Beyond Greening: Strategies for a sustainable world," Harvard Business Review, pp. 66-76, 1997.

[3] J. Murray and D. King, "Oil is past it's tipping point," Nature, no. 481, pp. 433-435, 2012.

[4] W. Joost, "Reducing vehicle weight and improving U.S. energy efficiency -using integrated computational materials engineering," Journal of Materials, vol. 64, no. 9, pp. 1032-1038, 2012.

[5] P. Waurzyniak, "Advanced materials in automotive," Manufacutring Engineering, vol. 143, pp. 65-71, 2009.

[6] National Highway Traffic Safety Administration; Environmental Protection Agency, "2017-2025 Model Year Light-Duty Vehicle GHG Emissions and CAFE Standards: Supplemental," Washington D.C., 2011.

[7] O. Kwon and S. Baik, "Manufacture and application of advanced high strength steel sheets for auto manufacture," POSCO, Pohang, 2005.

[8] W. Callister, Material science and engineering: an Introduction, New York: John Wiley and Sons, Inc, 2007.

[9] W. Wang, C. He, Z. Zhao and X. Wei, "The limit drawing ratio and formability prediction of advanced high strength dual-phase steels," Materials and Design, pp. 3320$3327,2011$.

[10] W. Xu, D. Westerbaan, S. Nayak, D. Chen, F. Goodwin and Y. Zhou, "Tensile and fatigue properties of fiber laser welded high strength low alloy and DP980 dual-phase steel joints," Materials and Design, vol. 43, pp. 373-383, 2013.

[11] N. Farabi, D. Chen and Y. Zhou, "Tensile properties and work hardening behavior of laser-welded dual-phase steel joints," Journal of Materials Engineering and Performance, pp. 222-230, 2012.

[12] M. Xia, N. Sreenivasan, S. Lawson, Y. Zhou and Z. Tian, "A comparative study of formability of diode laser welds in DP980 and HSLA steels," Journal of Engineering 
Materials and Technology, vol. 129, pp. 446-452, 2007.

[13] N. Farabi, D. Chen, J. Li, Y. Zhou and S. Dong, "Microstructure and mechanical properties of laser welded DP600 steel joints," Material Science and Engineering A, vol. 527, pp. 1215-1222, 2010.

[14] J. Cao, Y. Gong, K. Zhu, Z. Yang, X. Luo and F. Gu, "Microstructure and mechanical properties of dissimilar materials joints between T92 martensitic and S304H austenitic steels," Materials and Design, pp. 2763-2770, 2011.

[15] N. Farabi, D. Chen and Y. Zhou, "Microstructure and mechanical properties of laser welded dissimilar DP600/DP980 dual-phase steel joints," Journal of Alloys and Compounds, vol. 509, pp. 982-989, 2011.

[16] L. Quintino, A. Costa, R. Miranda, D. Yapp, V. Kumar and C. Kong, "Welding with high power fiber lasers - A preliminary study," Materials and Design, vol. 28, pp. 12311237, 2007.

[17] C. Cui, X. Cui, X. Ren, T. Liu, J. Hu and Y. Wang, "Microstructure and microhardness of fiber laser butt welded joint of stainless steel plates," Materials and Design, pp. 761764, 2013.

[18] H. Chen, A. Pinkerton, L. Li, Z. Liu and A. Mistry, "Gap-free fibre laser welding of Zncoated steel on Al alloy for light-weight automotive applications," Materials and Design, pp. 495-504, 2011.

[19] M. Sokolova, A. Salminena, M. Kuznetsovb and I. Tsibulskiyb, "Laser welding and weld hardness analysis of thick section S355 structural steel," Materials and Design, pp. 5127-5131, 2011.

[20] W. Duley, Laser Welding, New York: John Wiley and Sons, Inc., 1999.

[21] J. Nilsson and P. D. N., "High-power fiber lasers," Science, vol. 332, no. 6032, pp. 921$922,2011$.

[22] C. P. Christensen, "New laser source technology," Science, vol. 224, pp. 117-123, 1984.

[23] C. P. Christensen, "Some emerging application of lasers," Science, vol. 218, pp. 115$121,1982$.

[24] H. B. Cary, Modern Welding Technology, New Jersey: Prentice-Hall Inc., 1979.

[25] R. Trem, "The future of automaking: tailor welded blanks," Welding Design and Fabrication, pp. 37-40, 2001. 
[26] G. Overton, "New technologies heat up laser-welding market," Laser Focus World, vol. 44, no. 10, pp. 90-94, 2008.

[27] G. Verhaeghe, "The fiber laser - a new comer material welding and cutting," Welding Journal, vol. 8, no. 84, pp. 56-60, 2005.

[28] R. Mueller, "Choosing the Low Cost Method for Manufacturing," Lasers for Manufacturing Event, Milton, 2011.

[29] R. Term, "The future of automaking:tailor welded blanks," Welding Design Fabrication, vol. 2, pp. 37-40, 2001.

[30] F. Saunders and R. Wagoner, "Forming of tailor-welded blanks," Metallurgical and Materials Transactions A, vol. 27A, pp. 2605-2616, 1996.

[31] B. Rooks, "Tailor-welded blanks bring multiple benefits to car design," Assembly Automation, vol. 21, no. 4, pp. 323-328, 2001.

[32] Smitty, "Boron Extraction," PennWell Public Safety and Hosted Bloggers, 18 November 2009. [Online]. Available: http://boronextrication.com/2009/11/understanding-steelblanks/. [Accessed 27 September 2013].

[33] N. Farabi, D. Chen and Y. Zhou, "Fatigue properties of laser welded dual-phase steel joints," Procedia Engineering, pp. 835-843, 2010.

[34] W. Xu, D. Westerbaan, S. Nayak, D. Chen, F. Goodwin, E. Biro and Y. Zhou, "Microstructure and fatigue performance of single and multiple linear fiber laser welded DP980 dual-phase steel," Material Science and Engineering A, vol. 553, pp. 51-57, 2012.

[35] J. Long, D. Haynes and P. Hodgson, "Characteration of galvanneal coatings on strip steel," Materials Forum, pp. 62-67, 2004.

[36] M. de la Garza, M. Moreno, M. Mata, P. Zambrano, R. Colas and Y. Houbaert, "Characterization of gavannealed HSLA steels," Advanced Materials Research, pp. 159166, 2009.

[37] S. Wienstroer, M. Fransen, H. Mittelstadt, C. Nazikkol and M. Volker, "Zinc/iron phase transformation studies on galvannealed steel coatings by x-ray diffraction," Advances in X-ray Analysis, pp. 291-296, 2003.

[38] M. Rashid, "High strength low alloy steels," Science, vol. 208, no. 4446, pp. 862-869, 1980.

[39] S. Kou, Welding Metallurgy, New Jersey: John Wiley \& Sons Inc, 2003. 
[40] D. Porter and K. Easterling, Phase transformations in metals and alloys, Boca Ratton: Taylor \& Francis Group, 1992.

[41] M. Hazratinezhad, N. Mostafa Arab, A. Sufizadeh and M. Torkamany, "Mechanical and metallurgical properties of pulsed neodymium-doped yttrium aluminum garnet laser welding of dual phase steels," Materials and Design, vol. 33, pp. 83-87, 2012.

[42] E. Biro, J. McDermid, J. Embury and Z. Y., "Softening Kinectics in the Subcritical HeatAffected Zone of Dual-Phase Steel Welds," The Minerals, Metals \& Materials Society, vol. 41A, pp. 2348-2356, 2010.

[43] Y. Song, L. Hua, D. Chu and J. Lan, "Characterization of the inhomogeneous constitutive properties of laser welding beams by the micro-Vickers hardness test and the rule of mixture," Materials and Design, vol. 37, pp. 19-27, 2012.

[44] S. Panda, J. Li, V. Baltazar Hernandez, Y. Zhou and F. Goodwin, "Effect of Weld Location, Orientation, and Strain Path on Forming Behavior of AHSS Tailor Welded Blanks," Journal of Engineering Materials and Technology, vol. 132, pp. 041003-1041003-11, 2010.

[45] M. Alam, J. Karlsson and A. Kaplan, "Generalising fatigue stress analysis of different laser weld geometries," Materials and Design, vol. 32, pp. 1814-1823, 2011.

[46] G. Dieter, Mechanical metallurgy, New York: McGraw-Hill, 1986.

[47] M. Chapetti, N. Katsura, T. Tagawa and T. Miyata, "Static strengthening and fatigue blunt-notch sensitivity in low-carbon steels," International Journal of Fatigue, vol. 23, pp. 207-214, 2001.

[48] D. Parkes, W. Xu, D. Westerbaan, S. Nayak, D. Chen, F. Goodwin and Y. Zhou, "Microstructure and fatigue properties of fiber laser welded dissimilar joints between high strength low alloy and dual phase steels," Materials and Design, vol. 51, pp. 665675, 2013.

[49] J. Chen, B. Young and B. Uy, "Behavior of high strength structural steel at elevated temperatures," Journal of Structural Engineering, vol. 132, no. 12, pp. 1948-1954, 2006.

[50] R. Hertzberg, Deformation and fracture mechanics of engineering materials, New Jersey: John Wiley \& Sons, Inc., 1996.

[51] J. Hollomon, "Tensile deformation," Trans. AIME, vol. 162, pp. 268-290, 1945.

[52] M. Molaei and A. Ekrami, "The effect of dynamic strain aging on subsequent mechanical properties of dual-phase steels," Journal of Materials Engineering and Performance, vol. 19, pp. 607-610, 2010. 
[53] R. Queiroz, F. Cunha and B. Gonzalez, "Study of dynamic strain aging in dual phase steel.," Materials Science and Engineering A, vol. 543, pp. 84-87, 2012.

[54] A. Ekrami, "High temperature mechanical properties of dual phase steels," Materials Letters, vol. 59, pp. 2070-2074, 2005.

[55] T. Waterschoot, A. De, S. Vandeputte and B. De Cooman, "Static strain aging phenomena in cold-rolled dual-phase steels," Metallurgical and Materials Transactions A, vol. 34A, pp. 781-791, 2003.

[56] F. Ozturk, S. Toros and S. Kilic, "Tensile and spring-back behaviour of DP600 advanced high strength steel at warm temperatures," Journal of Iron and Steel Research, vol. 16, pp. 41-46, 2009.

[57] S. Gündüz, "Effect of chemical composition, martensite volume fraction and tempering on tensile behaviour of steels," Materials Letters, vol. 62, pp. 2381-2383, 2009.

[58] S. Gündüz and A. Tosun, "Influence of straining and ageing on the room temperature mechanical properties of dual phase steel," Materials and Design, vol. 29, pp. 19141914, 2008.

[59] D. Westerbaan, D. Parkes, S. Nayak, D. Chen, B. Biro, F. Goodwin and Y. Zhou, "Effects of concavity on tensile and fatigue properties in fibre laser welding of automotive steels," Science and Technology of Welding and Joining, 2013.

[60] M. Xia, E. Biro, Z. Tian and Y. Zhou, "Effects of Heat Input and Martensite on HAZ Softening in Laser Welding of Dual Phase Steels," ISIJ International, vol. 48, no. 6, pp. 809-814, 2008.

[61] H. Shao, J. Gould and A. C., "Laser blank welding high-strength steels," Metallurgical and Materials Transactions, vol. 38B, pp. 321-331, 2007.

[62] C. Ma, D. Chen, S. Bhole, G. Boudreau, A. Lee and E. Biro, "Microstructure and fracture characteristics of spot-welded DP600 steel," Material Science and Engineering A, vol. 485, pp. 334-346, 2008.

[63] G. Nazarenko, "Relation between structure of steel and its yield point elongation," Metal Science and Heat Treatment of Metals, vol. 4, pp. 27-33, 1959.

[64] N. Yurioka, M. Okumura, T. Kasuya and H. Cotton, "Prediction of HAZ Hardness in Transformable Steels," Metal Construction, vol. 19, no. 4, pp. 217-223, 1987.

[65] C. Dawes, Laser Welding, New York: McGraw-Hill Inc., 1992.

[66] F. Campbell, Elements of Metallurgy and Engineering Alloys, Materials Park: ASM 
International, 2008.

[67] D. Askeland and P. Phule, The Science and Engineering of Materials, Toronto: Thomson Canada Ltd. , 2006.

[68] V. Baltazar-Hernandez, S. Nayak and Y. Zhou, "Tempering of Martensite in Dual-Phase Steels and its Effect on Softening Behaviour," Metallurgical and Material Transactions A, vol. 42, no. 10, pp. 3115-3129, 2011.

[69] M. Xia, M. Kuntz, Z. Tian and Y. Zhou, "Failure Study on Laser Welds of Dual Phase Steel in Formabilty Testing," Science and Technology of Welding and Joining, vol. 13, no. 4, pp. 378-387, 2008.

[70] N. Sreenivisan, M. Xia, S. Lawson and Y. Zhou, "Effect of Laser Welding on Formability of DP980 Steel," Journal of Engineering Materials and Technology, vol. 130, pp. 041004-1-9, 2008. 


\title{
Appendix: List of Publications
}

\author{
Education \\ Master of Applied Science (April 2014) \\ Ryerson University, Toronto ON \\ Mechanical Engineering \\ Bachelor of Applied Science (April 2010) \\ University of Toronto, Toronto ON \\ Material Science and Engineering
}

\section{List of Publications (during my MASc studies at Ryerson University)}

1. D. Parkes, W. Xu, D. Westerbaan, S.S. Nayak, Y. Zhou, F. Goodwin, S. Bhole and D.L. Chen, "Microstructure and fatigue properties of fiber laser welded dissimilar joints between high strength low alloy and dual phase steels," Materials and Design, vol. 51, pp. 665-675, 2013.

2. D. Parkes, D. Westerbaan, S.S. Nayak, Y. Zhou, F. Goodwin, S. Bhole and D.L. Chen, "Tensile properties of fiber laser welded joints of high strength low alloy and dual-phase steels at warm and low temperatures," Materials and Design, vol. 56, pp. 193-199, 2014.

3. D. Westerbaan, D. Parkes, S.S. Nayak, D.L. Chen, E. Biro, F. Goodwin and Y. Zhou, "Effects of concavity on tensile and fatigue properties in fibre laser welding of automotive steels," Science and Technology of Welding and Joining, vol. 19, pp. 6068, 2014.

4. D. Parkes, D. Westerbaan S.S. Nayak, Y. Zhou, F. Goodwin, S. Bhole and D.L. Chen, "Fatigue and microstructure comparison between galvanized and galvannealed DP980-DP600-HSLA triple dissimilar welds". (Under internal review)

5. D. Parkes, D. Westerbaan S.S. Nayak, E. Biro, Y. Zhou, F. Goodwin, S. Bhole and D.L. Chen, "Fiber laser welding of dual-phase DP980 steel: Effects of heat input and chemistry on softening and performance". (Under internal review)

\section{Conference Papers}

1. D. Westerbaan, S. Nayak, D. Parkes, W. Xu, D.L. Chen, S. Bhole, F. Goodwin, E. Biro and Y. Zhou, "Microstructure and mechanical properties of fiber laser welded DP980 and HSLA steels," Sheet Metal Welding Conference 2012, Livonia, MI, USA.

2. D. Parkes, Q.L. Cui, D. Westerbaan, S.S. Nayak, Y. Zhou,F. Goodwin, D. Liu, S.D. Bhole and D.L. Chen, "Effect of Fiber Laser Welding on the Fatigue Properties of Dissimilar Welded Joints between DP980 and HSLA Steels". (Approved for publication Jan.16/2014) 